Agre: Agriculture

Forest Service

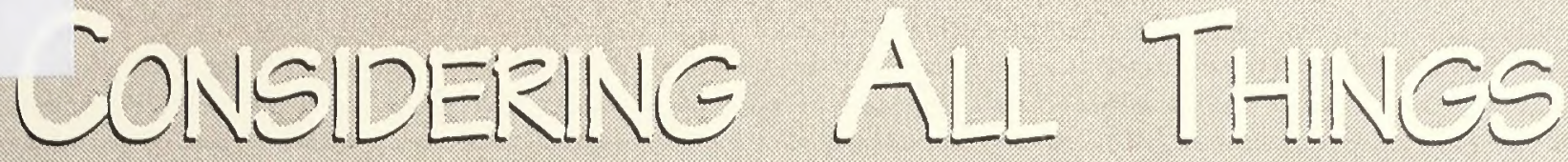

United States

Department of

the Interior

Summary of the Draft Environmental Impact Statements

Bureau of Land

Management

Eastside Environmental Impact Statement

Upper Columbia River Basin Environmental Impact Statement

5is

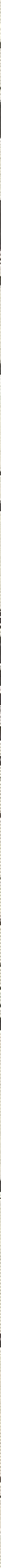




\section{The Interior Columbia Basin Ecosystem Management Project is Designed to...}

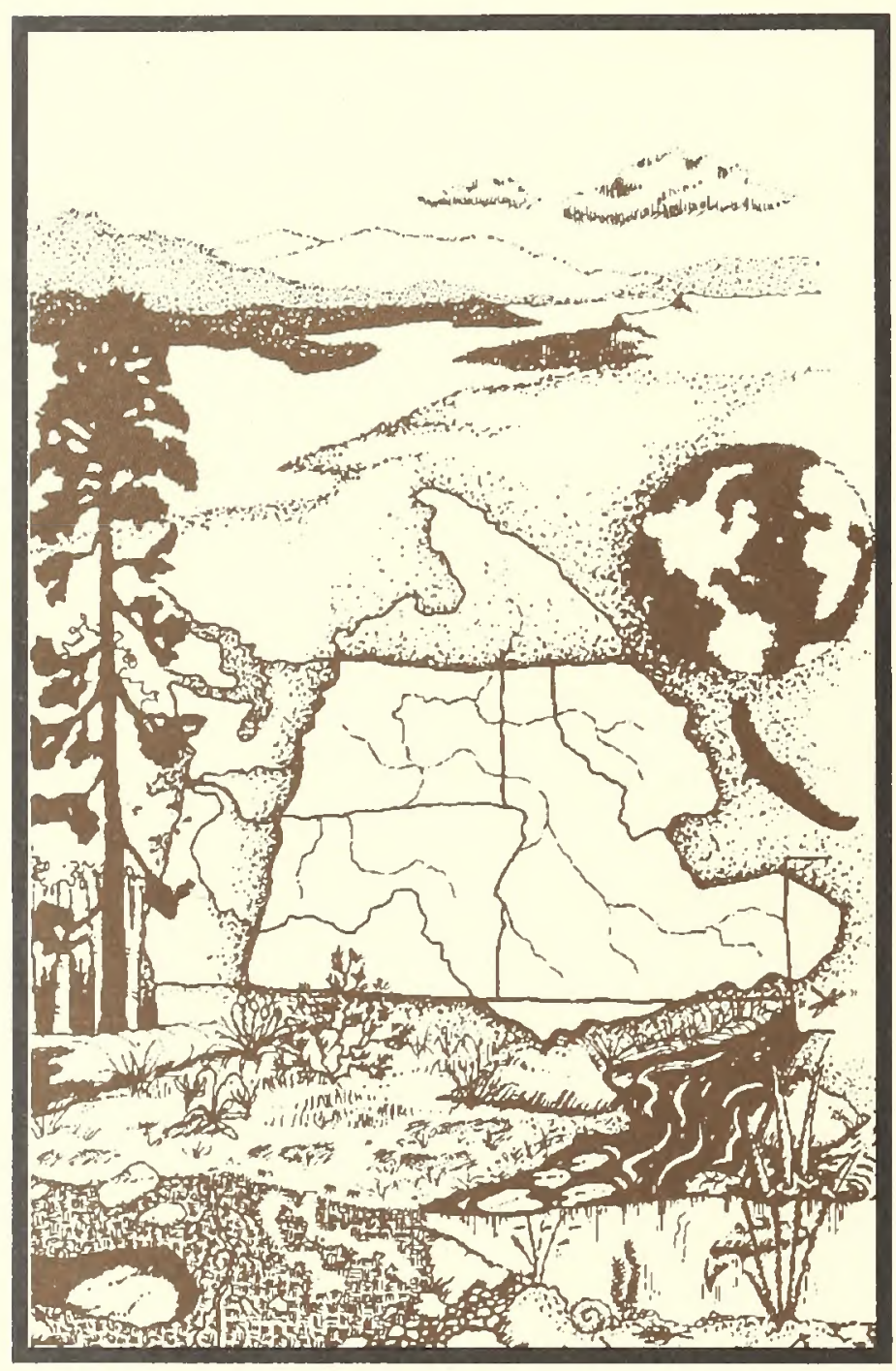

Develop big-picture ecosystem management strategies that aim to restore forest and rangeland health while providing sustainable resources and jobs for people.

Address broad-scale problems that cross jurisdictional lines (for example, endangered species, species population viability, forest and range health, etc.) in one effort, saving money and time.

Replace interim strategies such as PACFISH with flexible approaches that will better protect fish and other species and provide management needed to reduce ecological risks in riparian and upland areas.

Provide for species viability with an ecosystem approach, rather than a species-by-species approach, thus reducing the chance of more listings and litigation.

Provide an opportunity for counties, states, Federal agencies, American Indian Tribes, and citizens to cooperate and perhaps depolarize divided opinions about conservation and public land management.

\section{The Project Team}

The BLM and the Forest Service are the leaders in this interagency effort. The project is guided by an Executive Steering Committee, composed of Forest Service Regional Foresters, BLM State Directors, and Station Directors from Forest Service Research. Other participating agencies include: U.S. Fish and Wildlife Service, Environmental Protection Agency, National Marine Fisheries Service, Natural Resource Conservation Service, National Park Service, Bureau of Indian Affairs, Bureau of Mines, Army Corps of Engineers, Bonneville Power Administration, U.S. Geological Survey, and the Bureau of Reclamation, and several state agencies. County governments and American Indian Tribes have been particularly active participants in the project. Their perspectives and expedient feedback on draft documents have been invaluable.

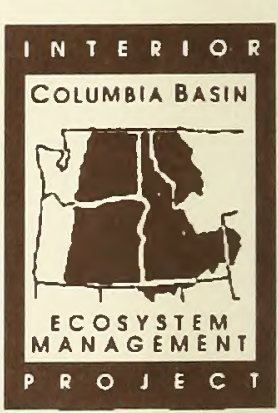




\title{
What's Inside?
}

\section{The Essentials - page 2}

What is the project's purpose?

How is this different from what we've done in the past?

Will this project make decislons that apply to private lands?

How will this strategy affect existing plans?

Why is it necessary to amend current plans?

Why are we looking at such a large area?

Is it legal to plan on an ecosystem basis?

What are we trying to accomplish?

How are American Indian Tribes Involved?

Which priorities will gulde us?

\section{Restoring Ecological Integrity - page 10}

What is an ecosystem?

What is a healthy, high-integrity ecosystem?

Why is it Important to keep ecosystems healthy?

What can we learn from the past?

Are we trying to go back to an arbitrary point In history?

How can we restore ecological integrity and health?

WIIl we still manage Forest Service and BLM lands to meet human needs?

What is adaptlve management?

\section{Learning from the Land and Its People - page 18}

What data was collected in the Sclentific Assessment?

How did we integrate the information to measure ecological integrity?

How did we measure economic resillency?

What condition is the Project Area in now?

What are the positive trends?

After 100 years of change...

\section{Alternative Pathways to a Sustainable Future - page 32}

Why seven different alternatives?

What issues are most important to people?

What is the Desired Range of Future Conditions?

Your guide to the alternatives

\section{Environmental Consequences - page 44}

How do the effects of the alternatives differ?

\section{Implementation - page 54}

How is natural resource planning done?

How will these ElSs change planning practices?

\section{The Next Step - page 56}

How can I stay Involved?

\author{
BLM Library \\ Denver Federal Center \\ Bldg. 50, OC-521 \\ P.O. Box 25047 \\ Denver, CO 80225
}

\section{LIBRARY}

SEP 112006

Bureau of Reclamation

Denver, Colorado 



\section{A Blueprint-in-Progres5...}

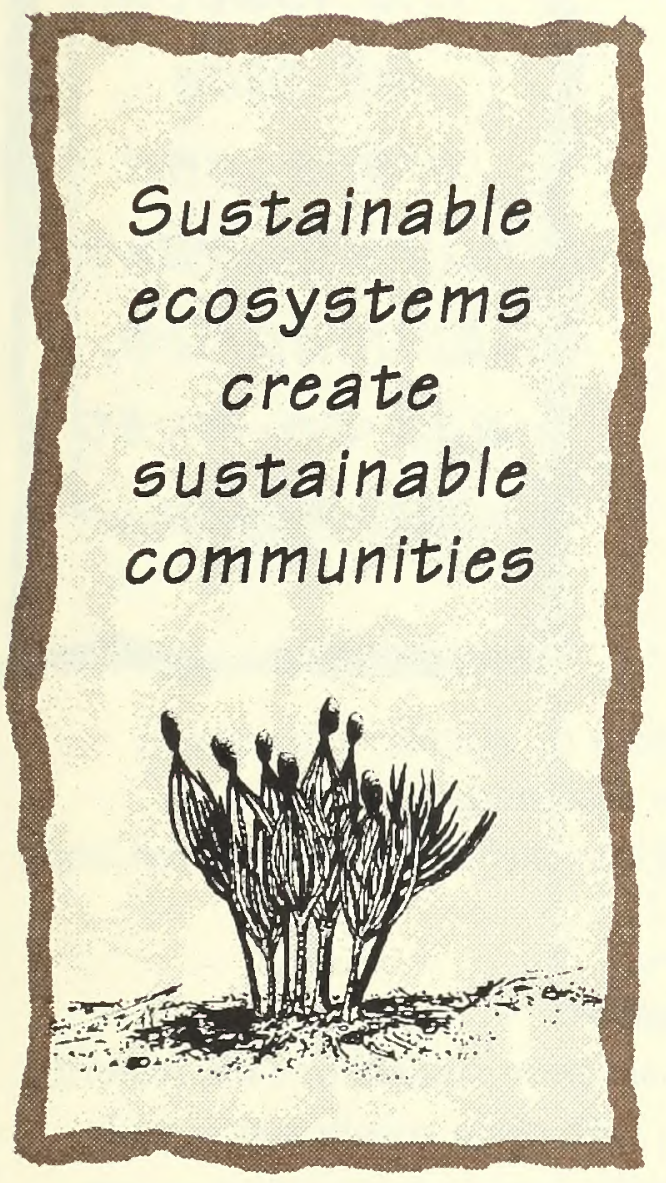

Welcome and thanks for your interest.

What you hold in your hands is a reader's guide to a pair of more detailed documents called Draft Environmental Impact Statements, or DEISs. The DEISs are essentially blueprints-in-progress for future management of 75 million acres of public lands administered by the Forest Service or Bureau of Land Management in the interior Columbia Basin and portions of the Klamath Basin and Great Basin.

They're called Draft EISs because we're still in the process of choosing a sound course, and we'd like your opinion.

For the past several years, we've been taking a big-picture look at the land drained largely by the Columbia River, a basin that stretches from the Cascades to the Rockies, and from Canada to northern Nevada. We've been exploring how ecological, economic, and social pieces fit together on the landscape over time, and how we humans affect and are affected by changes in that landscape. The practical fruit of this study is an array of management strategies with a single, overarching vision: a healthy and sustainable future for the ecosystems we manage and the human communities that depend on them.

We've seen in recent years that ecological integrity is not a given; like bodies, ecosystems can be stressed beyond their limits, pushed to the point of vulnerability. As stewards of these lands, our goal is to make sure that doesn't happen, and to find a way to provide for the needs of the present generation without denying future generations the opportunities we've enjoyed.

You can help us by letting us know what you think of the various alternatives: which ones you like, which you don't like, and why. Like the adaptive management we are exploring, this is a fluid process, and your comments will help us shape the Final Environmental Impact Statements into something we can all be proud of.

Before we tell you about the seven alternatives, we'll answer some questions you may already be asking.

Thanks for your belp! The Project Team 


\section{The Essentials}

What is the project's purpose?
In a nutshell, we're developing a state-of-the-art management strategy for the lands administered by the Forest Service (FS) or Bureau of I and Management (BLM) in the interior Columbia Basin and portions of the Klamath Basin and Great Basin, the area we call the Project Area. It will be broad-scale, scientifically sound, ecosystem-based, and developed in open collaboration with multiple agencies, governments, Tribes, and people like you. It will provide guidance for the next 10 to 15 years, with an eye toward healthy, sustainable ecosystems 50 to 100 years out.

Driving the design of this strategy are the needs to:

- Restore and maintain long-term ecosystem health and integrity.

- Support, within the capacity of the land, the economic and/or social needs of people, cultures, and communities, and provide sustainable and predictable levels of products and services from Forest Service- and BLM-administered lands.

How is this different from what we've done in the past?

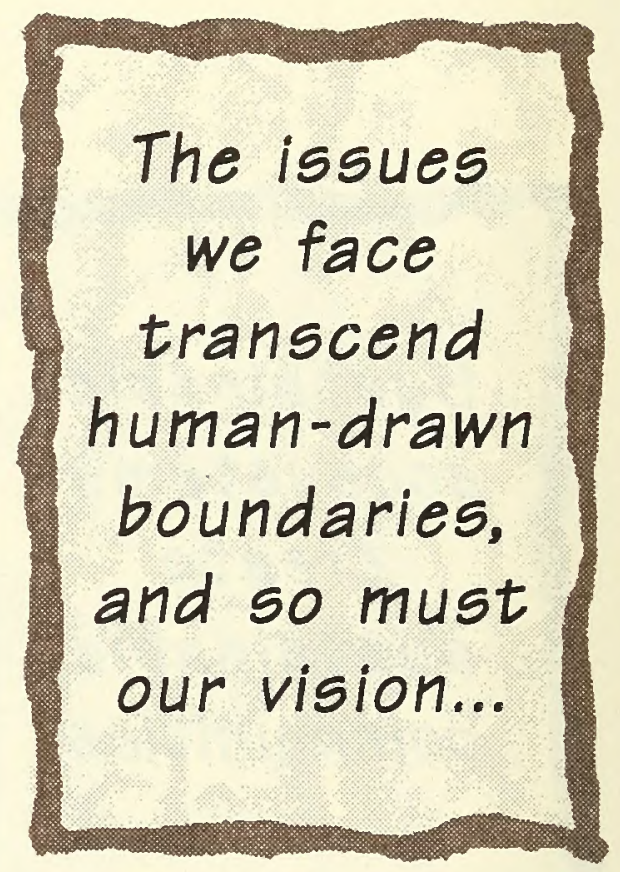




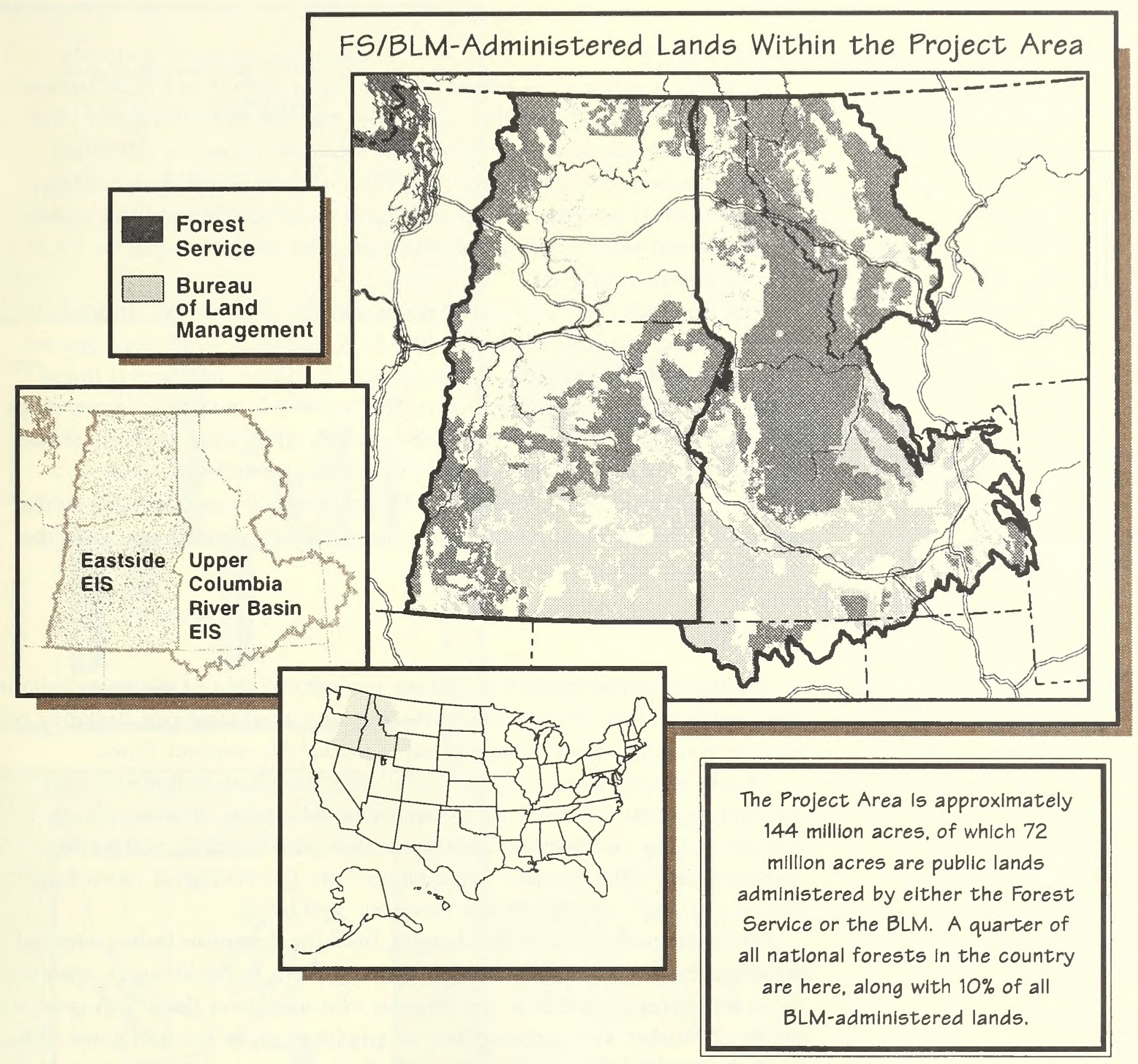

Will this project make decisions that apply to private lands?
No. The Records of Decision (RODs) that will follow the Final Environmental Impact Statements will provide direction only for public lands administered by the BLM or Forest Service in the Project Area. The EISs will make no management decisions for any state, local (city or county), tribal, or private lands. Regulations, policies, or provisions made by state or local agencies or private landowners will not be affected by decisions made in the RODs.

We studied data from private as well as public lands to give us a more complete picture of what is happening on adjacent lands, how our actions affect our neighbors, and vice versa. This wider lens will help us make better decisions, but these decisions will apply only to lands administered by the Forest Service or the BLM. 
How will this strategy affect existing plans?

Why is it necessary to amend current plans?
This plan is expected to amend current Forest Service and BLM land-use plans with ecosystem-based direction at the regional and subregional level. It will also replace the interim conservation strategies known as PACFISH (Pacific Anadromous Fish Strategy), INFISH (Inland Native Fish Strategy), and the Eastside Screens. These short-term rules were put in place within the last several years to protect aquatic and other resources until we could craft long-term strategies.

What you won't find in this plan is one-size-fits-all direction. Instead, it offers a broad, scientific context to help local managers weigh their options when dealing with 1) broad-scale issues, such as salmon habitat and forest health, which affect the entire Project Area, or with 2) mid-scale issues, such as juniper encroachment into rangelands, which affect large portions of the Project Area. We recognize that there will always be decisions more appropriately made at the local level. This plan is deliberately flexible so that managers, who are most familiar with site-specific conditions, can adapt the guidance to their area.

Traditional management has become too risky in light of declining salmon runs, costly wildfire and pest outbreaks, runaway weed invasions, declining soil fertility, mounting legal challenges, and unpredictable resource flows.

Thanks to long-term research, we can now trace how well-intentioned management practices have played out on the landscape. In many places, decades of large-tree harvest, fire suppression, road building, overgrazing, damming, and water diversion have tapped into our ecological "trust fund," in turn affecting our cultural and economic well-being.

People are well aware of the changes, from the American Indian who can no longer catch a ceremonial salmon in many rivers, to the livestock operator faced with acres of weeds, to the irrigator who sees lower flows in August, to the forest worker who cannot count on employment, to the firefighter whose life is threatened by a crowning fire. All of us are touched by effects we may not realize: an altered water cycle, a drop in soil fertility, impurities in the air, or a shift in the balance of plant and animal species.

Faced with these changes and new information about management effects, we realized it was time to sit down with our partners, take a careful look at the condition of the lands in our care, and plan for sustainability.

Our authority came from existing law and from a Presidential directive in July 1993 calling for the Forest Service to develop a scientifically sound and ecosystem-based strategy for management of forests east of the Cascades. The BLM joined the effort shortly thereafter, and two interagency EIS teams were formed-one located in Walla Walla, Washington, and one in Boise, Idaho. They divided the planning effort into two geographic areas, each with its own Draft EIS. This summary reports on both efforts. 


\section{Some Ecosystems Have Declined,}

Affecting

Native Species

and People...
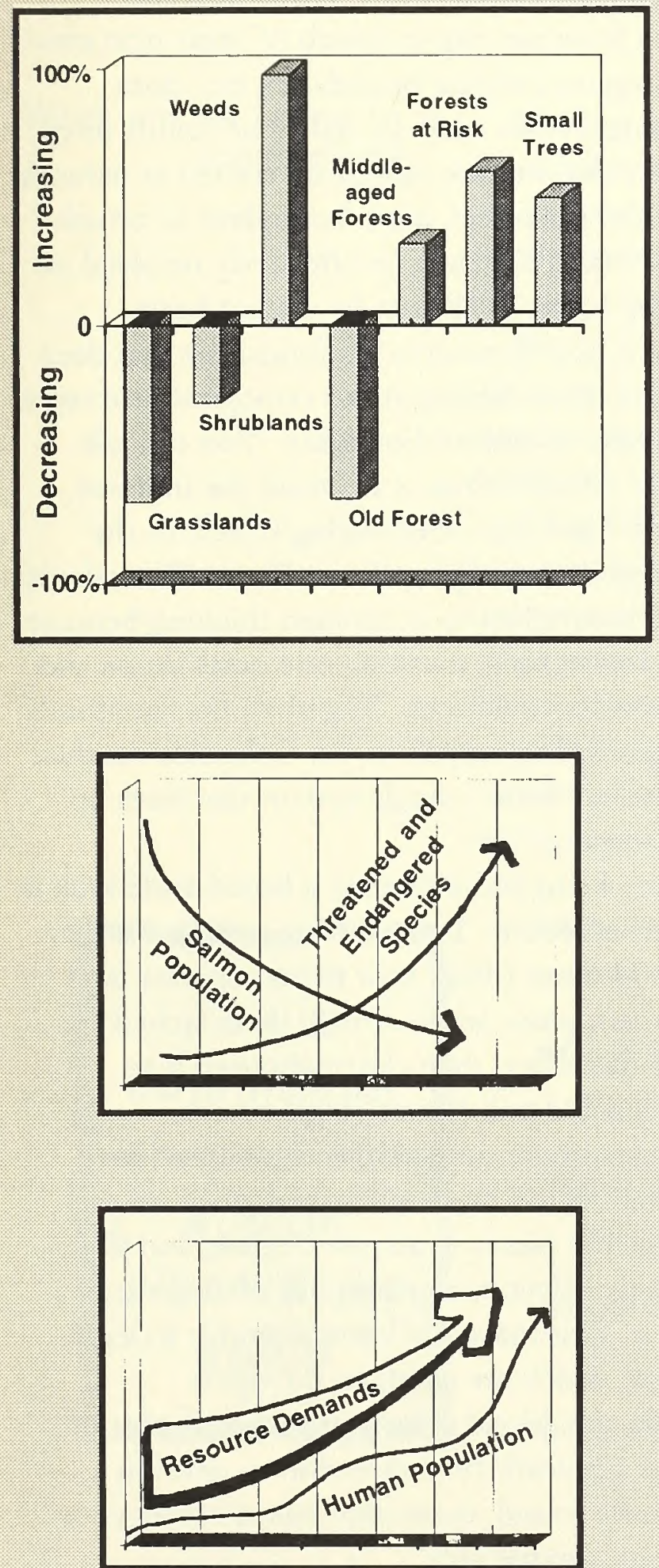

\section{But Core Pieces Remain} to Restore Integrity and Health...

\author{
In many places, \\ a nearly full \\ complement of \\ native species
}

New technologies

for broad-scale

understanding
Healing processes

such as nutrient

cycling largely intact

\author{
Examples \\ of healthy \\ ecosystems \\ providing for \\ human needs
}

A growing knowledge of how ecosystems persist and perform

Society's desire for sustainable public lands

\section{The Draft ElSs are Pulling the Pieces Together.}

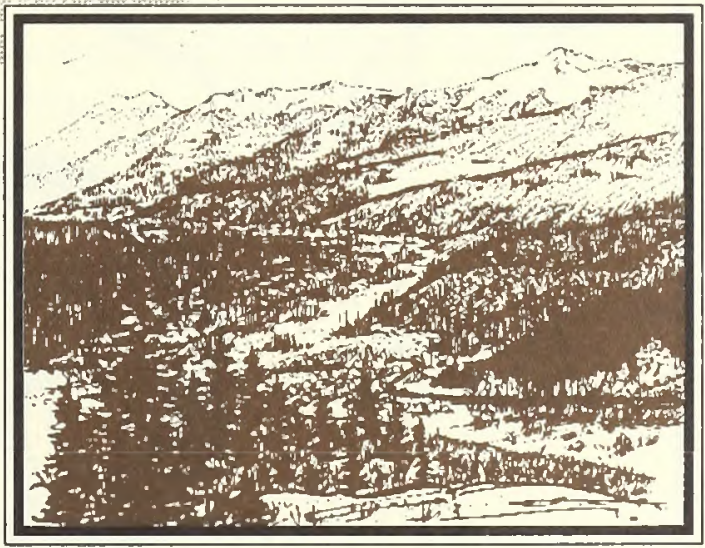

Creating Pathways to a Sustainable Future for Ecosystems and Human Communities. 
Why are we looking at such a large area?
As the old growth forest debate erupted on the west side of the Cascades, it became obvious that piecemeal solutions cannot mend large-scale problems. Here in the inland northwest, we were determined to address ecosystem health problems before they reached the courts or before catastrophic disturbances or extinctions made the issues tragically moot. The first step was to take a broad-scale look using nature's boundaries.

Perhaps the best reason to work at a bioregional scale is that the natural world works this way.

Mountain lions moving in search of their next meal don't recognize political boundaries, nor does groundwater divide itself by state and county lines. The issues that we face, which are rooted in nature's patterns and processes, lend themselves to broadscale analysis. They can't be effectively resolved on a forest-by-forest or district-by-district basis.

There is one division in the landscape that does make sense when talking about ecological processes, however: the watershed boundary. You can talk about watersheds at any scale, from the intimate canyon of Montana's Hellroaring Creek, to the broad bowl of the mighty Snake River. Watersheds also lend themselves to ecosystem thinking because they are hierarchical, meaning one nests inside and is connected to the other. Together, the thousands of tributaries that tumble to the Columbia on their way to the sea form a single system that laces up the landscape.

Besides being more natural, a broad-scale look is more cost-effective. Instead of inventing the data "wheel" 74 times (that's how many separate land management plans are in effect), we searched for available data once, then clearinghoused it so managers could pull from a single source.

Our experience, research, and case law have shown that we are more successful when we can show how the pieces in a system relate, and then weave these relationships into our management strategies. This makes us less vulnerable to legal challenges, which are costly to taxpayers.

Finally, this broad-scale perspective is part of President Clinton's 1993 direction to develop a scientifically sound, ecosystem-based strategy for agency lands in the area.
Natural resource issues transcend boundaries too... 
Is it legal to plan on

an ecosystem basis?

What are we trying to accomplish?
Yes. Federal agencies are required by law to consider ecological effects of proposed activities, including the "functioning of affected systems." Under the Endangered Species Act, Federal agencies must carry out their programs in a way that conserves listed species and the ecosystems upon which they depend. In the lawsuit over the Northwest Forest Plan covering the area of the northern spotted owl, Judge William Dwyer had this to say: "Given the current condition of the forests, there is no way the agencies could comply with environmental laws without planning on an ecosystem basis."

Working in a science/management partnership, we're trying to restore degraded ecosystems, hold the line on future degradation, and meet people's needs for ecosystem goods and services in an ecologically sustainable way. Ideally, we're working towards the day when the ecological conditions on all lands we manage will trend upward.

We realize this is not an easy task. Nature is incredibly complex, and social values and expectations are far from static. For these reasons, we're approaching our task with humility, and intend to stay tuned to changing ecological, social, and economic conditions.

A big part of staying tuned is maintaining open ties with the public. We held an unprecedented number of public meetings on this project, and collected comments through a toll-free number, a dial-up modem site, videoconferencing, 44 information centers, and a 5,000-person mailing list. We used the nearly 13,000 comments we received to shape the EIS issues; proposed action; purpose and need; as well as the themes and goals of the "action" alternatives (those that propose something other than current management). The goals of those five action alternatives are:

$\checkmark$ Goal 1. Sustain and where necessary restore the health of forest, rangeland, aquatic, and riparian ecosystems.

$\checkmark$ Goal 2. Provide a predictable, sustained flow of economic benefits within the capabilities of the ecosystem.

$\checkmark$ Goal 3. Provide diverse recreational and educational opportunities within the capability of the ecosystem.

Goal 4. Contribute to the recovery and delisting of threatened and endangered species.

$\checkmark$ Goal 5. Manage natural resources consistent with treaty and trust responsibilities to American Indian Tribes. 
How are American Indian Tribes involved?
The Federal government has a trust responsibility to American Indian Tribes which comes from agreements made by the United States in treaties, executive orders, and statutes. Part of that responsibility is to provide access to resources, such as salmon and deer, that Tribes have the right to use.

Whenever we propose actions that may affect access to those resources, we must consult with the affected Tribes.

Integrating tribal interests into the planning process is a positive and helpful experience. Tribes are interested in harvestable levels of resources in balance with each other, not exploitation of one resource at the expense of another. Tribal knowledge and experience of local areas and resources can be invaluable when making project decisions.

In the past, however, Tribes have not always been involved in the early stages of planning projects. This time, we appointed a Tribal Liaison Group to begin an involvement and consultation process, based on a government-togovernment relationship, with each of the 22 Tribes in the area. Recognizing that consultation is a process rather than an event, we consider it only a beginning.
Consulting early and regularly with American Indian Tribes whose rights are affected by management actions is part and parcel of this strategy.

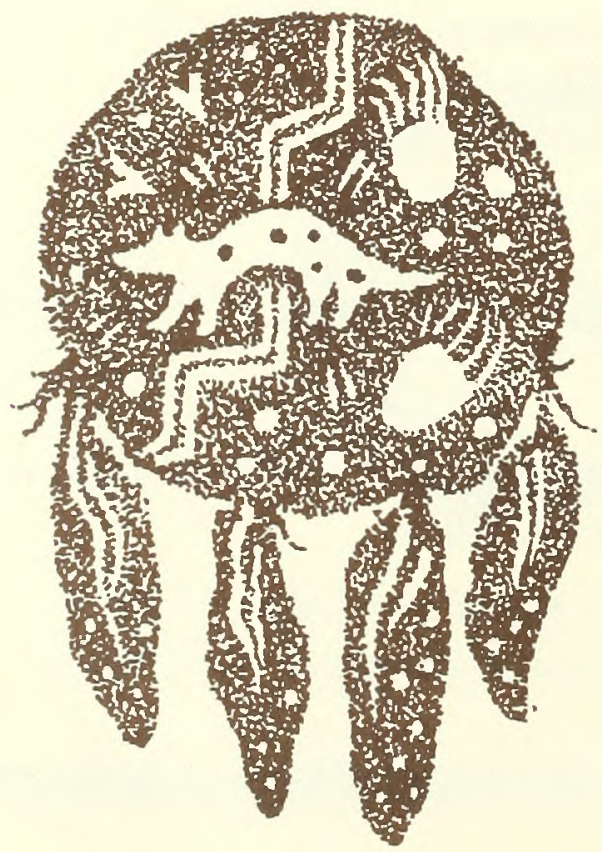

The Lands of Federally Recognized Tribes:

\begin{tabular}{|c|c|c|c|c|}
\hline * Tribal Headquarters & 8. & Fort Hall & 16. & Shoshoni NW Band \\
\hline 1. Blackfeet & 9. & Fort McDermitt & 17. & Spokane \\
\hline Burns Paiute & 10. & Kalispel & 18. & Summit Lake \\
\hline Coeur d'Alene & 11. & Klamath & 19. & Umatilla \\
\hline Colville & 12. & Kootenai of Idaho & 20. & Warm Springs \\
\hline Duck Valley & 13. & Nez Perce & 21. & Wind River \\
\hline Flathead & 14. & Pit River & 22. & Yakama \\
\hline Fort Bidwell & 15. & Quartz Valley & & \\
\hline
\end{tabular}

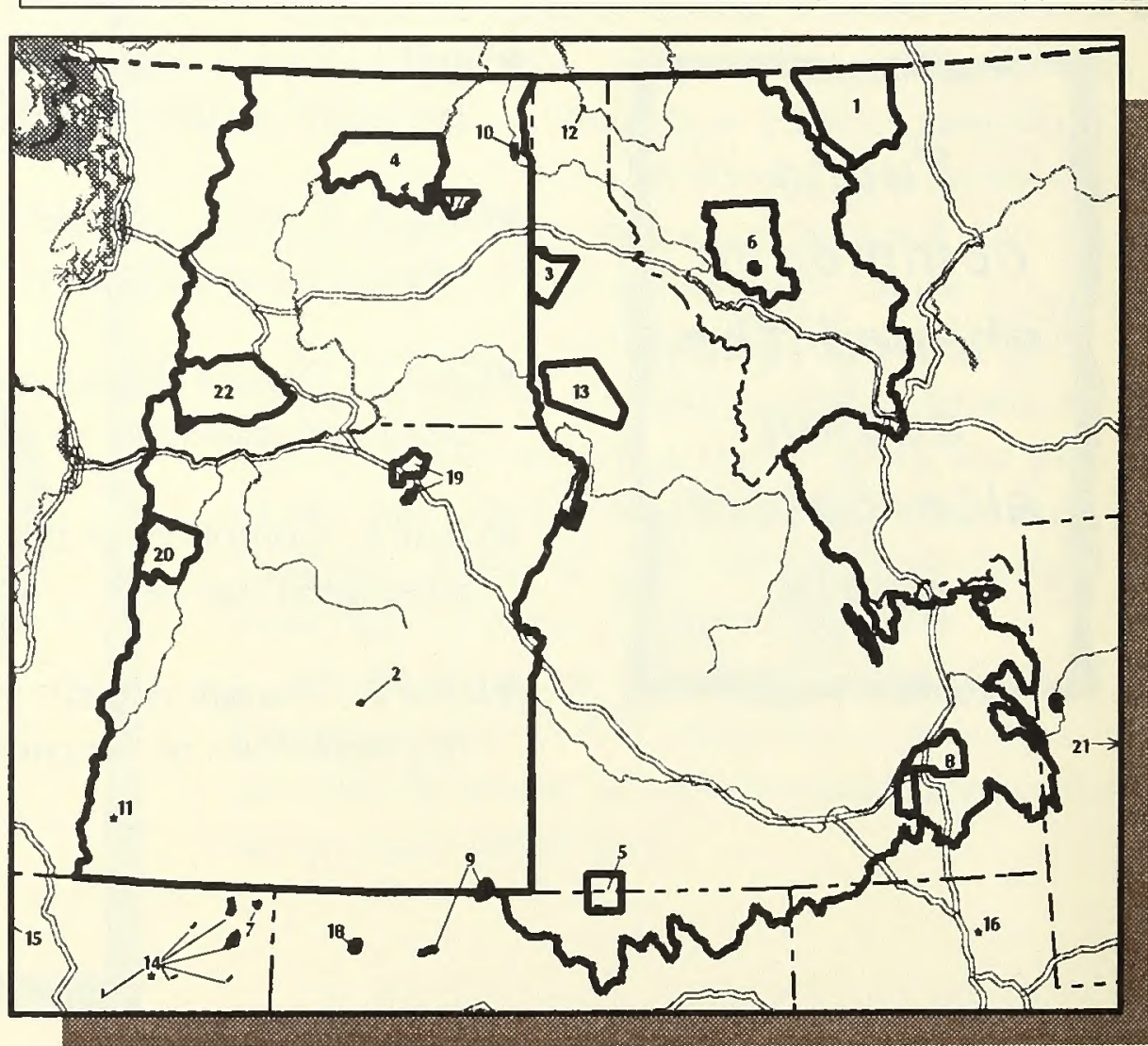


Which priorities will guide us?
As private lands become developed, public lands become "arks" of genetic diversity, clean water, scenic beauty, forage, fiber, etc. Realizing how past management activities have affected these very resources, we had to rethink our priorities. Leaders in both agencies have recently issued the following priorities to guide us, not only in this planning process, but in everything we do.

$\checkmark$ Protecting Ecosystems. The agencies will work to ensure the health and diversity of ecosystems while meeting people's needs. Special care for fragile or rare ecosystem components will be provided on lands administered by the Forest Service or BLM.

$\downarrow$ Restoring Deteriorated Ecosystems. The BLM and Forest Service will improve deteriorated ecosystems on lands they administer, based on scientific understanding and emerging technologies.

\section{$\rightarrow$ Providing Multiple Benefits for People Within the Capabilities of}

Ecosystems. Within the limitations of ecological integrity, health, and diversity, forests and rangelands also must meet people's needs for uses, values, products, and services.

We strongly believe that the best way to support economic, social, and ecological needs now and in the future is to learn to work within the capabilities of ecosystems. The challenge is to conserve healthy ecosystems and restore damaged ones so they will be physically able to provide clean

water, wildlife, recreation, timber, grazing, spiritual solace, and all the other goods and services that people value.

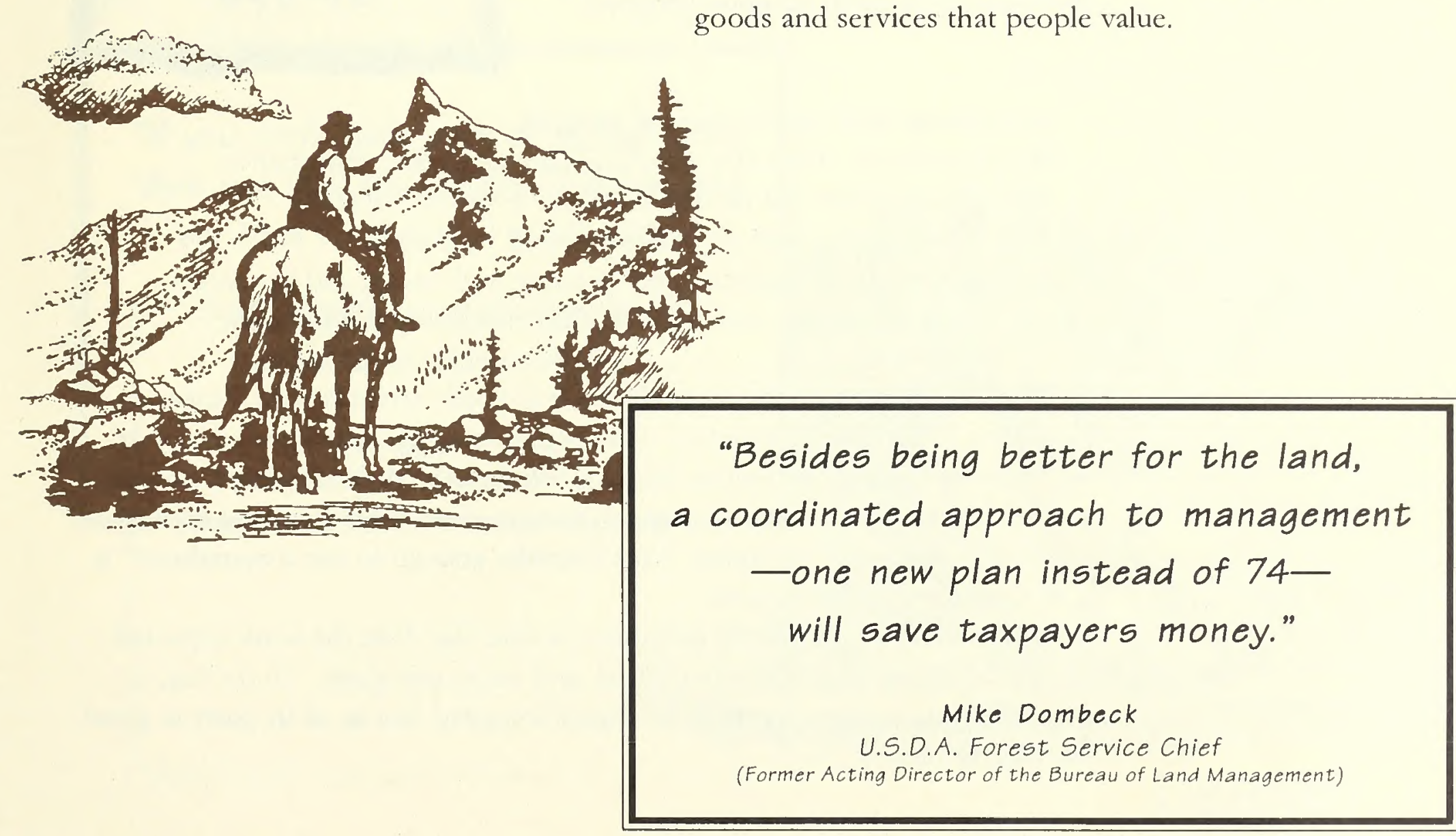




\section{Restoring Ecological Integrity}

What is an ecosystem?

What is a healthy,

high-integrity ecosystem?
A pond, a watershed, a mountain range, a desert: all are ecosystems. An ecosystem is a community of plants and animals (including humans) and their physical environment, all functioning together as an interdependent unit. They come in a variety of sizes, with smaller ecosystems embedded in larger ones on which they depend.

Ecosystems are dynamic and everchanging, every instant, every day, every season, every year.

Ecologist Aldo Leopold once referred to ecosystem health as the capacity of the land for self-renewal. Ecological integrity is the wholeness or completeness of an ecosystem, the degree to which it has all the parts and processes it needs to function properly.

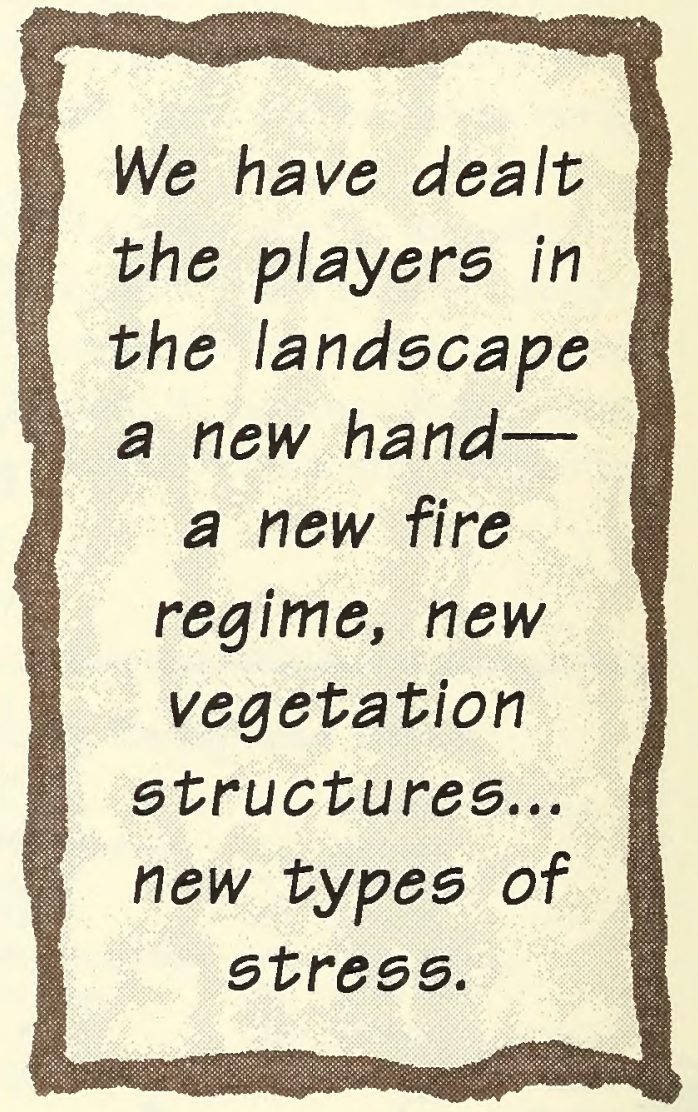

Ecosystems with high ecological integrity:

- Are resilient. They can withstand fires and other disturbance.

- Support native and desired non-native species diversity.

- Consist of a mosaic of well-connected habitats.

- Have functions (such as seed dispersal and decay) and processes (such as nutrient and water cycles) that operate effectively.

The idea of functioning properly is not a wholly scientific one, however. It is partly a judgment call based on what people want the ecosystem to do. It may help to think of it in terms of your own health. A doctor may pronounce you healthy until you mention that you want to run a marathon, and then a new set of standards will apply. "Am I healthy enough to run a marathon?" is a much more specific request.

In the same way, a healthy ecosystem is one that does the work expected of it in terms of environmental, social, and economic goals. To do this, it helps if the ecosystem has high ecological integrity, that is, all its parts in good working order. 
Why is it important to keep ecosystems healthy?
One of the signs that an ecosystem is in good working order is its ability to respond to disturbances such as fires, insects, or floods in a dynamic way. The system absorbs and recovers from disturbances without losing its processes or functions, the very things that allow it to heal.

Recovery may take varying amounts of time, and specific conditions may look different afterward. If the ecosystem is healthy, it will continue to produce populations of plants and animals that are diverse and viable, waters that are clear, air that is clean, and soils that are fertile. A sign of an unhealthy ecosystem is the presence of disturbances that are too large, too intense, or too frequent for the system to handle.

As you'll see on the following pages, healthy ecosystems provide a full range of life-support services. If ecosystems are whole and healthy, they can continue to perform these jobs in the environment even after disturbance. Ecosystems that are diverse enough to heal are also better equipped to keep on meeting human needs for timber, grazing, recreation, and so on. That's why healing degraded ecosystems, and keeping healthy ones healthy, are key priorities in this project.

"If you don't take care of ecosystems, then you lose the supply of goods and services from those ecosystems.

Sustainable ecosystems mean sustainable communities."

Jack Ward Thomas

Former U.S.D.A. Forest Service Chief

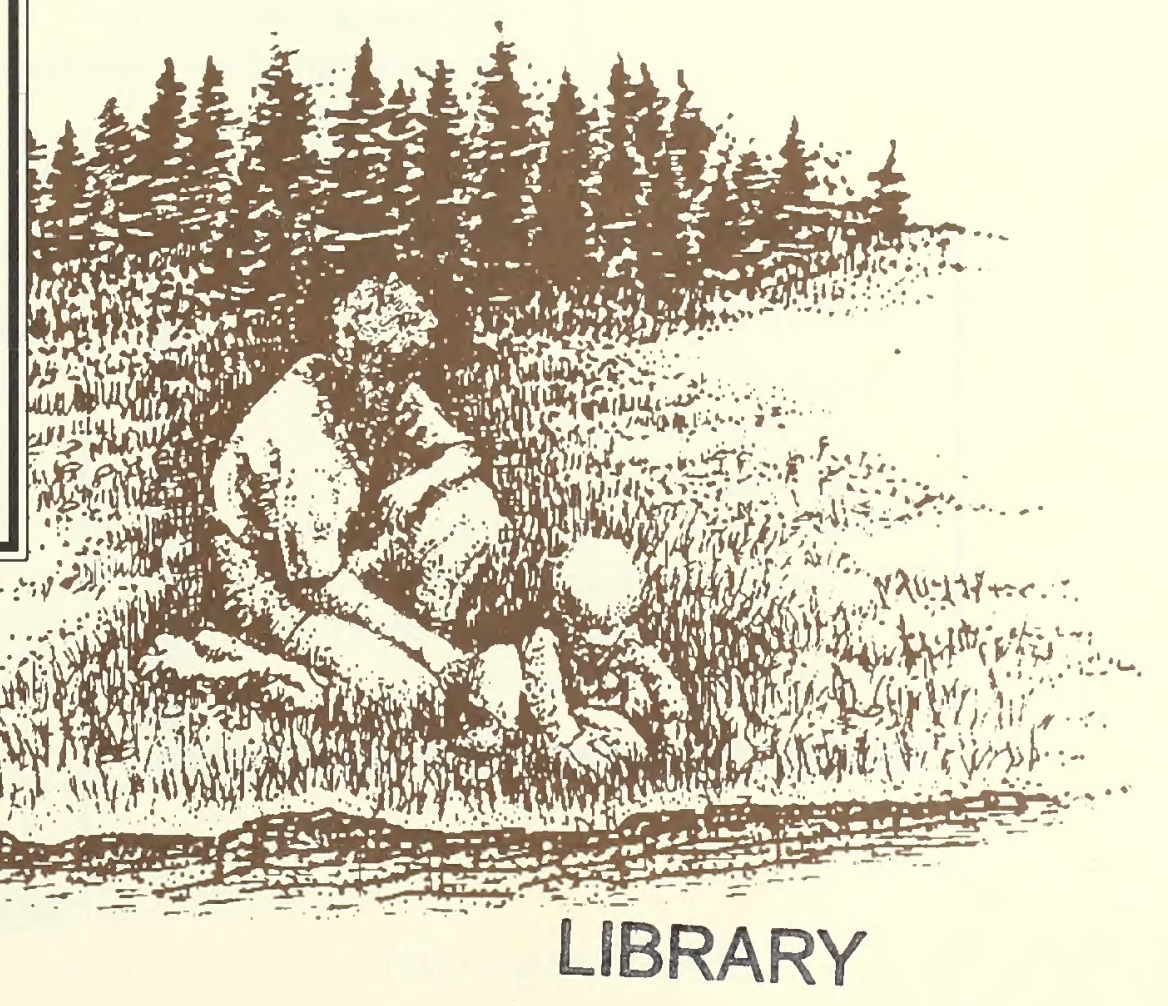




\section{Ecological Cycles}

We rely on ecosystems

for all the goods and

services they provide.

If ecosystems are

whole and healthy, they

can bounce back from

disturbance and

continue to cleanse,

recycle, supply, and

renew our world.
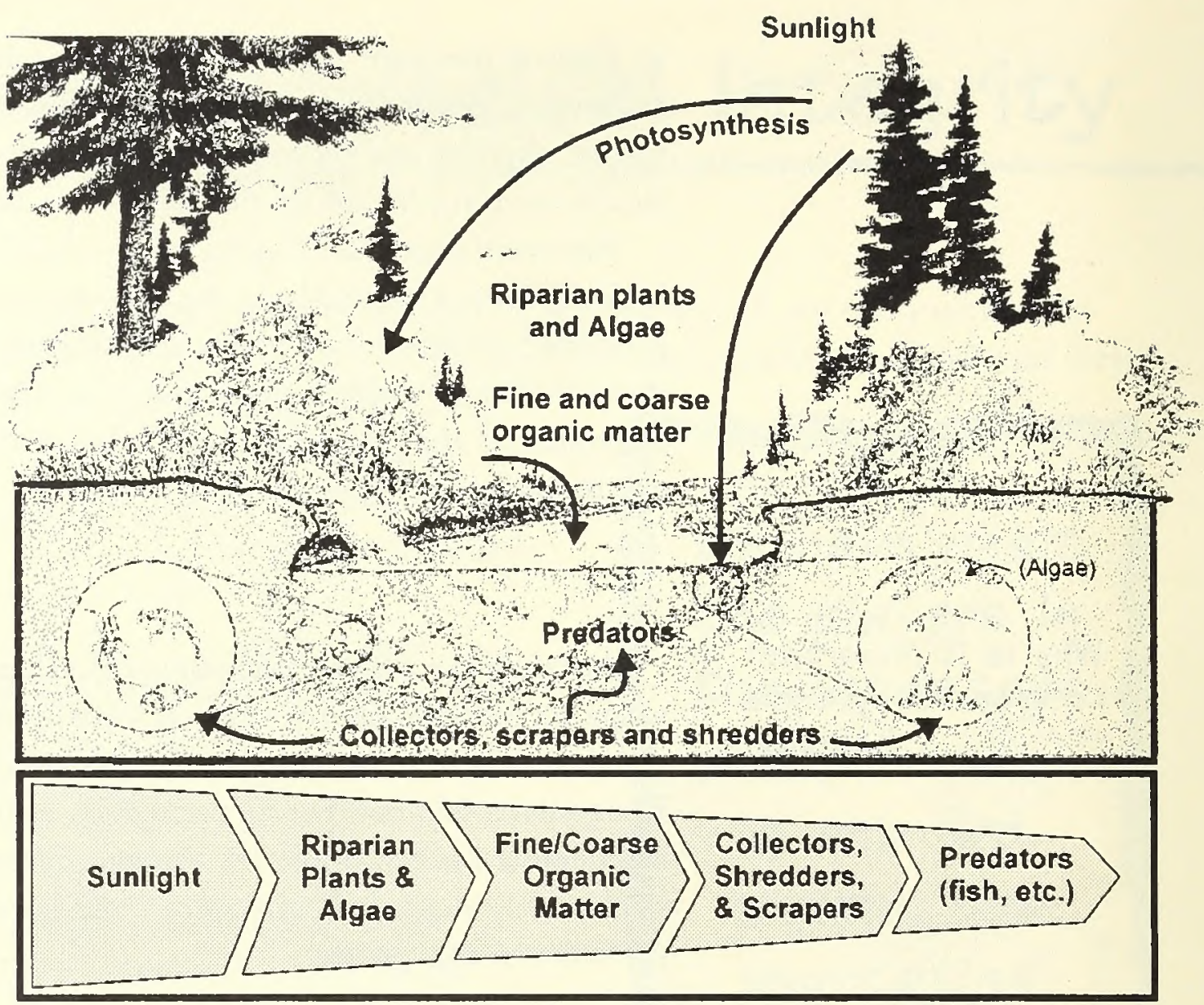

Aquatic Food Web

Ecosystem goods include:

* Food

* Construction materials

* Medicinal plants

* Wild genes for breeding domestic plants and animals that are more pest resistant, drought-hardy, etc.

* Tourism and recreation
Ecosystem services include:

* Maintaining hydrologic cycles

* Regulating climate

* Cleansing water and air

* Maintaining the gaseous composition of the atmosphere

* Pollinating crops and other important plants

* Generating and maintaining soils

* Storing and cycling essential nutrients

* Absorbing and detoxifying pollutants

* Providing beauty, inspiration, and new knowledge 


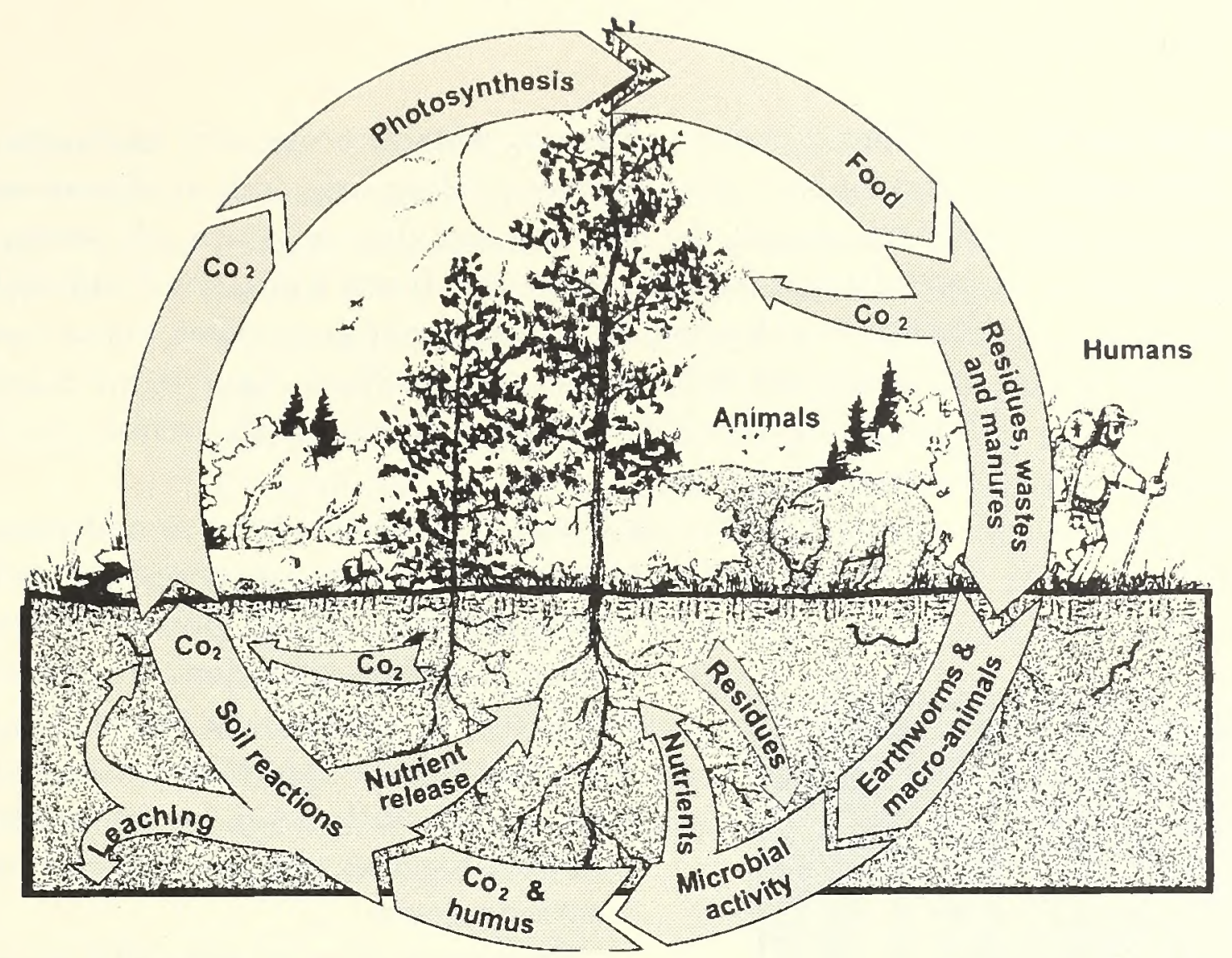

Carbon Cycle

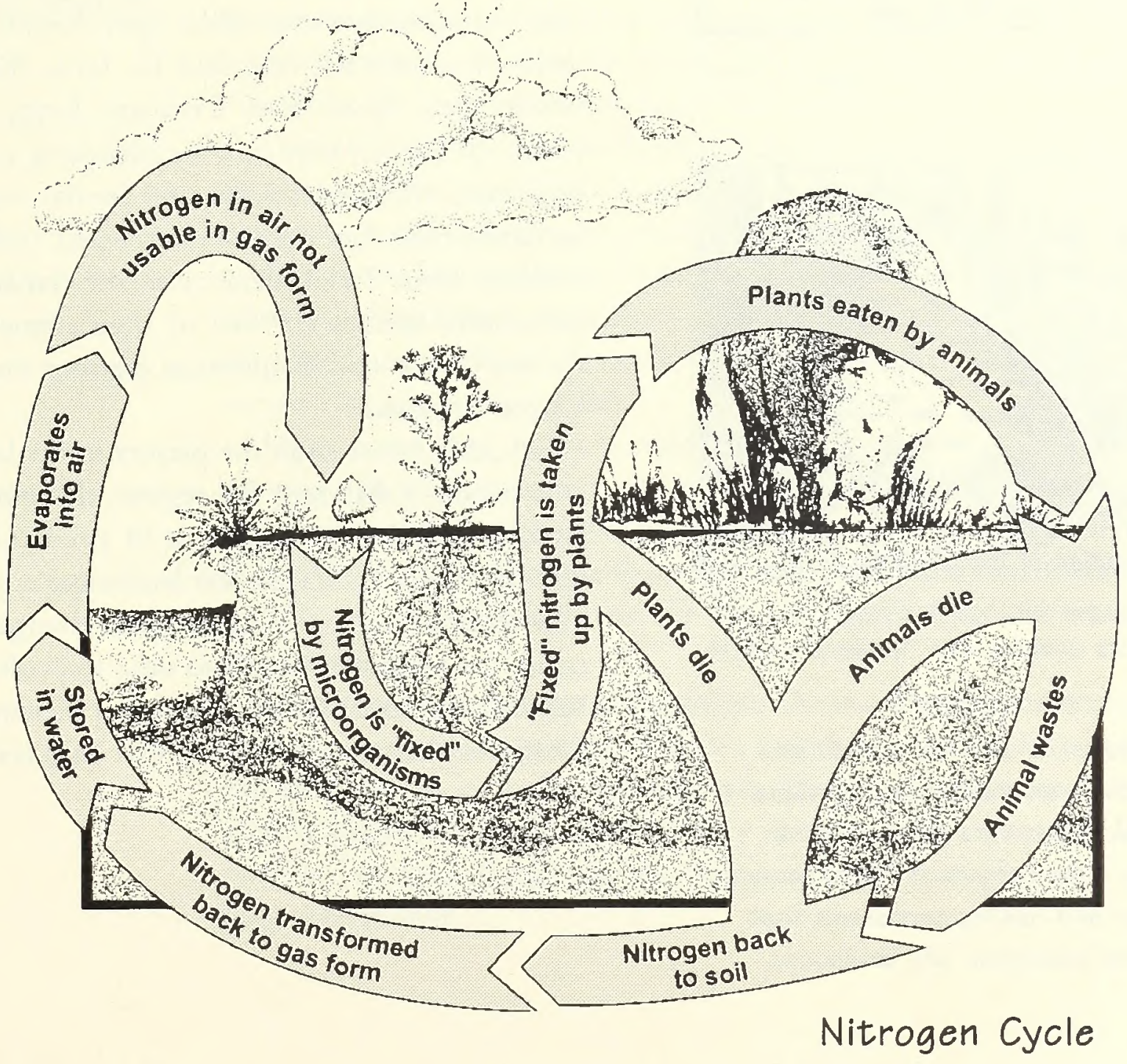


What can we learn from the past?

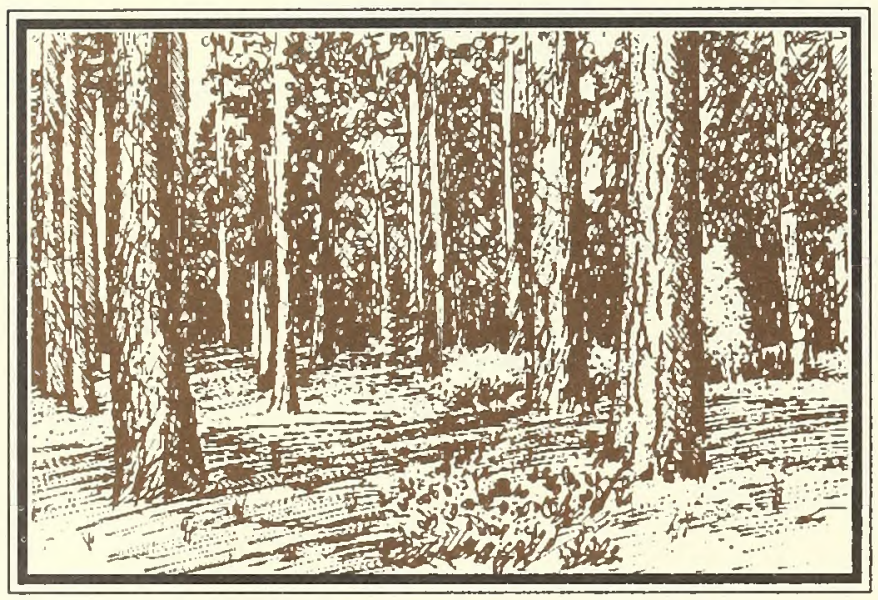

Western forests evolved with frequent fires.

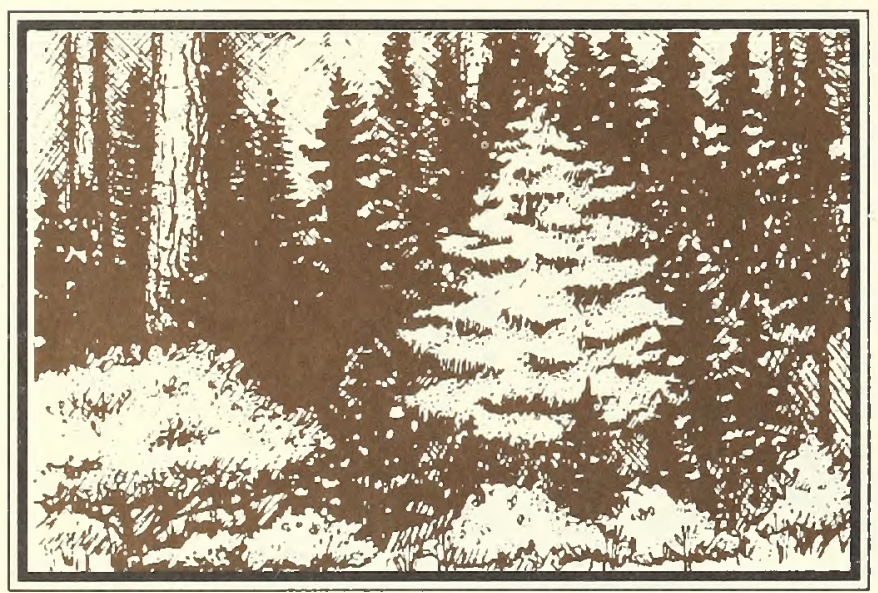

Eighty years without fire leads to uncharacteristic species and "ladders" of fuel.

The past teaches us what worked and what lasted-how healthy ecosystems sustained themselves through time.

Our challenge is to restore or mimic natural disturbance and healing processes that shaped and sustained the landscape. current ecosystem conditions. Ecosystems whose conditions are closer to the historic range, for instance, tend to be more in sync with natural disturbance regimes. They offer clues for management strategies that work together with, rather than at odds with, natural processes.

While many areas are still within their historic range, other forests, rangelands, and aquatic ecosystems in the Project Area no longer reflect native conditions. Some rangelands may have more shrubs or noxious weeds than grass, for instance. Old, open forests once swept by low-intensity fire may now be dense thickets of smaller, pest-prone trees. Formerly large, contiguous blocks of habitat may now be islands in a sea of highways, towns, reservoirs, and farms. Soils kept fertile by native microbes may be compacted and down to a skeleton crew. In all these cases, the remaining plant and animal species are "out of their element," evolved for conditions and disturbance regimes that are no longer in place.

It's as if we've dealt the players in the landscape a new hand-a different fire regime, different vegetation structure, different proportion of predators to prey, different soil conditions, less landscape continuity, and new types of stress. Because these changes have been rapid, the players haven't had time to evolve a response. Instead, communities are becoming increasingly frayed, losing the threads of diversity that lend resilience. 
Does that mean we want to go back to an arbitrary point in history?

How can we restore ecological integrity and health?
No. Even if we wanted to turn back the clock, the reality of roads, dams, human settlements, and mounting demands on our public lands would make it impossible-even in areas reserved from commodity production. The records of pre-European settlement are not targets in and of themselves, therefore, but tools for understanding. They give us a model of conditions and patterns that performed and persisted in our part of the world. The closer we can come to understanding those natural conditions and patterns, the healthier our future forests, rangelands, and aquatic ecosystems can be.

It's important to remember that "natural conditions and patterns" don't create a certain look that never changes. It's more of a behavior: a functioning well in the face of change. When these systems are operating at full capacity, they are naturally equipped to handle disturbance. They evolved, after all, with a steady diet of fires, insects, diseases, floods, human uses, and weather events. Change was and still is the only constant. Restoring the ecosystem's regenerative powers-its ability to take natural and human-caused changes in stride-is our real quest.

The good news is that most of the core ecological pieces, the building blocks of ecosystem health, are still in place in the Project Area. The management actions that were so instrumental in changing integrity, can, if we want them to, be used to restore desired structures, compositions, and functions, all while providing for human needs.

Harvests or thinnings could clear choked understories, for instance, encouraging the growth of more characteristic tree species. Leaving large trees and snags could help restore multi-story, old-forest structures. Prescribed fire could remove fuel build-ups, mimicking the cycles of natural fire. Grazing plans which include herding and season-of-use changes could actually improve rangeland health. Road restoration could reduce erosion and improve habitat security for sensitive wildlife.

Using these tools in the service of an ecosystem-based philosophy, we can provide a flow of resources for human use, and do it in a way that moves the landscape toward a more self-sustaining condition. The ecosystem manager becomes like the master gardener whose ultimate goal is not just to grow this year's tomatoes, but to build the soil that will grow lots of different vegetables for years to come.

Other tools are conceptual in nature. New computer mapping software allows us to look at a variety of scales, and then layer the information so we can see patterns in the living landscape. At the same time, new study approaches in the social sciences allow us to see how humans influence these systems, tracking changes as they ripple through multiple scales and over long time frames. 
Another conceptual tool developed specifically for this project is the Framework for Ecosystem Management, prepared by our Science Integration Team. Its principles, listed below, offer managers a compass to help orient them to ecosystem-based thinking.

- Ecosystems are dynamic and evolutionary.

$\checkmark$ Ecosystems can be viewed as being organized within a hierarchy, with each level having a variety of time and space scales.

- Ecosystems have biophysical and social limits.

-There are limits to the predictability of ecosystem patterns and processes; conditions and events may be predictable at some scales and not at others.

Will we still manage Forest Service and BLM lands to meet human needs?
Yes. Ecosystem management is designed to meet human needs, but to do so in ways that also meet ecosystem needs. This challenges us to expand our focus-to sustain not only the "deliverables," but also the ecosystem patterns and processes that are the source of those deliverables.

How will we know which ecosystem patterns and processes are important? Fortunately, we are surrounded by examples (and we have past records) of ecosystems that have been self-perpetuating and meeting the needs of all inhabitants, including humans, for a millennium. By paying more attention to natural disturbance regimes, vegetative structure, composition, and function, we hope to incorporate the genius loci-wisdom of the placeinto our management actions.

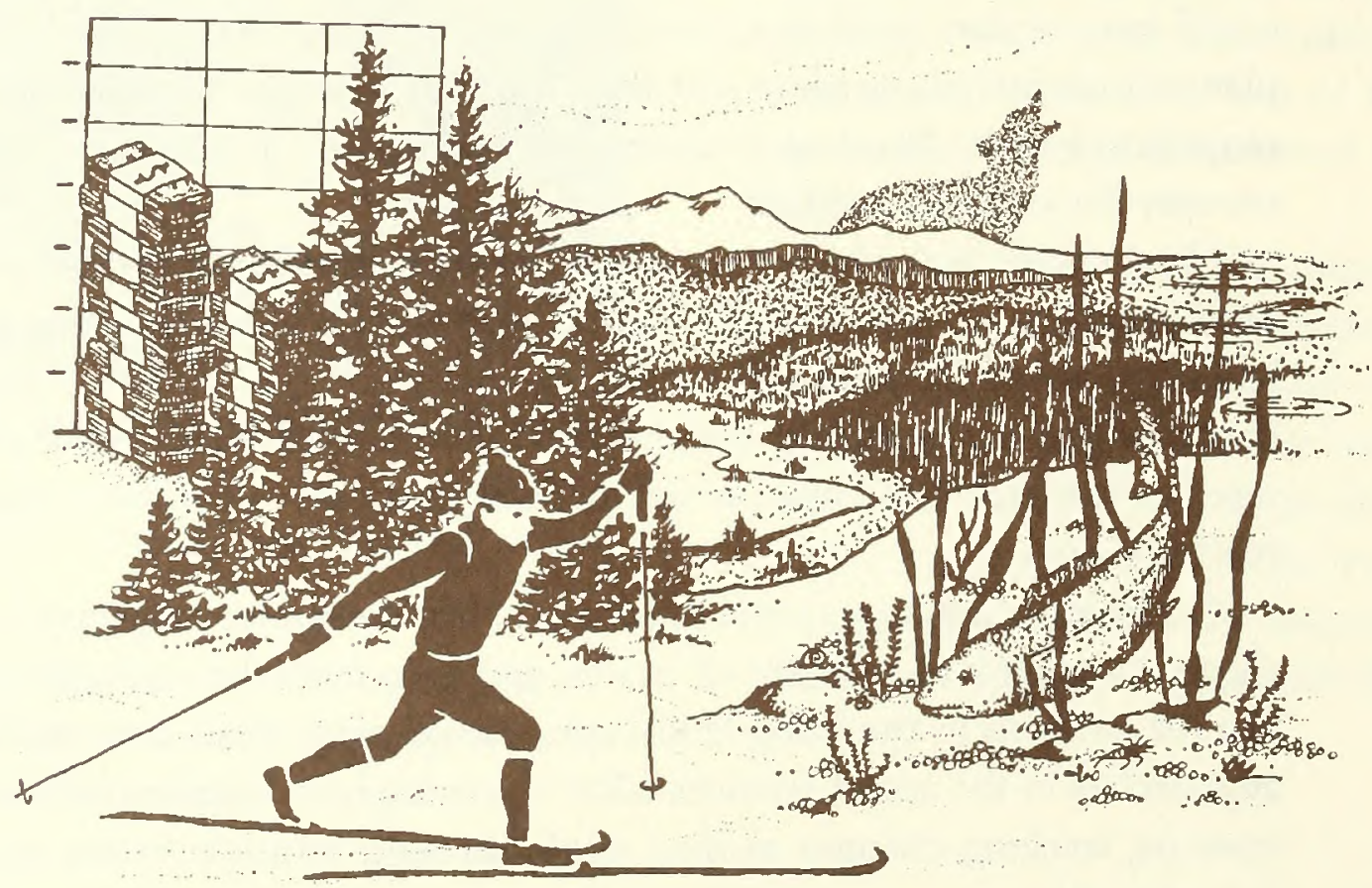


What is adaptive management?
Adaptive management, or learning-as-we-go, works via a series of feedback loops that drive mid-course corrections. Basically, we try something, study the results, then use what we learn to work smarter.

Adaptive management is both respectful and realistic. It realizes that ecosystems are not only more complex than we know, but perhaps more complex than we can know. Regardless of our incomplete knowledge, humans will continue to influence ecosystems. All we can do is go forward with the best information we have at hand, continue to ask hard questions, and vow to reinvest what we learn into our next project.

As part of our own schooling as ecosystem managers in this landscape, we conducted a scientific assessment unrivalled in depth and breadth. This next section describes what we have learned from both the people and the land.

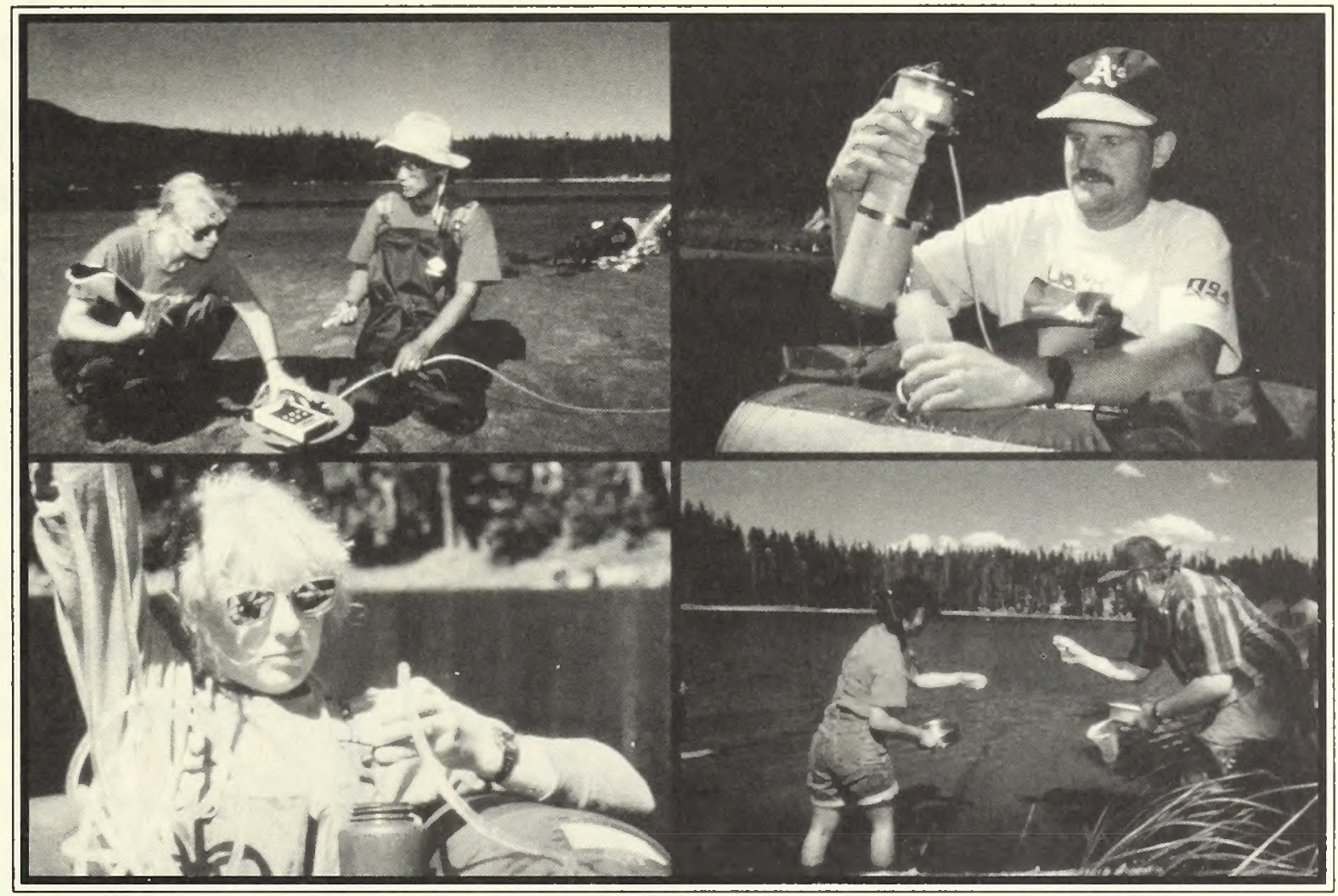

Ecosystem management has a steep learning curve.

The key to managing complex systems at a broad scale is to monitor, monitor, monitor... then adapt based on what we learn. 


\section{Learning from the Land and Its People}

What data was collected in the

Scientific Assessment?
At the time it was conducted, this was the largest ecosystem assessment of its kind in the world. The task was momentous: take an area as vast as France and find a way to gauge both its social/economic and ecological health. We were to collect data on everything from manufacturing plants to sensitive plants.

Some of the data had already been collected by other Federal agencies, local governments, and the larger research community, but it was scattered and inconsistent. No one had ever arrayed the data so it could be compared across the landscape, nor had anyone attempted to merge the measures into an integrated whole.

In all, the Science Integration Team analyzed over 170 different layers of information using a computerized mapping tool called a Geographic Information System (GIS). You can think of each GIS layer as a plastic sheet on top of a map-one has information about human population trends, one shows the streams where salmon strongholds remain, etc. Looking through the layers, you begin to notice social, economic, and ecological trends. Native species trouble spots and fragile areas stand out, as do places of opportunity and resilience. This information, in GIS form, will now be available to anyone who needs it, and will be a lasting legacy of this project.
Scientists are taught to turn up the power on their microscopes to get a better look.

What they really need to do is get $a$ macroscope. 


\section{Examples of GIS Layers}
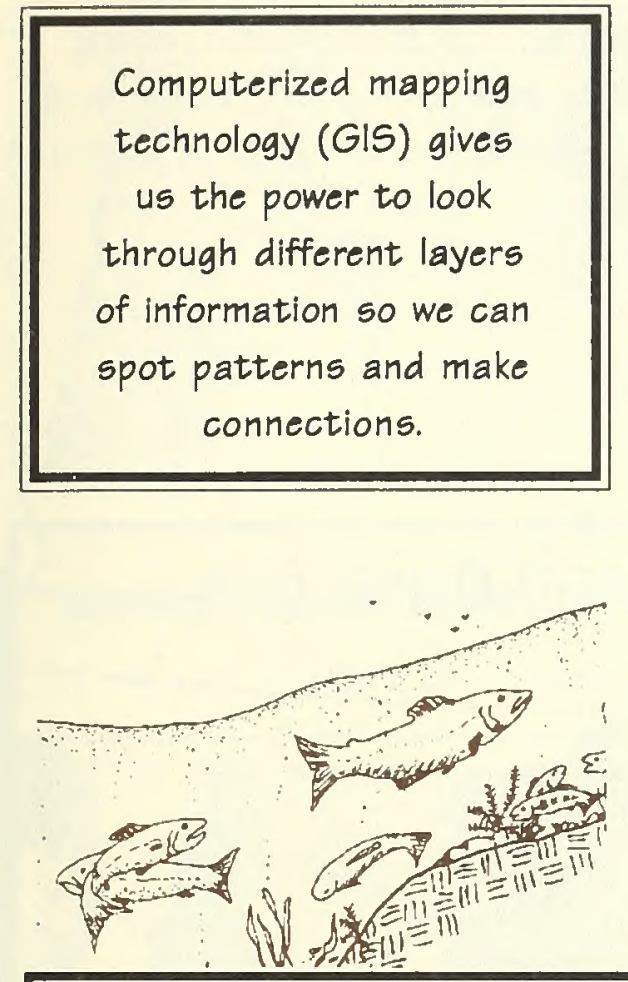

Distribution of Stream-Type Chinook Salmon

(HIstorlc and Current Habltat Zones)
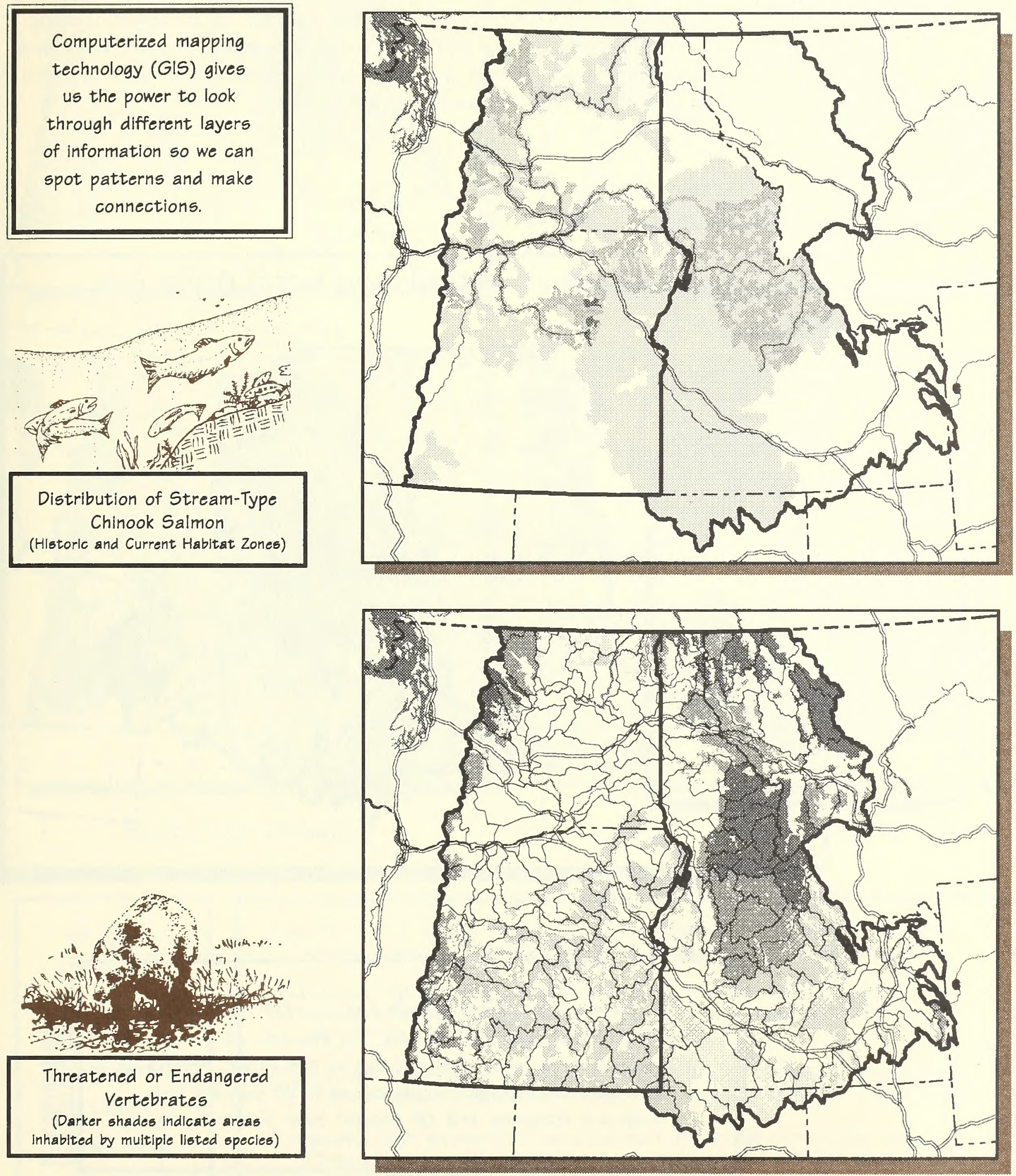
How did we integrate the information to measure ecological integrity?
The challenge was to integrate these layers of information into a meaningful measurement that would let us characterize conditions, risks, and opportunities on the landscape. The measurement we used is called "ecological integrity." Composite ecological integrity was measured by using indicators or "proxies" that represent ecological functions and processes. Areas where these indicators are present and operating would be rated higher than areas where they are absent or not functioning.

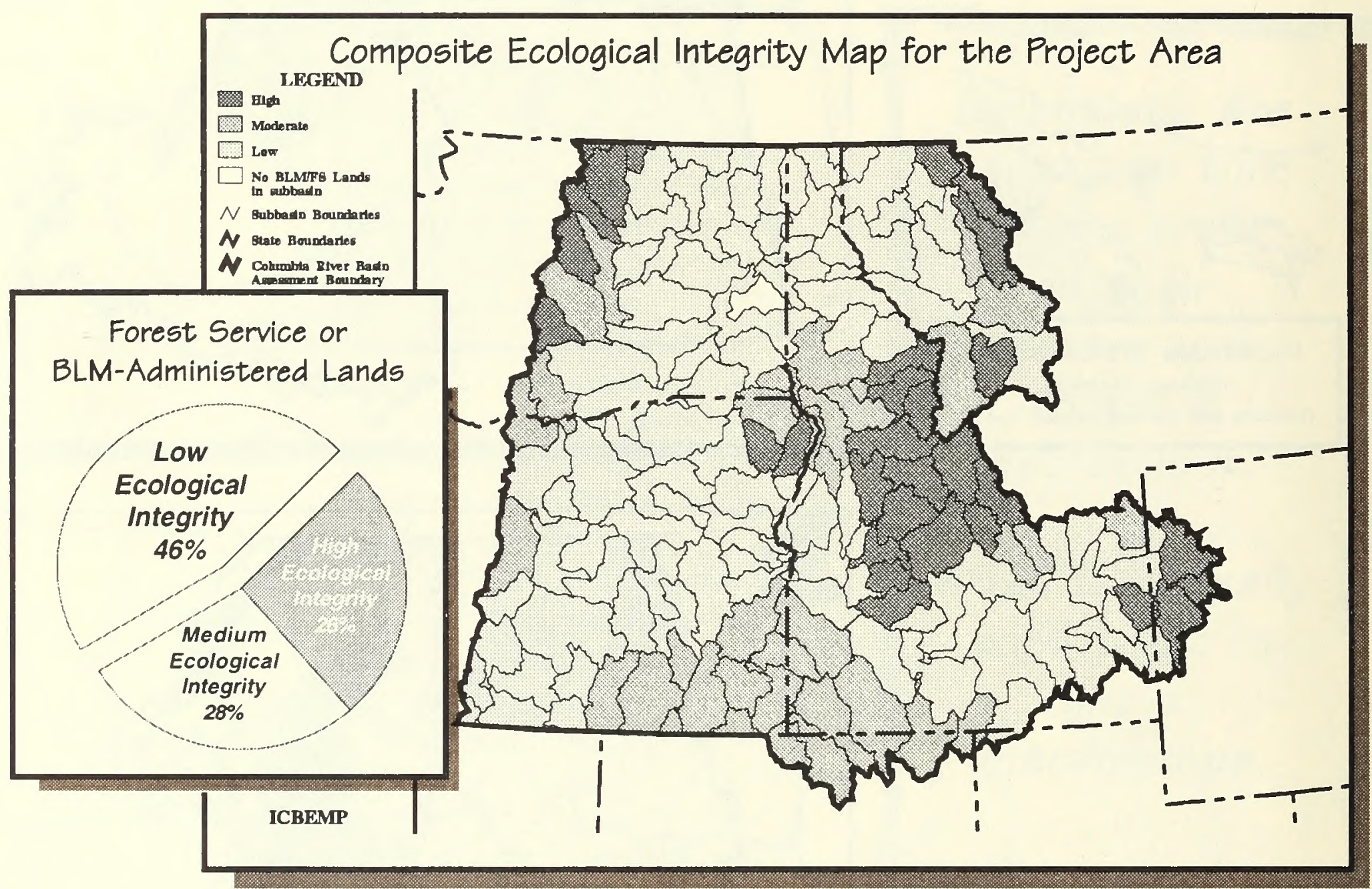

In general, the more a system has changed from natural conditions, the lower its integrity. At present, 46 percent of the Project Area lands administered by the Forest Service or BLM have low ecological integrity, while 28 percent have moderate integrity, and 26 percent have high integrity. 


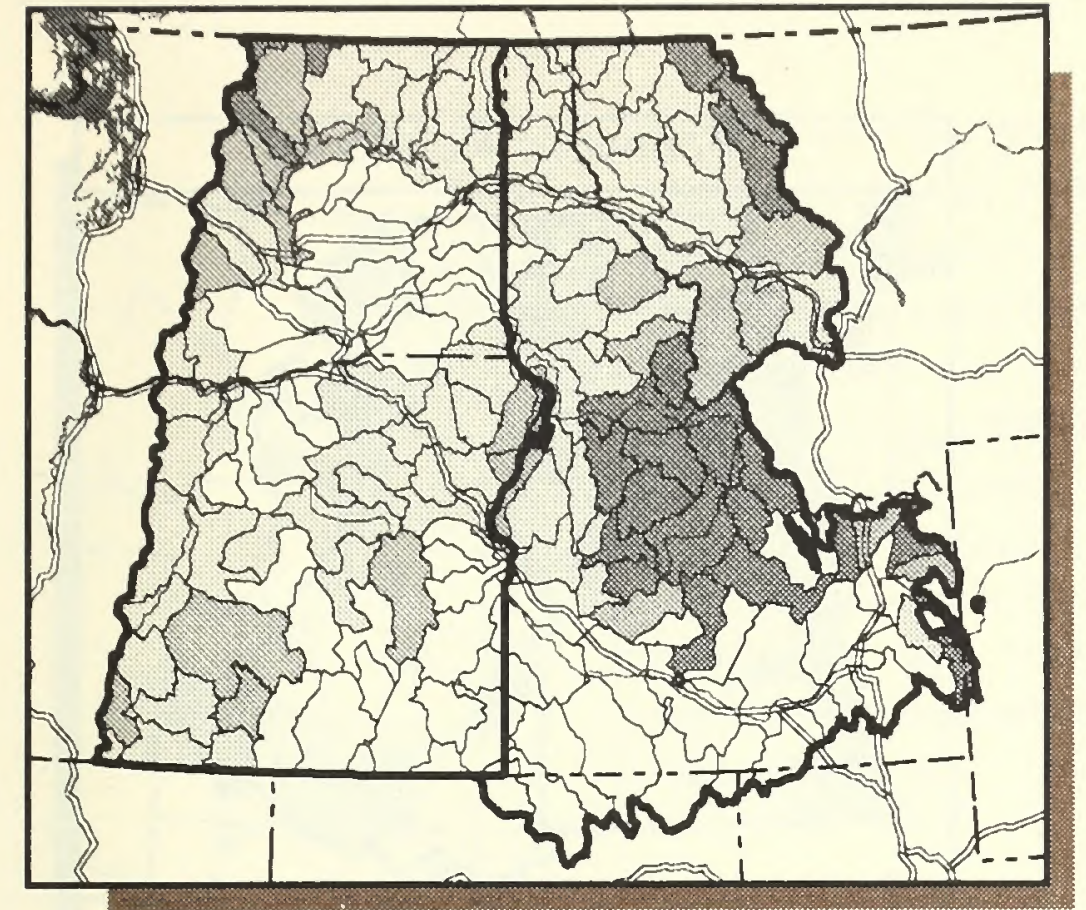

Forest Integrity

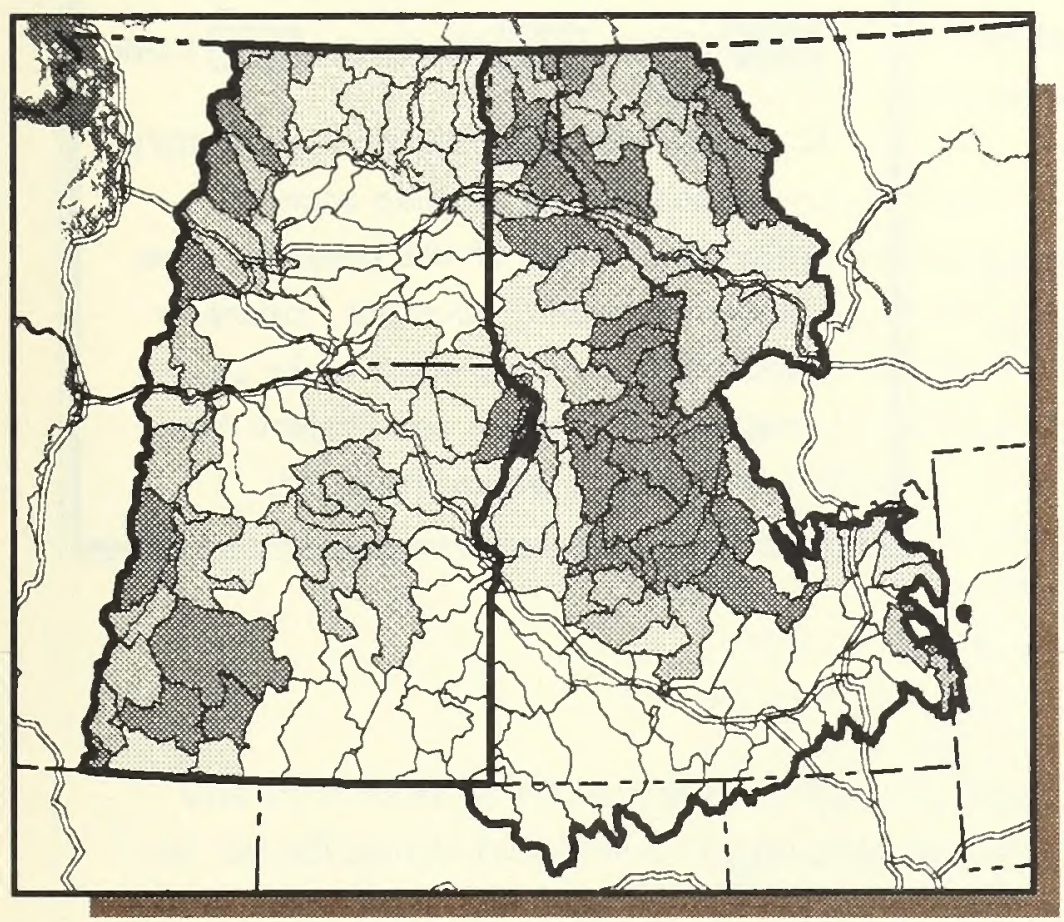

Hydrologic Integrity

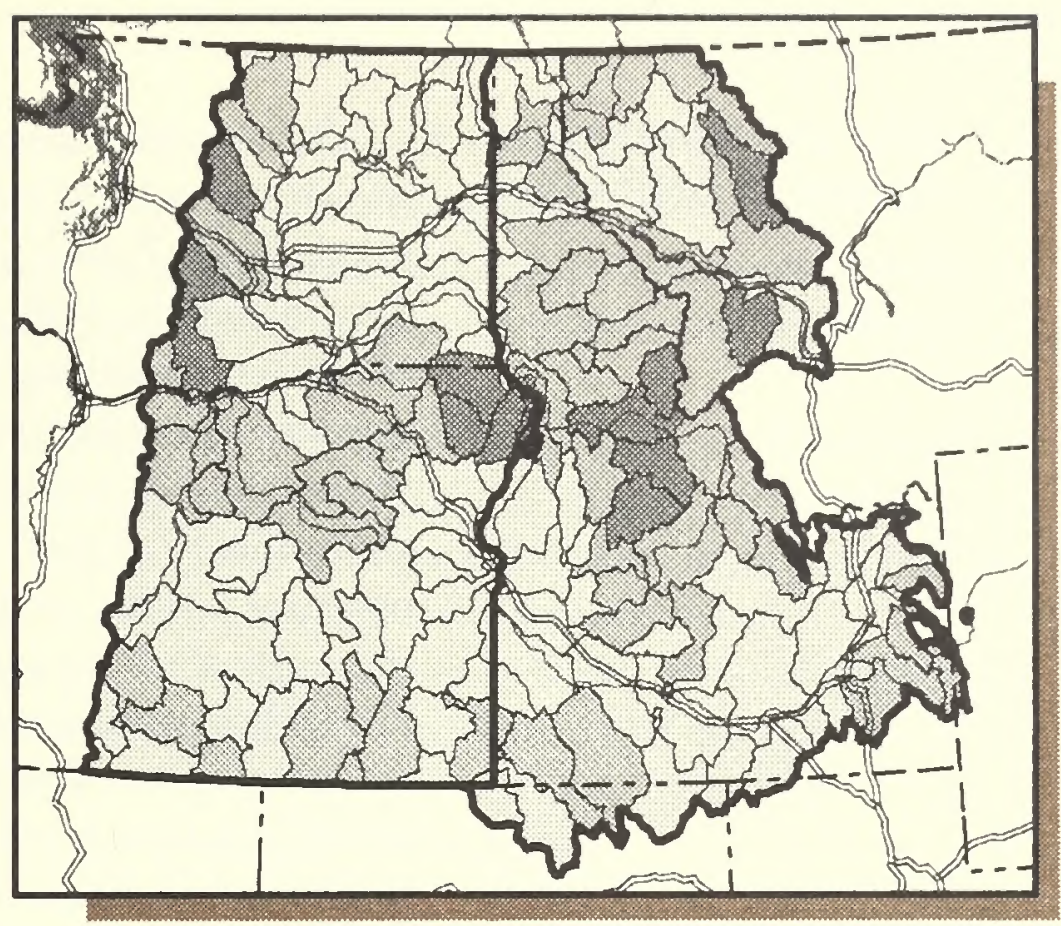

Aquatic Integrity

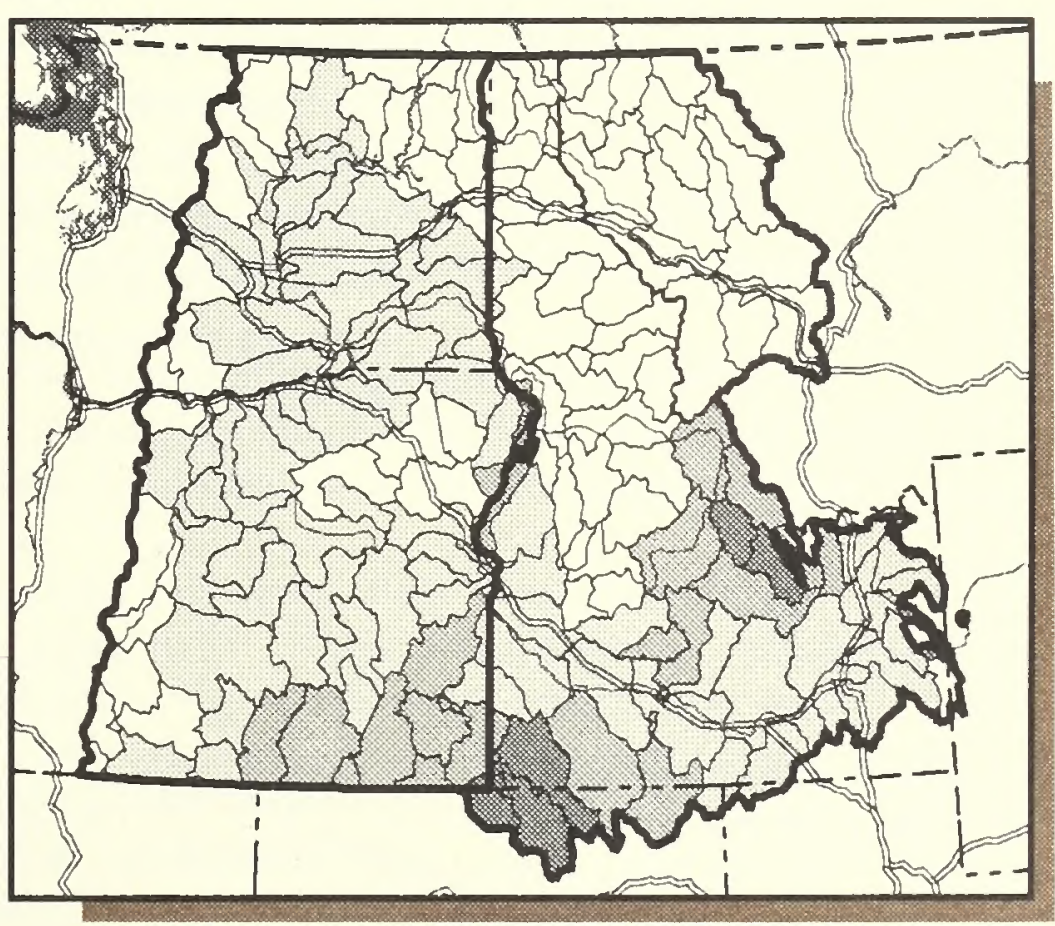

Range Integrity

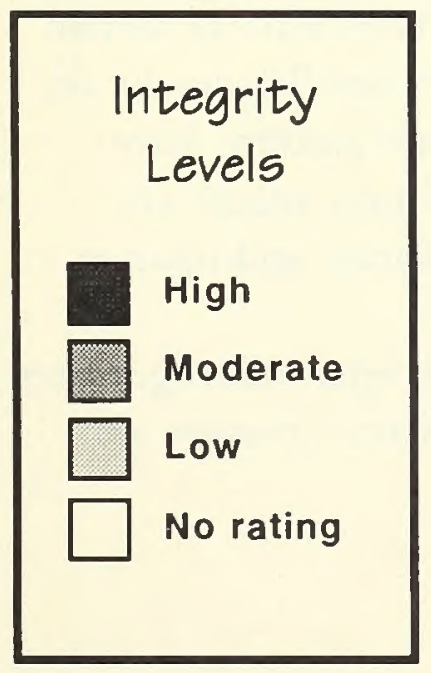

Aquatic high integrity: Possessing a full complement of native fishes and other aquatic species that are well distributed in high-quality, well-connected habitats.

Hydrologic high integrity: A network of streams where upland, floodplain, and riparian areas have resilient vegetation; these networks support aquatic and terrestrial environments that are diverse and productive.

Forest high integrity: A mosaic of plant and animal communities; well-connected, high quality habitat; diverse assemblages of native and desired non-native species.

Rangeland high integrity: A mosaic of plant and animal communities; wellconnected, high-quality habitat; diverse assemblages of native and desired non-native species. 
How did we measure economic resiliency?
The Scientific Assessment also revealed social and economic trends in the Project Area. One of the most telling is community resiliency: a community's ability to diversify its economy so it is less vulnerable to market upheavals. When we look at the regional level, economies in the Project Area are diverse and have high resiliency. At the county level, however, economic resiliency varies.

Over half of the counties have low resiliency. Rangelanddependent counties located in drier areas have especially low resiliency. As a result, BLM and Forest Service land management policies can have a greater economic impact on these counties.

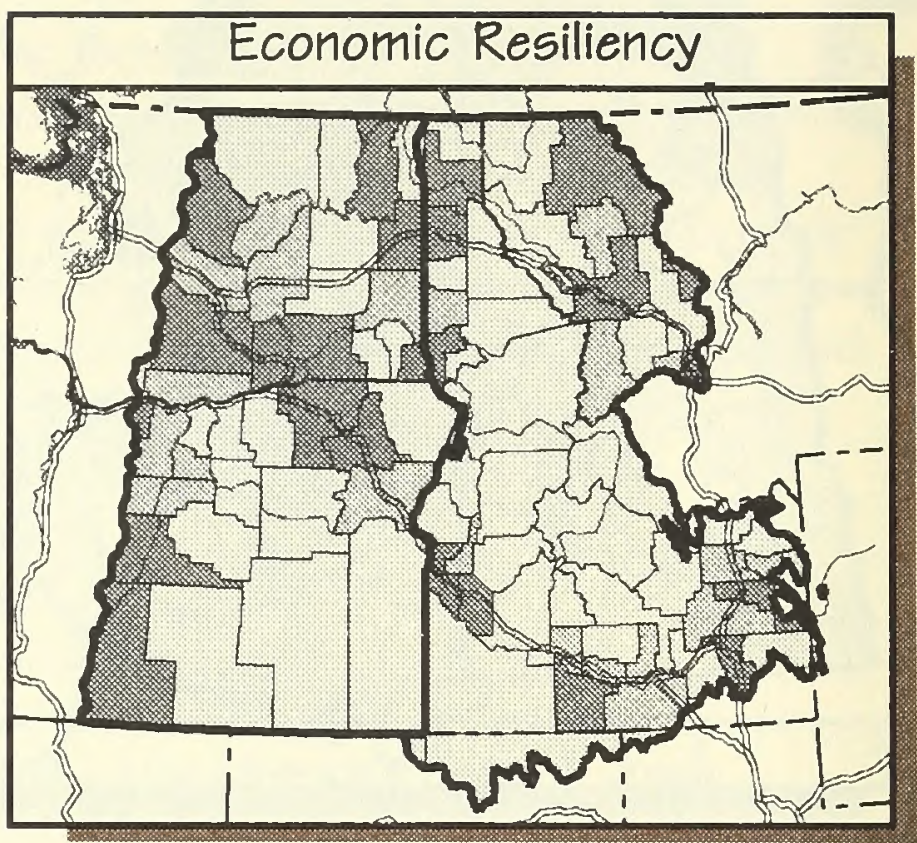

High Medium Low

Economic resiliency refers to a county's sensitivity to outside economic influences. Most of the population live in high-resiliency counties. Sparsely populated counties, which make up the majority of lands in the Project Area, tend to be low-resiliency.
What condition is the Project Area in now?
The interior Columbia Basin is a spectacular stretch of both wild and settled country. Its landscapes range from wind-sculpted alpine forests to fertile agricultural valleys to fossil-studded desert plateaus. Each year, more people visit or move to this area, iured by its scenic beauty, its rich resources, and the opportunity to unwind in some of the country's premier wildlands.

When we look at the landscape as a whole, however, we realize that all is not well. After more than a century and a half of sometimes intense human use, many areas are showing signs of stress. Native cold water fish stocks are rapidly declining, soil fertility is at risk, forest structures and patterns have changed from naturally occurring conditions, wildfire and pest attacks are becoming more severe, noxious weeds are invading rangelands, and riparian and aquatic health is deteriorating.

As a result, resource flows have become unpredictable, legal challenges have increased, and human communities are at risk. Low-resiliency counties are especially affected. 
As public land managers, we oversee some of the areas that have been hardest hit, but we also manage some of the "strongholds," areas that have the elements needed to rebuild damaged areas. For this reason, it's important to fully understand the trajectory of our management actions, and be willing to change if we see adverse effects.

Consider, for example, the practice of excluding fire, a policy that was wellintentioned and socially sanctioned. What we didn't realize at the time was that fire was essential to the health of many western forests: a steady diet of light underburns helped thin the forest and reduce the likelihood of catastrophic fires. Now, after 50 to 80 years without periodic burns, crowded forests of moisture-stressed trees invite insect and disease outbreaks and explosive fires.

What are the positive trends?
These conditions have provided a serious wake-up call for natural resource managers in the Project Area. To make sure damage does not continue, we've already made many course corrections, positive moves that will be formalized in the alternatives.

- Soil productivity-best management practices in use today reflect improved understanding of how soils respond to various treatments, especially at the fine scale.

$\checkmark$ Road construction and management-best management practices in use today reflect improved understanding of drainage, erosion potential, fish passage concerns, slumpage problems, and other hazards of road building and maintenance.

- Rangeland management—strides have been made toward improving rangeland conditions on public lands. Modernized allotment management plans, developed in cooperation with livestock permittees, have been especially effective. More improvements can and should be made.

- In historic times, as far as we know, no vertebrate species has become regionally extinct on Federal lands in the Project Area. High profile species that are endangered-such as the grizzly bear and bald eagle-are now protected by recovery plans. Attention has shifted to species that are not as well known.

Taking lessons from the past is key to continuing these and other positive trends. To give you an overview of where we've been during the last 100 years and where we are now, we present the findings from the Affected Environment chapter of the Draft EISs in graphic form on the following pages. Not all of the findings are negative, but some should ring alarm bells and strengthen our resolve as a society to find agreeable solutions for the sake of the land and future generations. If you would like more detailed information, see Chapter 2 of the Draft EISs, or order a copy of the Integrated Assessment for the Interior Columbia Basin and Portions of the Klamath Basin and Great Basin. 


\section{Forestlands}

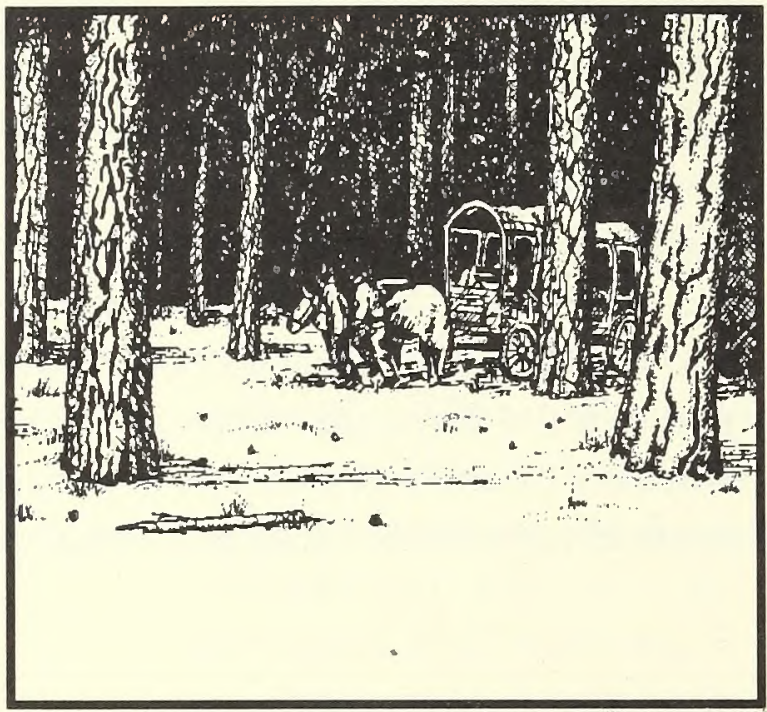

\section{0 years ago:}

- Dry forests featured large, widely spaced sun-loving trees.

- Frequent, light fires cleared competing vegetation.

- Plant and animal species migrated freely through large habitat blocks.

\section{Rangelands}

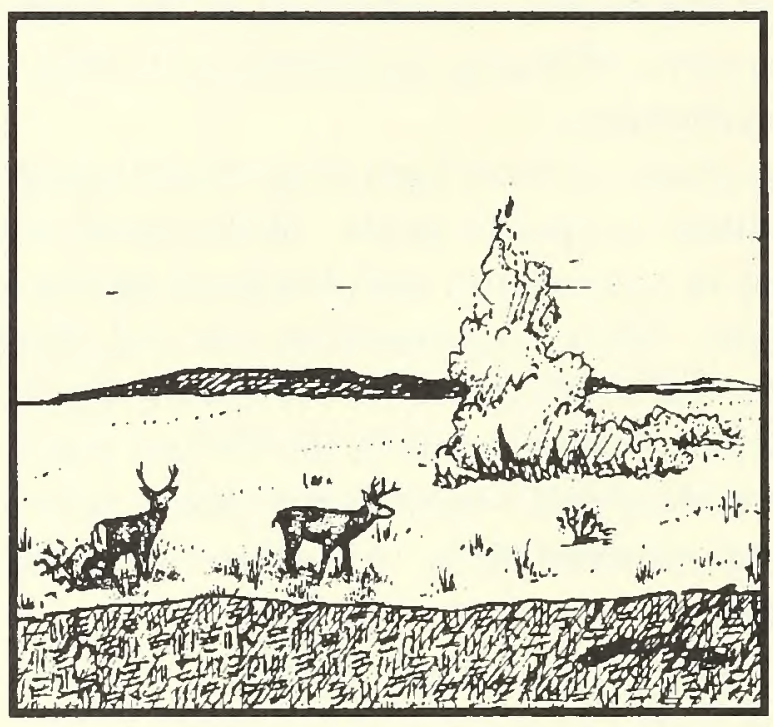

100 years ago:

- Frequent fires cleared organic debris and encouraged perennial shrubs and grasses

- Native species evolved with one another; there were no exotics.

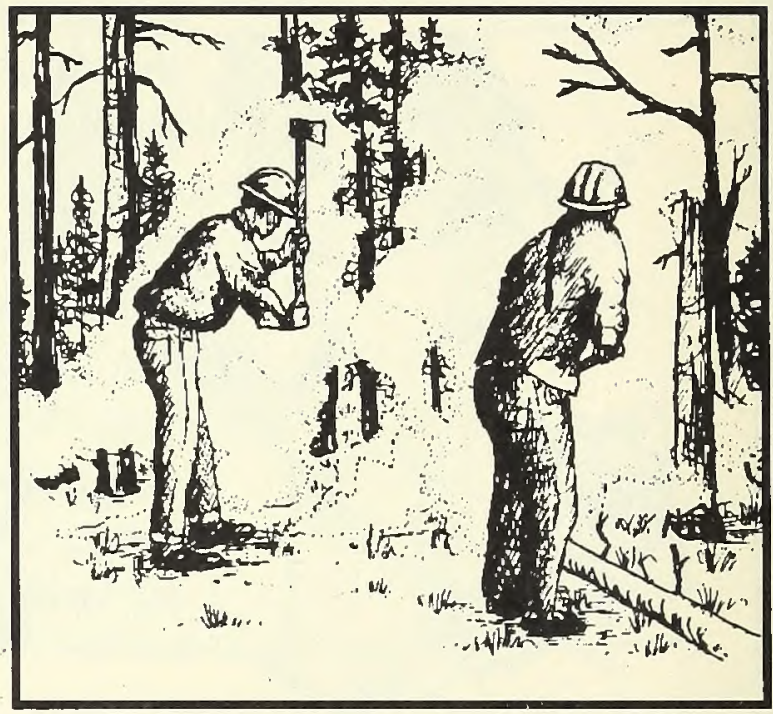

Over the last century:

- Large trees were harvested.

- Fires were suppressed, allowing shadetolerant species to fill the understory.

- Human access increased, dividing up habitat blocks, especially on private lands.

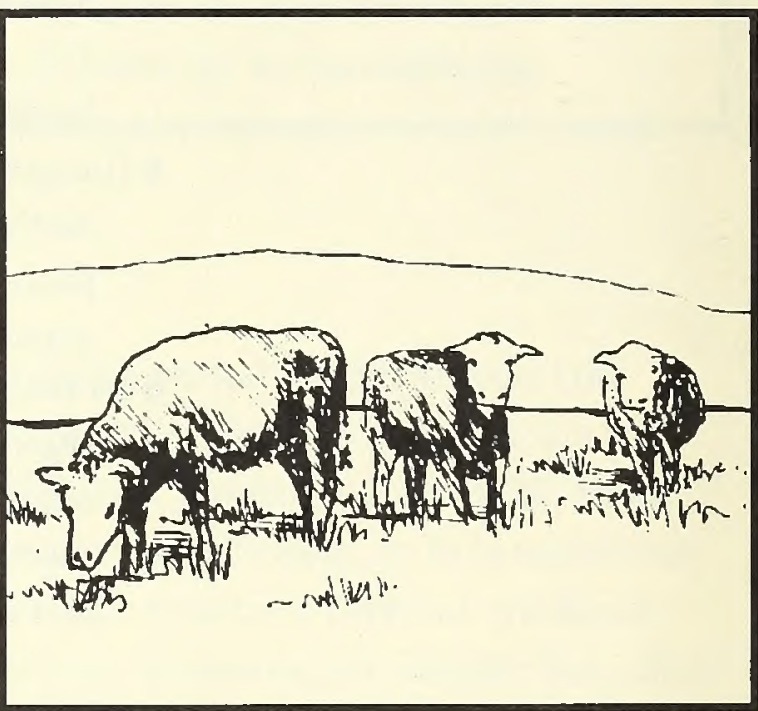

Over the last century:

- Fires were suppressed, and build-up of fuels was reduced by grazing.

-Exotic weeds invaded.

\section{Where We Have Been...}




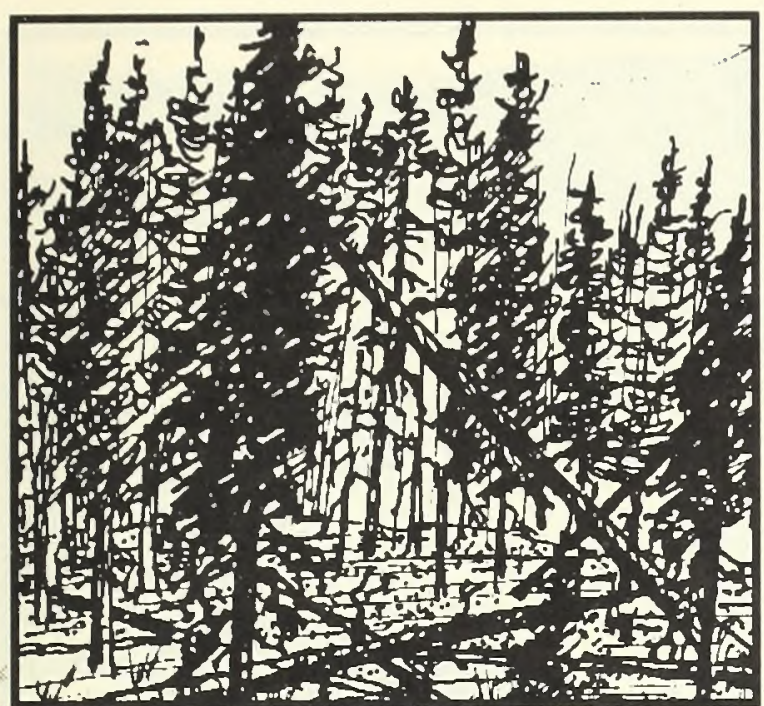

As a result:

-Dry forests feature smaller, densely grown, shade-tolerant trees.

- Dense understories create fuel build-up.

- Altered habitats make some species vulnerable.

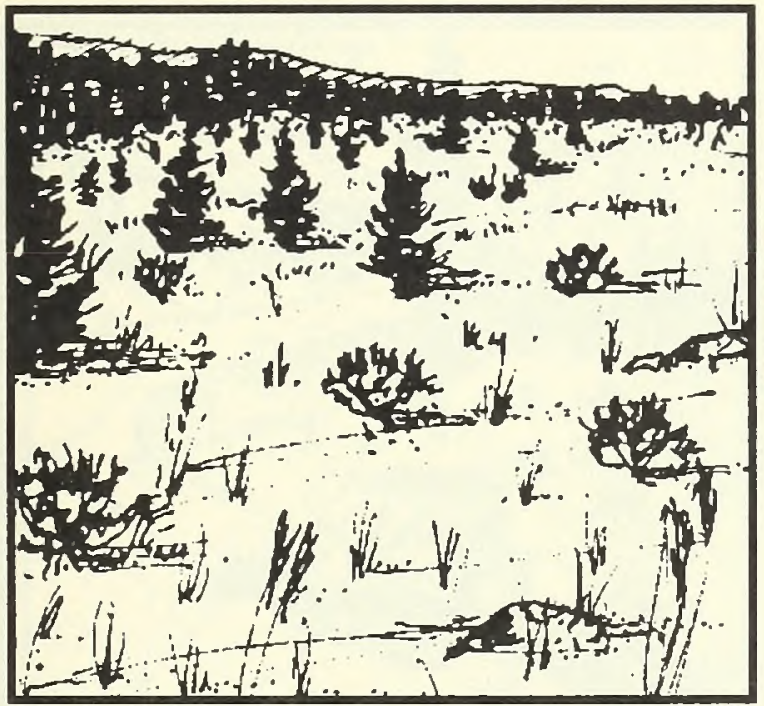

As a result:

- Light burns are less frequent.

- Woody species encroach, outcompeting native perennial grasses and forbs.

- Exotic weeds outcompete native plants

- "Islands" of native plants are genetically isolated.

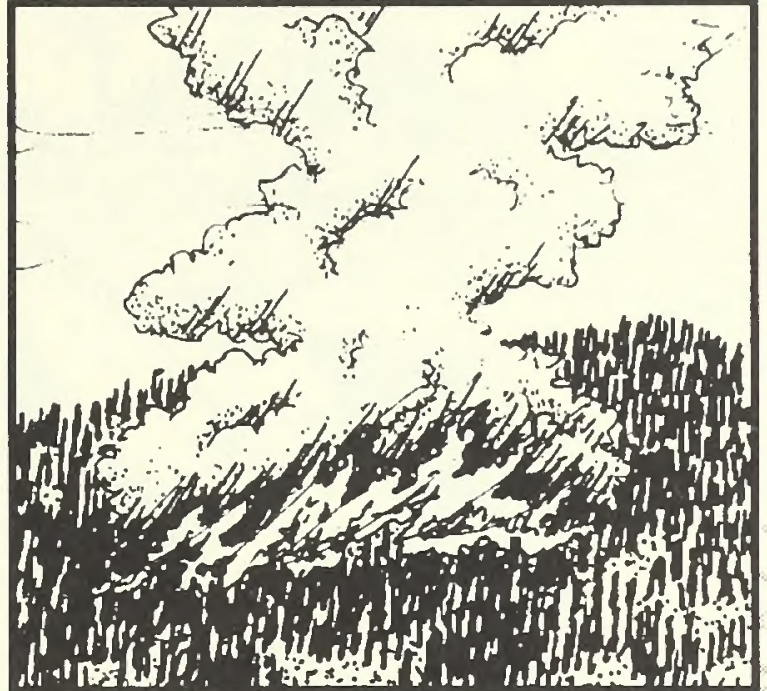

That means:

- Crowded trees compete for water and nutrients; become susceptible to insects and disease.

- Fires are more likely to be catastrophic and costly.

- Public lands are the last refuge for some plant and animal species.

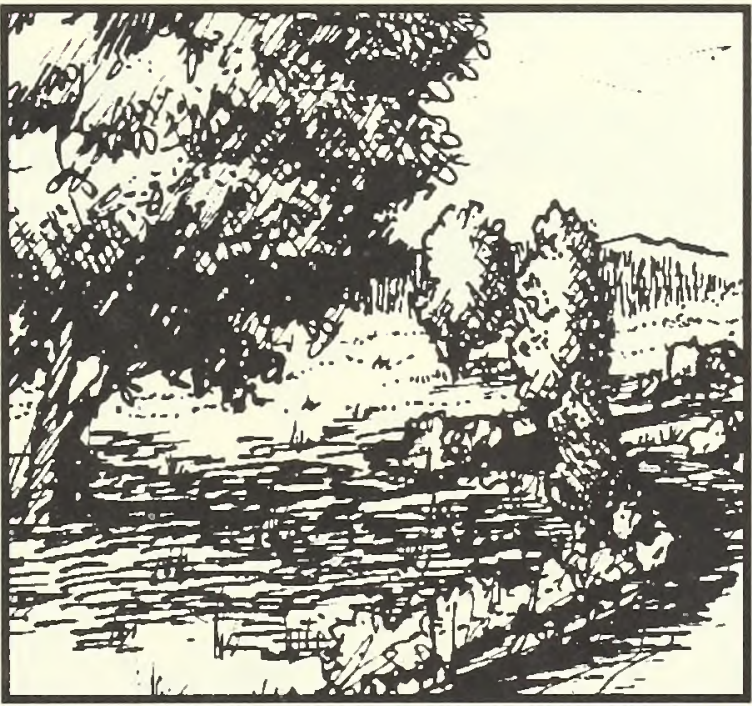

That means:

-Risk of more lethal, soil-damaging fires.

- Less native habitat for rangeland birds and animals.

- Simplified ecosystems are less resilient. less adaptable to change.

- Less genetic interchange; biodiversity declines.

\section{Where We Are Now...}




\section{Aquatic Ecosystems}
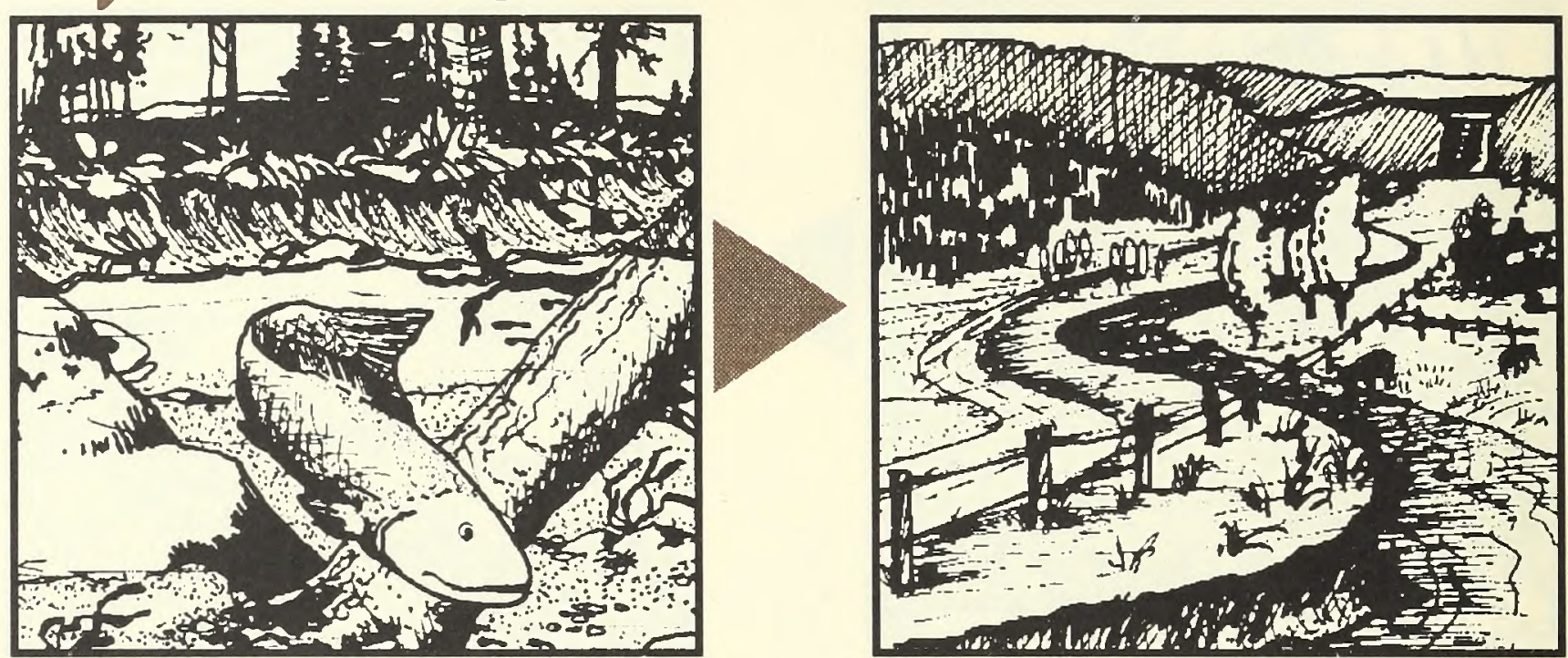

100 years ago:

- Hydrologic functions (including groundwater recharge, movement. and storage) were intact.

- Riparian (streambank) plant communities were diverse and well distributed.

- Fish species were diverse and well distributed.

\section{Soils}
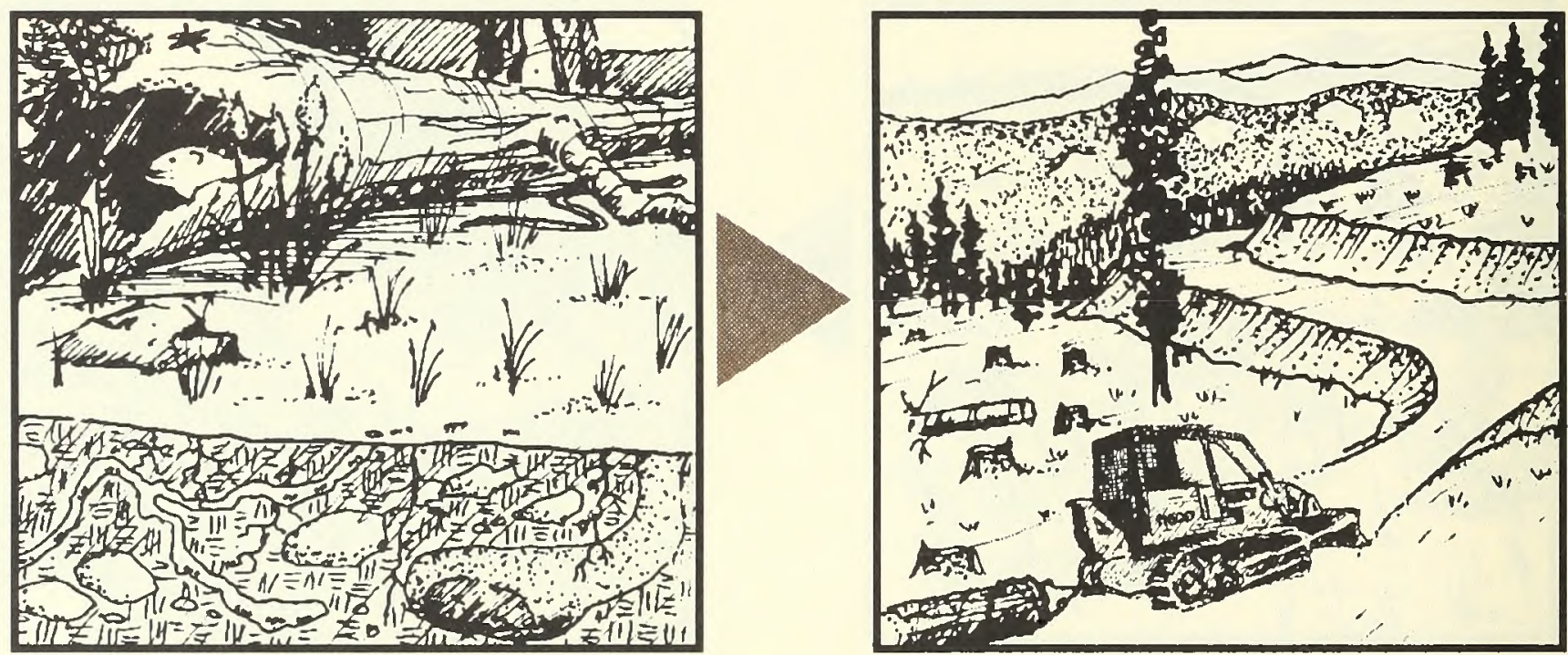

100 years ago:

- Soil functions and processes were intact:

Rock decomposing into soils.

Soil horizons, or layers, forming.

- Organic material composted by

bacteria, insects, and other nutrient cyclers

Over the last century:

- Humans have altered hydrologic systems via dams, water diversions, groundwater withdrawal, roading, mining, and urbanization

- Excessive grazing and streambank timber harvest have altered riparian plant communities.

- Exotic aquatic species have been introduced.

Over the last century:

- Timber harvest, stock grazing, road building, agriculture, etc. have disturbed the soil.

- Vegetation has changed, and therefore organic contributions to the soil have changed.

- Fire regimes are now different from those in which the soil formed.

\section{Where We Have Been...}




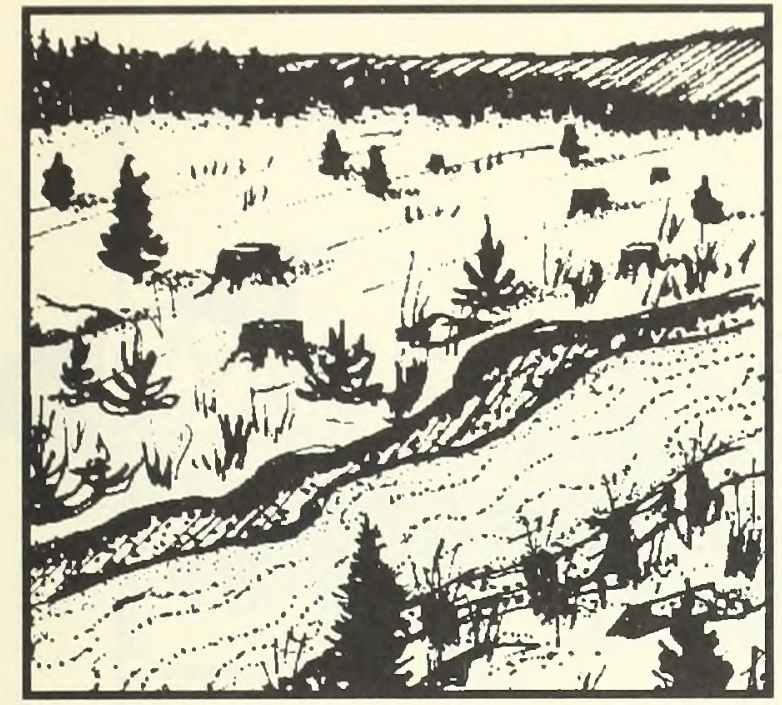

As a result:

- Hydrologic functions have changed (water quality, streamflow amount/timing,

streambank stability, natural sediment levels).

- There are fewer riparian areas and wetlands and some streams have fewer pools.

- Native aquatic species populations have declined.

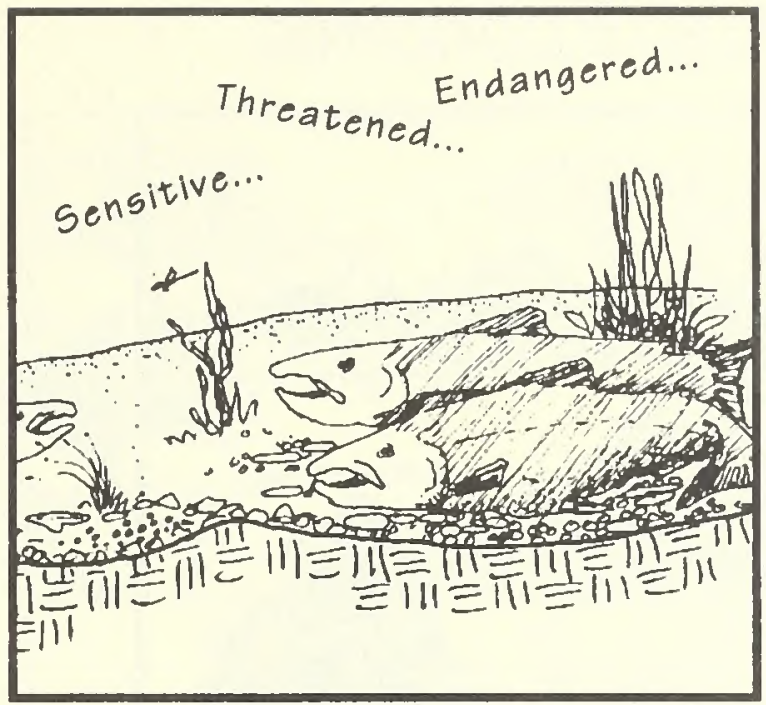

That means:

- Some migratory fish can't make it from sea to spawning beds.

- Native fish are no longer found throughout their range; populations are becoming isolated.

- Some species are near extinction.

-Despite declines, the core pieces needed to rebuild habitat still exist.

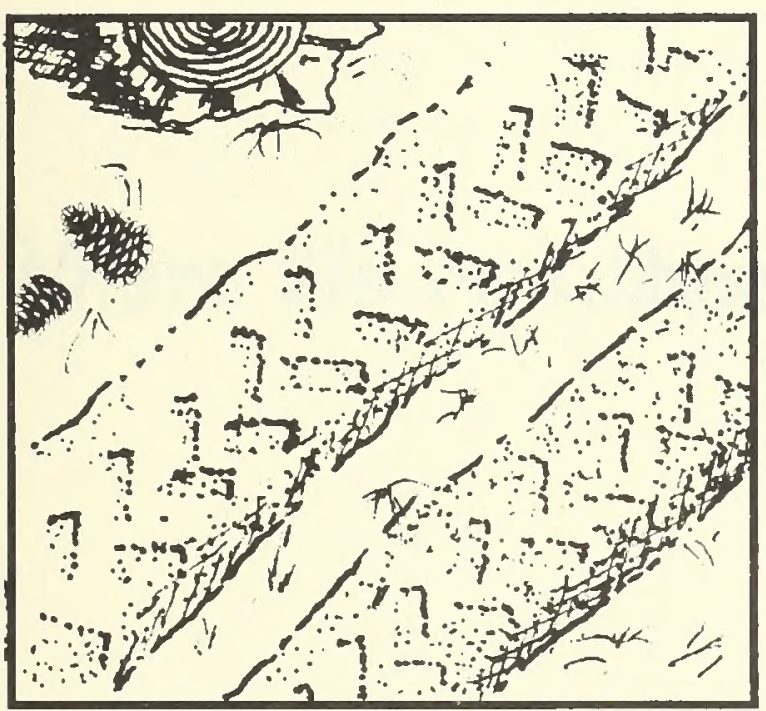

As a result:

- Some soils are:

- Compacted.

- Lacking sufficient organic matter.

- Inhabited by changed microbial communities.

- Subject to uncharacteristic fire impacts

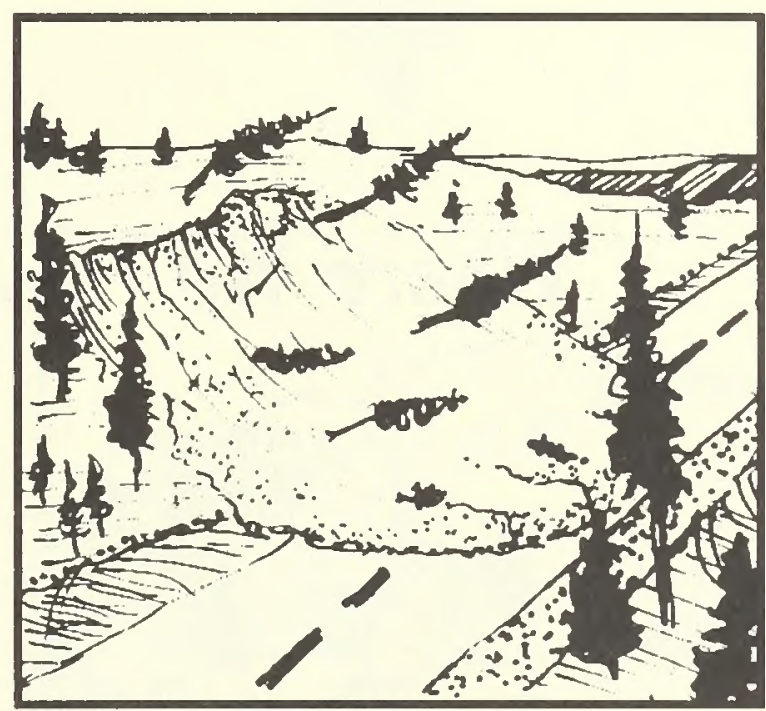

That means:

- Some soils are:

- Less able to absorb and transport water.

- Less able to filter pollutants.

- More vulnerable to erosion.

- Not as fertile.

\section{Where We Are Now...}




\section{Social/Economic}
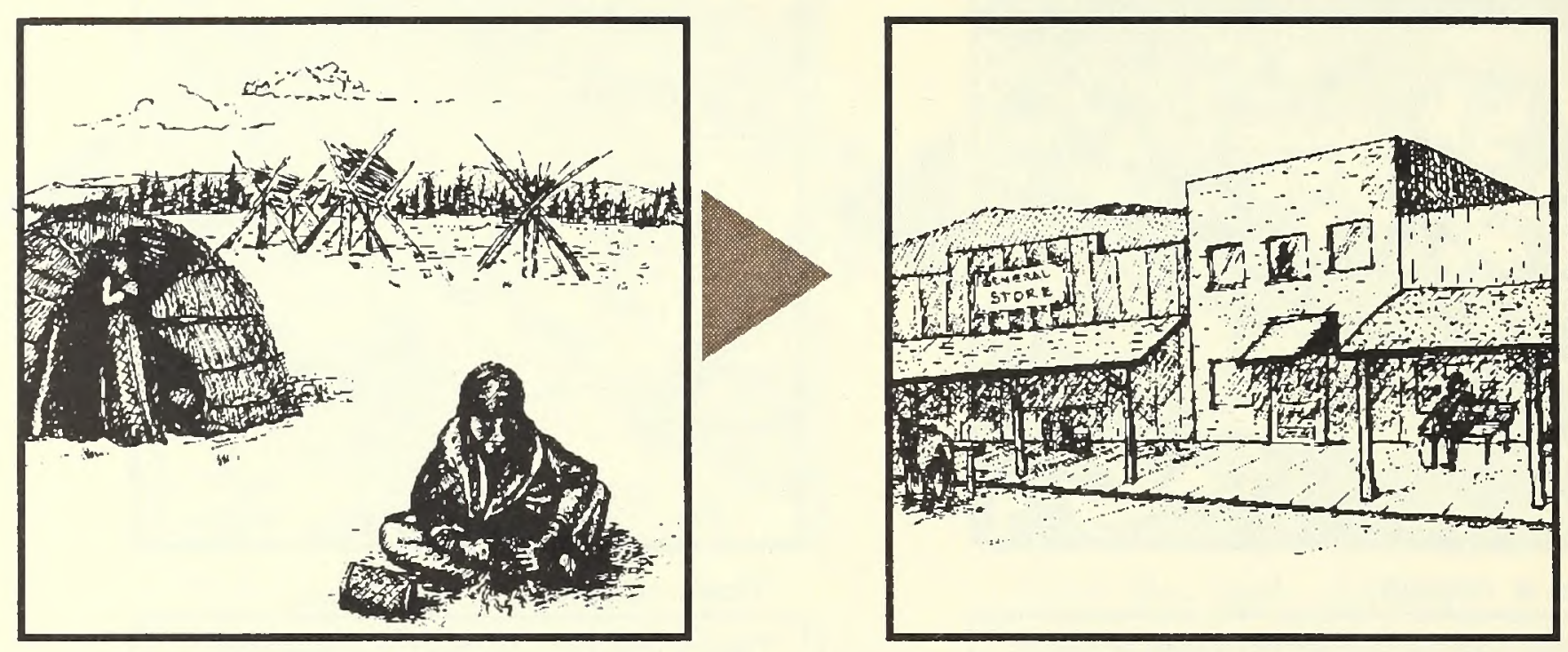

First Nations

- Tribes migrated with the seasons.

- Survival depended upon natural resources.

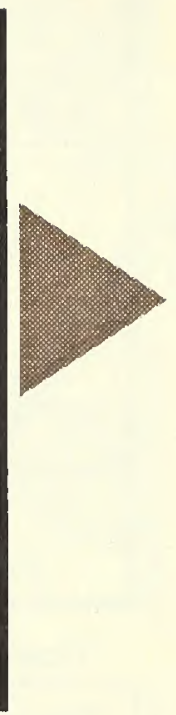

\section{European Settlers}

- Lived in isolated and relatively self-sufficient communities.

-Economies were tied directly to natural resources.

- Believed that natural resources existed for the benefit of residents.

\section{Where We Have Been...}




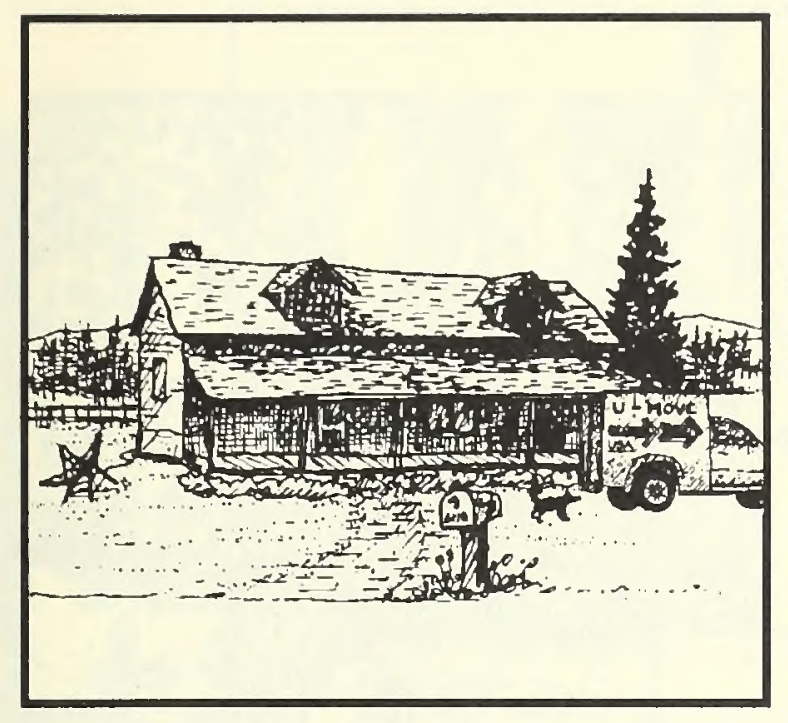

Settling the West, Again

- High quality of life spurs immigration into rural areas.

- Technology diversifies economy.

- Fewer jobs are directly dependent on resources.

- Resource issues become part of national debate.

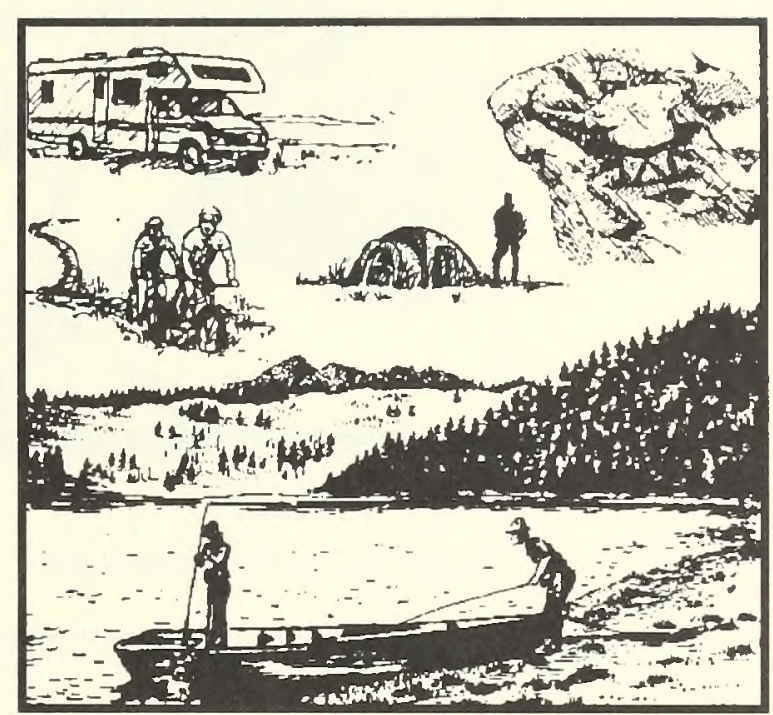

A Boon for Some Communities

- Rural communities in scenic areas have more economic resilience.

- Regional economies are more diverse and less dependent on extractive resources.

- Higher demand and value is placed on recreation resources.

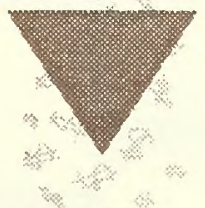

\section{Where We Are Now...}

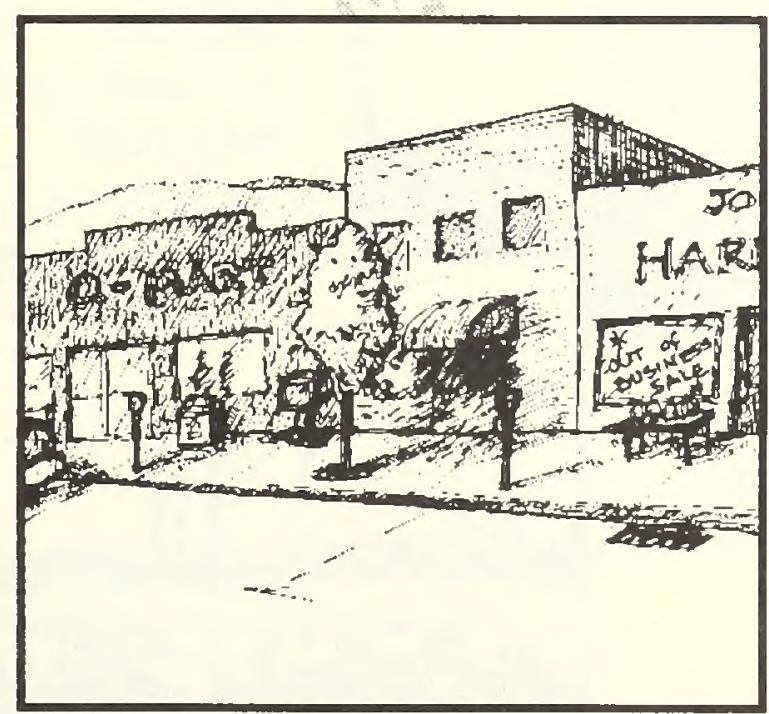

Hard Times for Others

- At the same time, isolated, resourcedependent communities are experiencing economic downturns.

- Local sawmills can no longer depend on local timber supplies.

- Some counties receive lower timber revenue payments, causing shortfalls in $\mathrm{road} / \mathrm{school}$ funds 


\section{Our Land Use Policies Have}

Evolved...

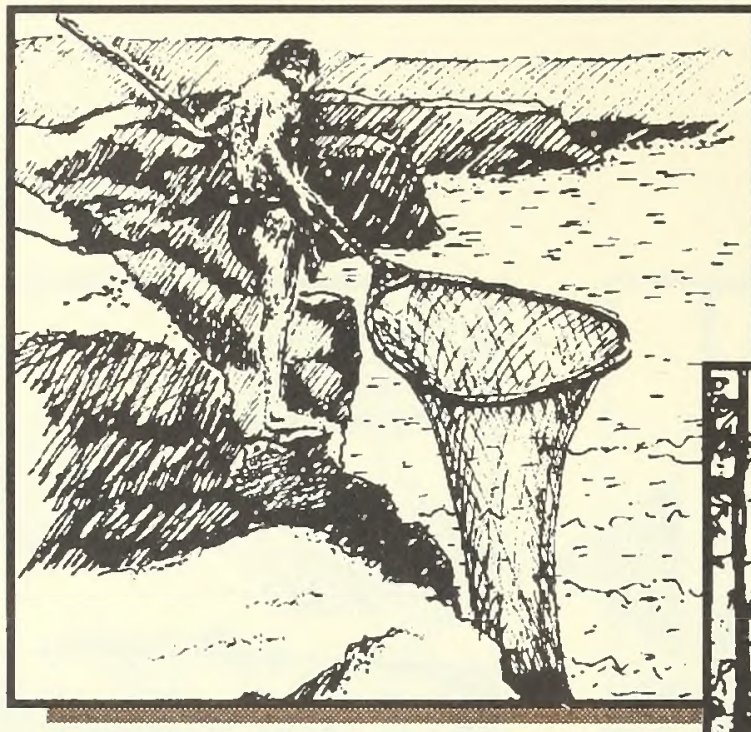

Pre-1800s

Coexist with nature

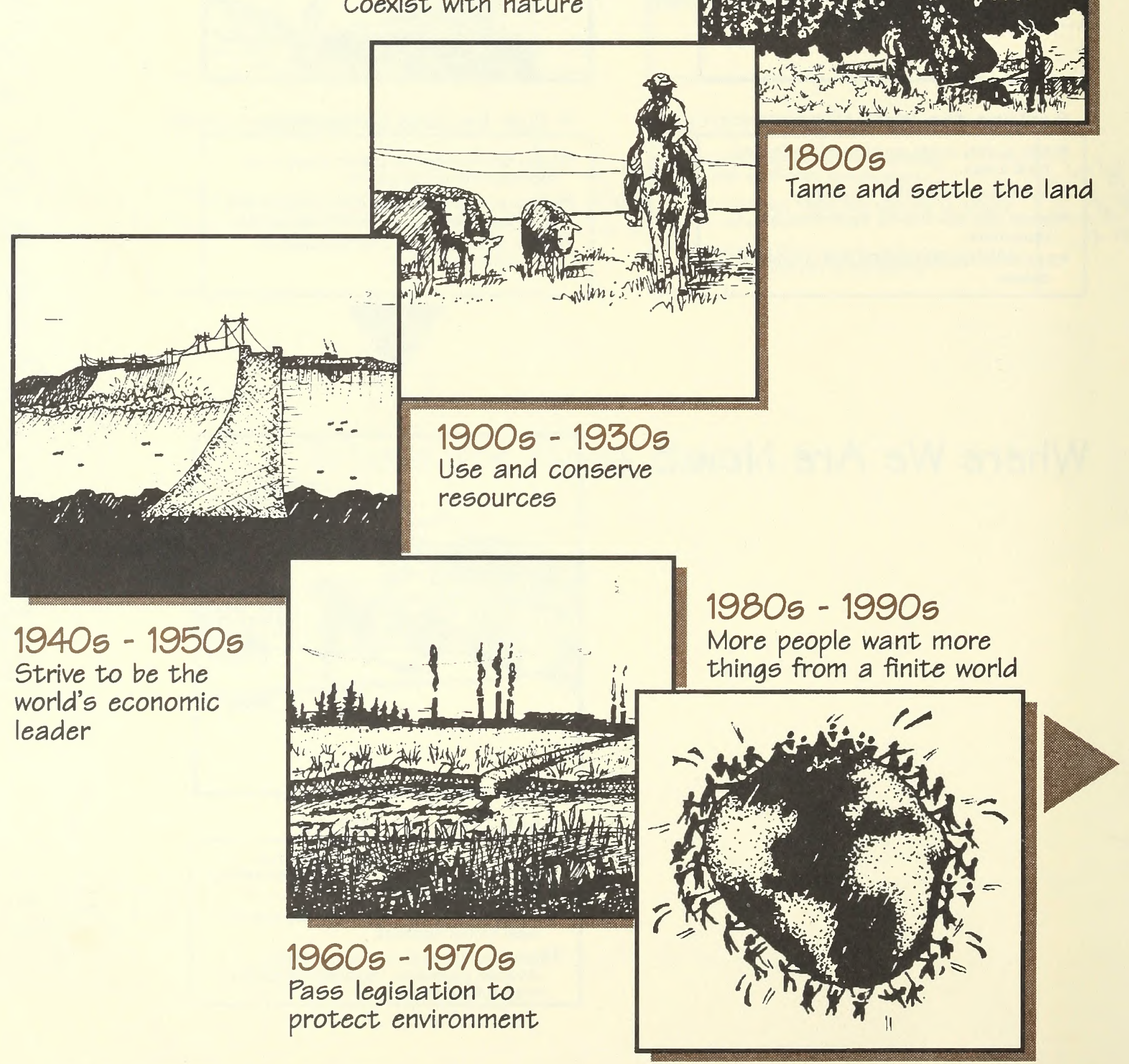




\section{We Need A New Strategy...}

\section{Management Options for the Next 10-15 Years}

\section{Alternative 1}

What if Forest Service and BLM management

plans (most of them written in the 1980s) are used?

\section{Alternative 2}

What if these existing plans plus interim direction form the basis for a long-term strategy?

\section{Alternative 3}

What if existing management is altered just enough to address the most serious problems?

\section{Alternative 4}

What if active restoration is the focus and management actions resemble natural processes such as fire, windstorms, and insect and disease infestation?

\section{Alternative 5}

What if biological capability and economic efficiency are used to determine "priority management areas"?

\section{Alternative 6}

What if we take a cautious approach to restoration, and carry out broad-scale actions only when scientific research and monitoring have demonstrated their effectiveness?

\section{Alternative 7}

What if we protect species viability and ecological integrity mostly through reserves and passive management? 


\section{Alternative Pathways to a Sustainable Future}

Why seven different alternatives?
While our scientists were gathering information about current conditions, we gave our EIS Teams the task of building the bridge from where we are now to where we want to be. More specifically, we asked them to build several possible bridges.

The laws require that we do it this way because our management approach, and the mix of goods and services we provide along the way, is as much a social decision as it is a scientific one. Within ecological capabilities, a wide range of management options may be equally sound, and a wide range of resulting landscape processes, conditions, and trends may be socially desirable.

Because we wanted our alternatives to represent a full spectrum of options, we worked closely with the public, going through what we describe as a mutual learning process. Job one was to identify issues that the action alternatives would address.
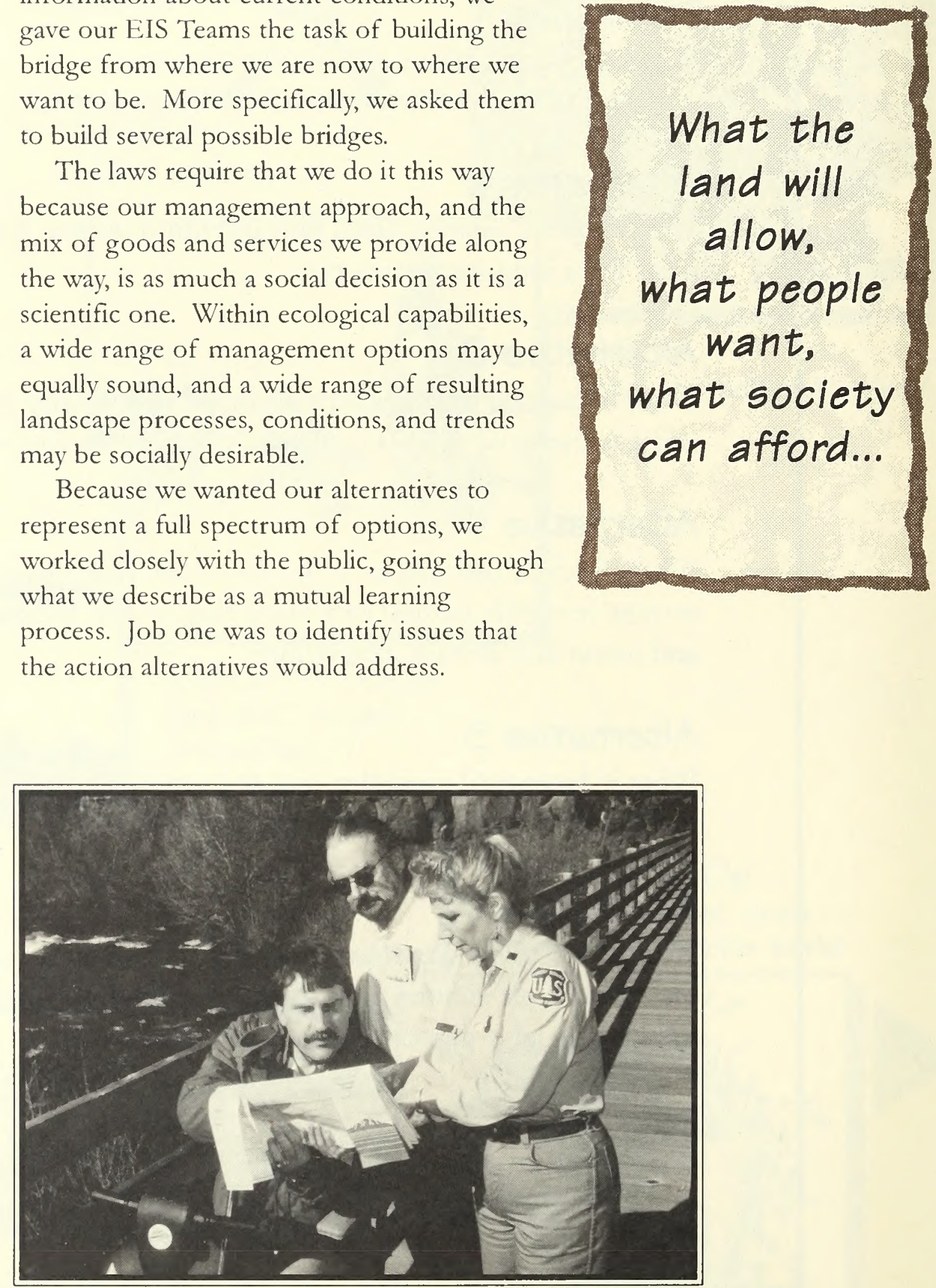
What issues are most important to people?
After months of public scoping and discussion, we boiled the issues down to the following questions.

- Issue 1: In what condition should ecosystems be maintained?

- Issue 2: To what degree, and under what circumstances should restoration be active (with human intervention) or passive (letting nature take its course)?

- Issue 3: What emphasis will be assigned when trade-offs are necessary among resources, species, land areas, and uses?

- Issue 4: To what degree will ecosystem-based management support economic and/or social needs of people, cultures, and communities?

- Issue 5: How will ecosystem-based management incorporate the interactions of disturbance processes across landscapes?

- Issue 6: What types of opportunities will be available for cultural, recreational, and aesthetic experiences?

- Issue 7: How will ecosystem-based management contribute to meeting treaty and trust responsibilities to American Indian Tribes?

With these seven issues, the five goals, the purpose and need, the scientific findings, and the alternative themes in mind, the EIS Teams were then asked to craft several possibilities for the "vision" portion of the alternatives. They did this by looking at what the land is capable of, what people value and desire, and what we as a society can afford. Where these three circles intersected, they defined a "Desired Range of Future Conditions," which varies for each alternative.

This Desired Range of Future Conditions is the condition that we expect the land and its resources to be in under various scenarios. These conditions can't be summed up in a sentence or two, however, because there is a Desired Range of Future Conditions that applies to each and every resource and issue listed. Your best bet is to go to Chapter 3 of the Draft EIS and read them one by one. Or, you can get the gist of what the desired futures will be by looking at the "how to" portions of each alternative (Themes, Management Emphases, Activity Levels, etc.), which are featured in the following guide. 


\section{Your Guide to the Alternatives}

Although there are seven alternatives, only Alternatives 3-7 qualify as "action" alternatives. Alternatives 1 and 2 are considered "no action" because they reflect what would happen if the 74 current management plans remained in effect. In general, Alternatives 1 and 2 emphasize traditional management techniques.

The real changes begin with Alternatives 3-7, which emphasize ecological treatments while providing for human needs. Alternative 3 would "fix only what's broken," focusing on places most in need of restoration; Alternative 4 would practice active restoration across the landscape; Alternative 5 would assign certain areas to timber, recreation, and other uses, using economic efficiency and biological capability to set the priorities; Alternative 6 would practice a more cautious approach to restoration than Alternative 4; and Alternative 7 would create a system of biological reserves, with areas outside reserves resembling Alternative 3 management.

What follows is a guide to the finer points of these five possible pathways, displayed so that you can make head-to-head comparisons.

First, the similarities. To varying degrees, all the action alternatives: 1 ) respond to issues raised in public scoping, 2) address the five common goals developed for the EISs, 3) address the purpose and need, and 4) attempt to remedy the undesirable conditions and trends noted in the Scientific Assessment. Though they funnel toward the same goals, the slant they take, and the degree to which they succeed is what distinguishes them. Weighing these differences and choosing the best path is the task before us now.

Here are some ways you can compare the alternatives using this summary:

Step 1: Compare the themes of the alternatives (see opposite page).

- Step 2: Compare action alternatives with existing plans (see page 36).

- Step 3: Find yourself on the map (see cluster maps on page 37).

$\checkmark$ Step 4: Compare management emphases (see tables on page 38).

- Step 5: Compare activity levels (see tables on pages 40-43).

Step 6: Compare environmental consequences, and social/economic effects (see charts on pages $47-53$ ). 


\section{Step 1 - Comparing the Themes of the Alternatives}

\section{Alternative 1: No Action}

Continues management specified under 74 existing Forest Service or BLM land-use plans (including recent direction from the Northwest Forest Plan within certain national forests and one BLM resource area)
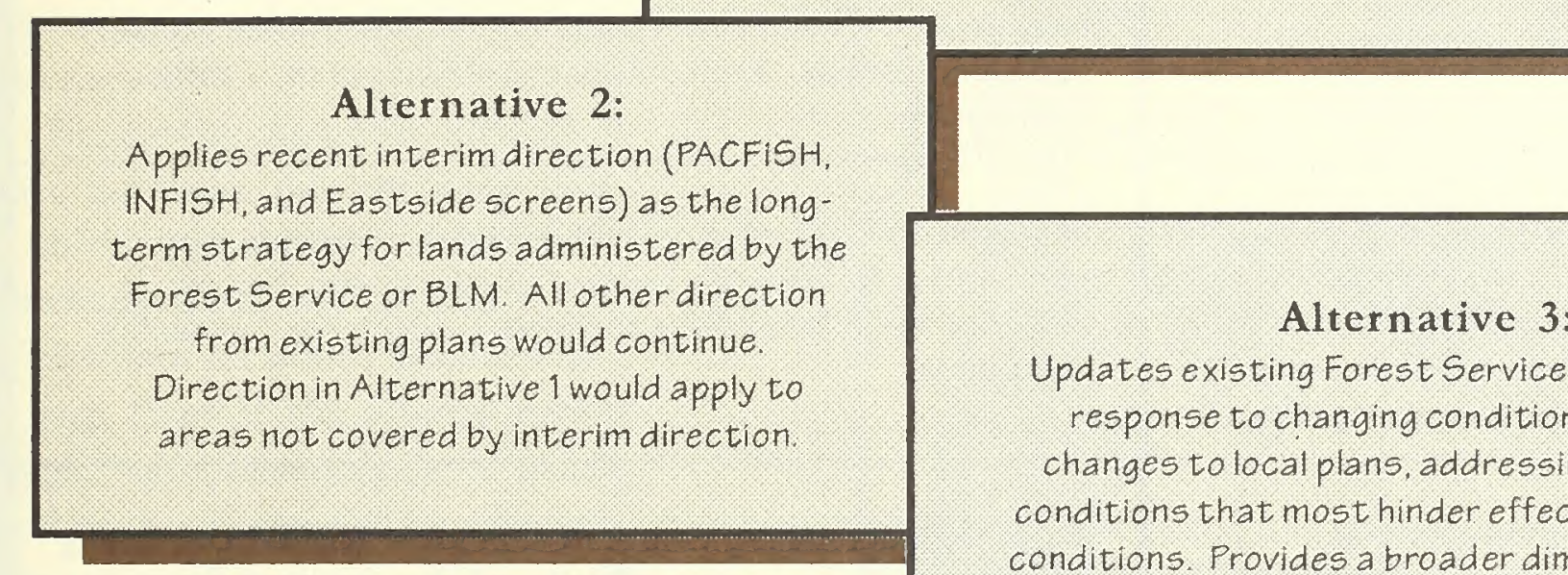

Applies recent interim direction (PACFISH, INFISH, and Eastside screens) as the long erm strategy for lands administered by the orest Service or BLM. All other direction from existing plans would continue Direction in Alternative I would apply to areas not covered by interim direction.

Alternative 3 :

Updates existing Forest Service or BLM plans in response to changing conditions. Minimizes changes to local plans, addressing only priority conditions that most hinder effectiveness or legal conditions. Provides a broader dimension and more integrated management regarding priority largescale issues than Alternatives 1 or 2.

\section{Alternative 4:}

Aggressively restores ecosystem health through active management using an integrated ecosystem management approach. Priority is placed on forest, rangeland, and watershed health. Actions are designed to produce economic benefits whenever practical.

\section{Alternative 5:}

Emphasizes production of goods and services consistent with ecosystem management principles. Areas are targeted for specific uses based on biological capability and economic efficiency: other uses may occur but conflicts would be resolved in favor of the priority use of the emphasis area.

\section{Alternative 6:}

Emphasizes an adaptive management approach to restore and maintain ecosystems while providing for social and economic needs. Takes a slower, more cautious approach than other alternatives and implies the use of experimental processes, local research. and extensive monitoring.
Alternative 7 :

Emphasizes reducing risks to ecological integrity and species viability by establishing a system of reserves on Federallands. Reserves are selected for representation of vegetation and rare animal species. Management activities are limited within reserves and are similar to Alternative 3 outside the reserves. 


\section{Step 2 - Comparing Alternatives with Existing Plans}

\begin{tabular}{|c|c|}
\hline $\begin{array}{c}\text { Alternatives } 1 \text { and } 2 \\
\text { ("No Action"Alternatives) } \\
\text { Existing Management Plans }\end{array}$ & $\begin{array}{l}\text { Alternatives } 3-7 \\
\text { ("Action" Alternatives) }\end{array}$ \\
\hline $\begin{array}{l}\text { Written with the assumption that } \\
\text { ecosystems were healthy. }\end{array}$ & $\begin{array}{l}\text { Written knowing that some ecosystems are unhealthy and altered } \\
\text { by years of human use. Some of these changes were desired by } \\
\text { society, but have nonetheless created long-term challenges. } \\
\text { Other events, such as climate cycles, exotic weed expansion, and } \\
\text { management of non-Federal lands, influence how these Federal } \\
\text { lands are managed. Their cumulative effects are more fully } \\
\text { considered. }\end{array}$ \\
\hline $\begin{array}{l}\text { Emphasis is on commodity production } \\
\text { with mitigation for other resource } \\
\text { values. Activities are planned without } \\
\text { much consideration of historic ranges } \\
\text { of variability or disturbance regimes. }\end{array}$ & $\begin{array}{l}\text { Managers consider what vegetative patterns, structure, and } \\
\text { composition are desirable to carry into the future. Natural } \\
\text { resources in excess of these needs are available for commodity } \\
\text { production. }\end{array}$ \\
\hline $\begin{array}{l}\text { Traditional approaches, such as } \\
\text { clearcutting, are used to optimize } \\
\text { timber yield on lands available for } \\
\text { timber production. }\end{array}$ & $\begin{array}{l}\text { Focus is on developing a range of vegetation structures, including } \\
\text { mature growth stages, that reflect conditions expected under } \\
\text { more natural disturbance regimes. }\end{array}$ \\
\hline $\begin{array}{l}\text { Timber harvest volumes come from all } \\
\text { size classes. }\end{array}$ & $\begin{array}{l}\text { Most timber harvest volume comes from smaller trees and } \\
\text { younger age classes. Tree thinning is used to sustain residual } \\
\text { overstory trees. }\end{array}$ \\
\hline Prescribed fire is used less frequently. & $\begin{array}{l}\text { Prescribed fire is used in a way that mimics natural disturbance } \\
\text { processes, in order to restore naturally occurring patterns and } \\
\text { structures. }\end{array}$ \\
\hline Less emphasis on restoration. & $\begin{array}{l}\text { More emphasis on restoring forest and rangeland health, so } \\
\text { ecosystems can be self-sustaining and productive. }\end{array}$ \\
\hline $\begin{array}{l}\text { No overall fish and riparian } \\
\text { management strategy. Interim plans } \\
\text { address only parts of the Project Area. }\end{array}$ & $\begin{array}{l}\text { Provides a more consistent, landscape-level approach for } \\
\text { managing aquatic and riparian resources. Focuses on } \\
\text { maintaining or improving aquatic/riparian functions and } \\
\text { processes rather than mitigating commodity production. }\end{array}$ \\
\hline $\begin{array}{l}\text { No overall weed management strategy } \\
\text { that guides control of exotic weeds in } \\
\text { the Project Area. }\end{array}$ & $\begin{array}{l}\text { Emphasizes an overall Integrated Weed Management strategy } \\
\text { that incorporates education of the land user, techniques for } \\
\text { prevention of weed spread, and use of a combination of weed } \\
\text { control methods. }\end{array}$ \\
\hline $\begin{array}{l}\text { Public involvement is legally mandated } \\
\text { by the National Environmental Policy } \\
\text { Act and other public policies. }\end{array}$ & $\begin{array}{l}\text { Goes beyond legal requirements, and puts more emphasis on how } \\
\text { decisions are made. There is more meaningful participation } \\
\text { among stakeholders, including Tribes and local governments. }\end{array}$ \\
\hline
\end{tabular}




\section{Step 3 - Cluster Maps}

What forest cluster am I in ?

Orofino, Idaho is in Forest Cluster 3

The Project Area is divided into clusters of lands with similar conditions, opportunities, and risks. Each cluster has a general management emphasis and a mix of activity levels which vary by alternative.

Remember, however, that this does not mean that activities such as thinning, harvesting, watershed restoration, etc. will happen everywhere on public land in that cluster. Even if the activity level is "high," only a percentage of public land in the cluster will be affected (see pages 41 and 43). Where in the cluster that percentage is located is largely a local decision, to be made by local resource managers. These managers are currently helping us develop a process for using broad-scale information at the local level.

\section{Cluster Numbers}

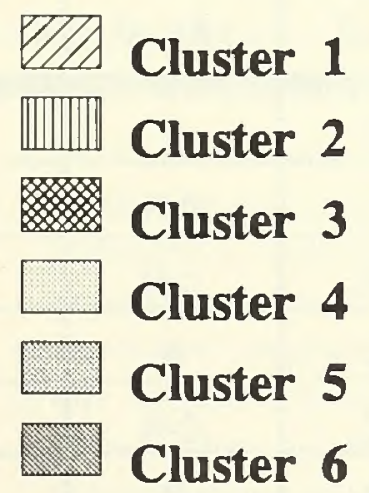

What range cluster am I in? Burns, Oregon is in Range Cluster 6

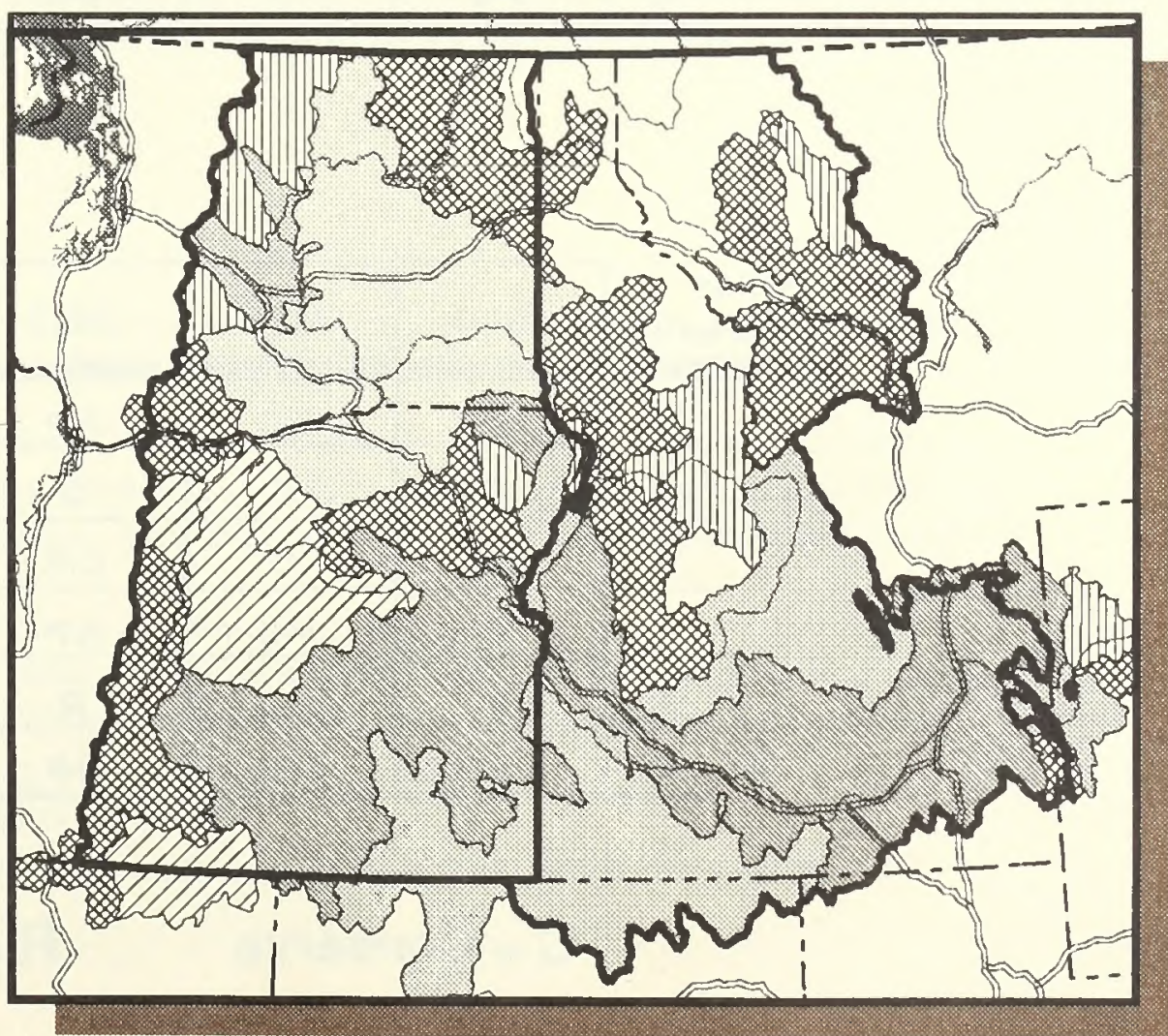




\section{Step 4 - Management Emphasis Table}

What is the management emphasis of my cluster by alternative?

Orofino, Idaho: For example, in Forest Cluster 3, under Alternative 6, Restore is the recommended management emphasis.

Burns, Oregon: For example, in Range Cluster 6, under Alternative 3, Restore/Produce is the recommended management emphasis.

\begin{tabular}{|c|c|c|c|c|c|c|c|}
$\begin{array}{l}\text { Forest } \\
\text { Clusters }\end{array}$ & Alt. 1 & Alt. 2 & Alt. 3 & Alt. 4 & Alt. 5 & Alt. 6 & Alt. 7 \\
\hline 1 & C & C & C-R & C-R & C & C-R & C \\
\hline 2 & P-C & C & R & R & C-R & R & C \\
\hline 3 & P & P-C & R & R & R & R & C-R \\
\hline 4 & P & P-C & R-P & R & P & R & C-R \\
\hline 5 & P & C-R & R & R & R & R & C-R \\
\hline 6 & P-C & C & C-R & R & R-P & C-R & C \\
\hline
\end{tabular}

\begin{tabular}{|c|c|c|c|c|c|c|c|}
$\begin{array}{l}\text { Range } \\
\text { Clusters }\end{array}$ & Alt. 1 & Alt. 2 & Alt. 3 & Alt. 4 & Alt. 5 & Alt. 6 & Alt. 7 \\
\hline 1 & P & P-C & R-P & R & R-P & R & C-R \\
\hline 2 & C & C & C & C-R & C & C-R & C \\
\hline 3 & P-C & C & C-R & R & C-R & C-R & C \\
\hline 4 & P & P-C & R-P & R & P-C & R & C-R \\
\hline 5 & P & P-C & R & R & P-C & C-R & C \\
\hline 6 & P & P-C & R-P & R & R-P & R & C-R \\
\hline
\end{tabular}

C = Conserve $\quad \mathbf{R}=$ Restore $\quad \mathbf{P}=$ Produce 


\section{Management Emphasis Definitions}

\section{C - Conserve emphasis}

Generally, a Conserve strategy is applied as the primary management strategy to areas with moderate to high ecological integrity.

a) Native biodiversity: priority emphasis on protection of large blocks of habitat and provisions for connectivity between blocks for aquatic and terrestrial populations or communities that are rare, sensitive, threatened, or endangered. Maintain and expand stronghold populations of native fish species. Protect small remnant areas of rare communities.

b) Forest and rangeland management: low overall emphasis on commodity production.

c) Fire management: suppress wildfires using control, contain, and confine strategies, as appropriate. Use prescribed fire and fuel management to restore areas with moderate integrity and maintain areas with high integrity.

d) Recreation management: maintain high-quality scenic values, emphasis on semi-primitive to primitive experiences. Maintain recreational access via trails/primary roads.

e) Road restoration: low emphasis; priority on problem areas.

\section{R - Restore emphasis}

Generally, a Restore strategy is applied to areas of moderate to low ecological integrity.

a) Native biodiversity: protection of remnant habitats with high integrity. Long-term management strategies use restoration to increase effective habitat size and provide for connectivity for aquatic and terrestrial populations or communities that are rare, sensitive, threatened, or endangered. Maintain and expand stronghold populations of native fish species.

b) Forest and rangeland management: emphasis on restoration of areas with moderate to low integrity using techniques that mimic natural processes and produce native species composition and structure. Produce commodities where available from restoration activities.

c) Fire management: suppress wildfires using control, contain, and confine strategies, with emphasis on protecting lives and property. Use prescribed fire and fuel management to restore areas with moderate to low integrity, and reduce short- and long-term wildfire risks.

d) Recreation management: maintain remnant areas with high-quality scenic values. Emphasize mixed recreational use activities. Maintain recreational access. Feather edges and improve scenic integrity in sync with natural patterns.

e) Road restoration: high emphasis; maintain, close, or remove roads to reduce negative watershed and terrestrial/ aquatic habitat effects.

\section{P - Produce emphasis}

Generally, a Produce strategy is applied to areas available and suitable for resource production in order to provide goods and services.

a) Native biodiversity: protection of remnant habitats with high integrity. Long-term management strategies use production and restoration to increase effective habitat size and provide for connectivity for aquatic and terrestrial populations or communities that are rare, sensitive, threatened, or endangered. Maintain and expand stronghold populations of native fish species.

b) Forest and rangeland management: emphasis on production where efficient.

c) Fire management: suppress wildfires using control, contain, and confine strategies, with emphasis on protection of lives, property, and commodity resources. Use prescribed fire and fuel management to support resource production and restore areas with low integrity and associated risks of wild fire.

d) Recreation management: emphasis on developed recreation.

e) Reduce negative impacts of roads while providing priority access for recreation, timber, and grazing. 


\section{Step 5 - Project Area Activity Level Table-Forest Clusters}

\section{What levels of activity} are recommended in my forest cluster?

Orofino, Idaho: For example, in Forest Cluster 3, under Alternative 4, medium levels of harvest are recommended. Medium means $5-9 \%$ of total acres of public forested land in Forest Cluster 3 could be treated per decade.

Where in the cluster that percentage is located is largely a local decision, to be made by local resource managers.

Here's how the acreages treated in Forest Cluster 3 were calculated:

\section{Total acres of Forest}

Cluster 3 in the Project Area: Total acres Medium Activity: $\quad$ X $5-9 \%$ $185-250$ thousand acres treated per decade

\section{Management Activities}

\section{Harvest (commercial)}

All commercial harvest methods (for example single tree selection, group selection, shelterwood, seed tree, overstory removal, clearcut, and commercial thinning from above and below).

\section{Thinning (pre-commercial)}

All pre-commercial thinnings used to alter forest structure, species composition, density, rate of growth, fuel ladders, fire behavior, etc.

\section{Decrease Road Density}

Permanent closure of primarily native surface roads.

\section{Watershed Restoration}

Includes increased road maintenance, improved road condition (surface and/or drainage), reduced road-related erosion, road obliteration, road decommissioning, increased large woody material, riparian plantings, in-channel restoration, etc.

\section{Prescribed Burning}

Management-ignited fire. 
Acres Treated (thousands/first decade only) or Miles Reduced (percentffirst decade only) \begin{tabular}{|l|l|l|l|l|l|l|}
\hline Alt. 1 & Alt. 2 & Alt. 3 & Alt. 4 & Alt. 5 & Alt. 6 & Alt. 7
\end{tabular}

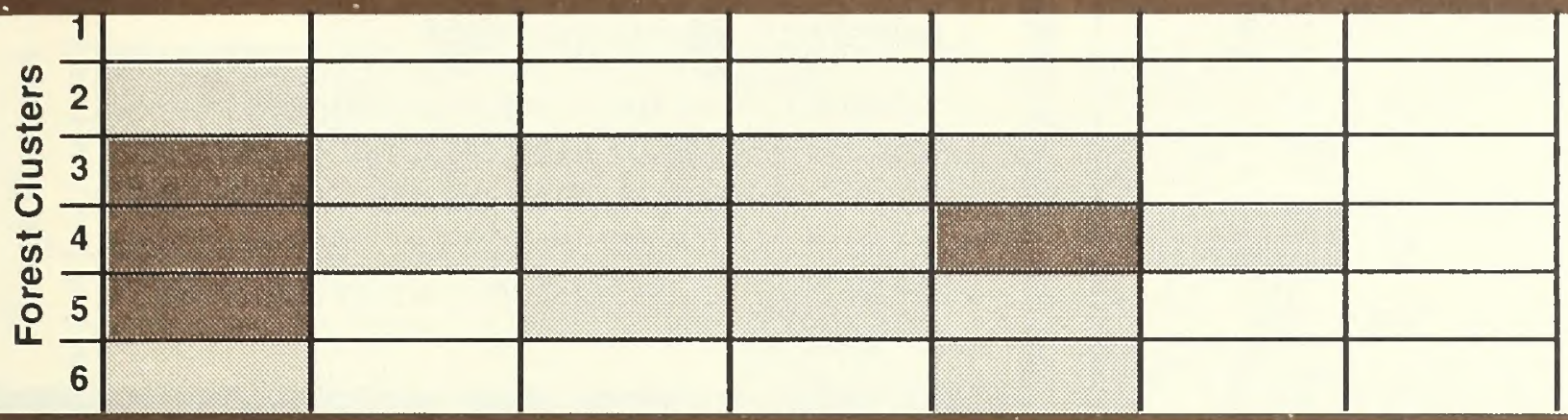

\section{Harvest}

$\%$ Decade

High $=8-10 \%{ }^{*}$-Alts. 1,2,7 Activity $9-11 \% *$-Alts.3-6

Medium $=4-8 \%{ }^{*}$-Alts. $1,2,7$ Activity $5-9 \%{ }^{*}$-Alts.3-6

$\square$ Low $=0-4 \%$-Alts. $1,2,7$ Activity $0-5 \%{ }^{*}$-Alts. 3-6

(" of total acres)

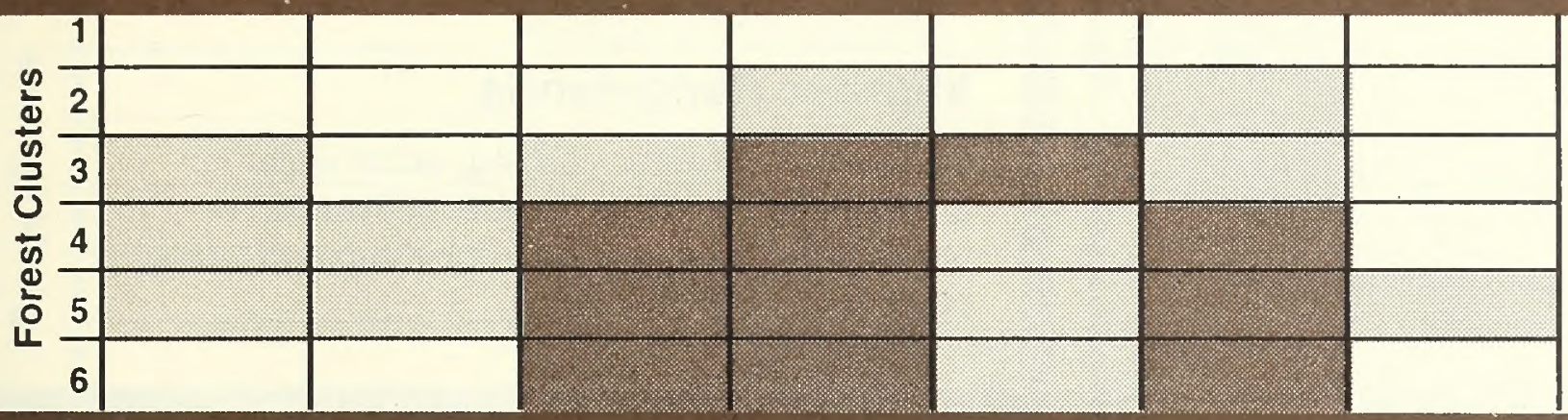

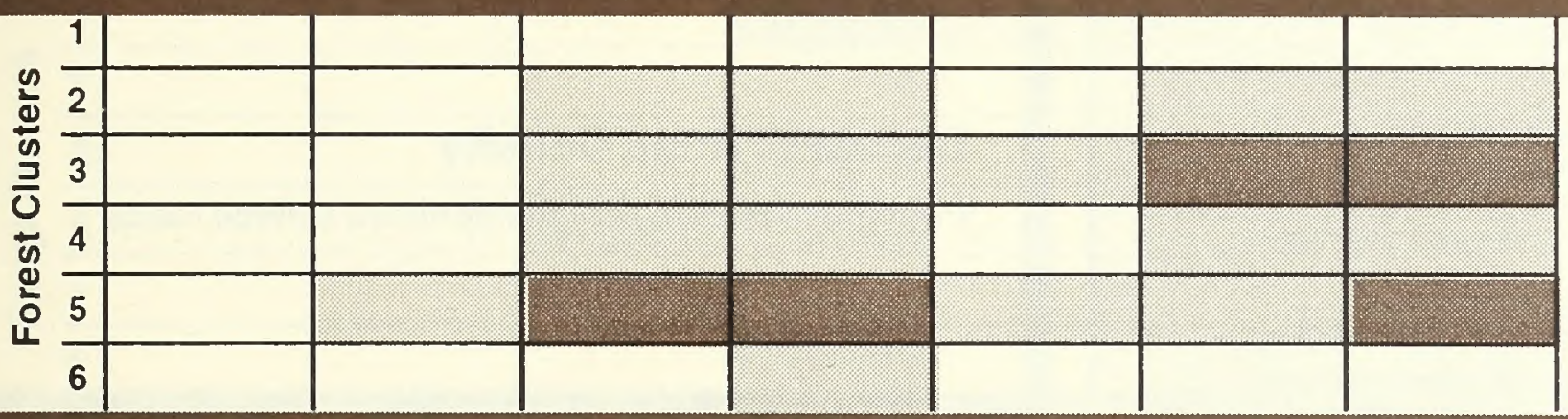

Road Miles Reduced $\% /$ First Decade Only

High = $50+\%$ of Activity total miles

$\rightarrow$ Medium $=25-50 \%$ of Activity total miles

$\square$ Low $=\begin{gathered}0-25 \% \text { of } \\ \text { Activity } \\ \text { total miles }\end{gathered}$

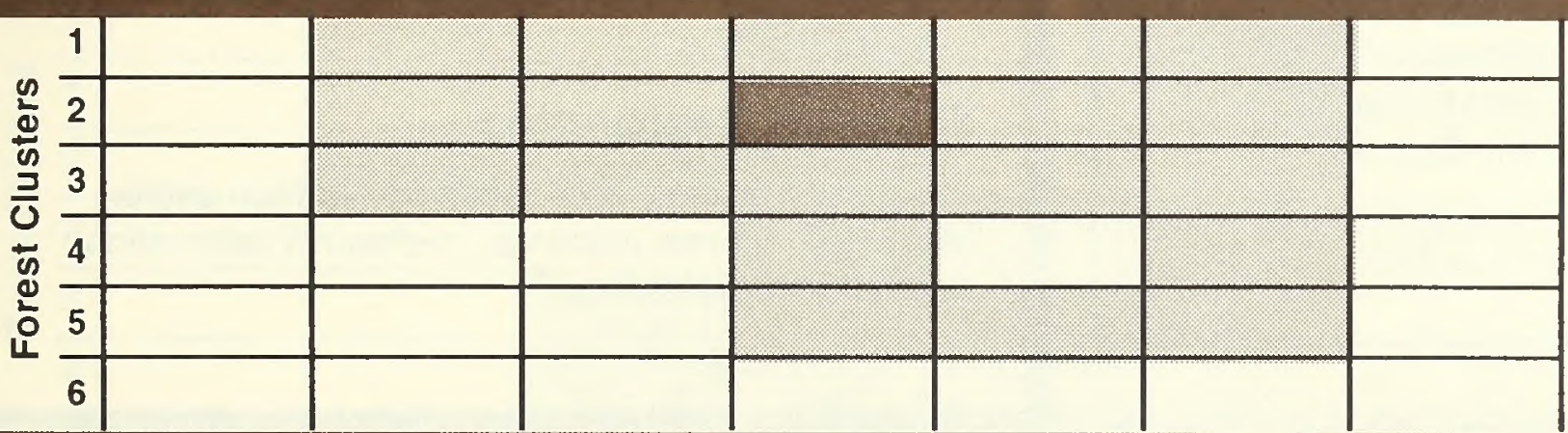

Watershed Restoration $\%$ /Decade

High $=6-8 \%$ of Activity total acres

Medium $=3-6 \%$ of Activity total acres

$\square$ Low $=0-3 \%$ of Activity total acres

Prescribed Burning $\%$ Decade

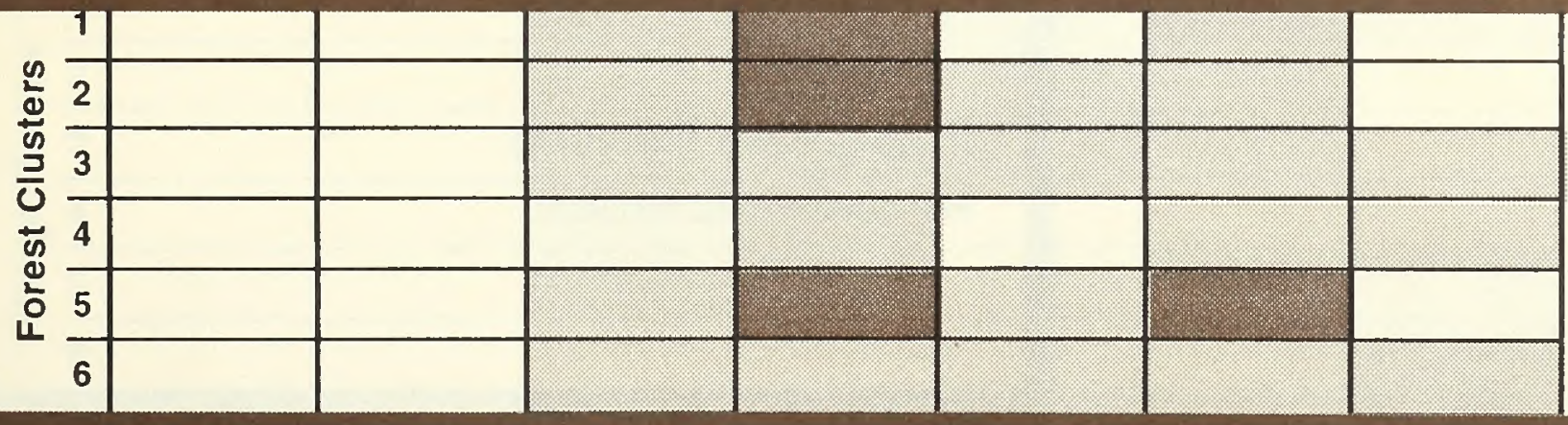
High $=9-11 \%$ of Activity total acres
Medium $=5-9 \%$ of
Activity total acres
Low $=0.5 \%$ of
Activity total acres 
Step 5 - Project Area Activity Level Table-Range Clusters

\section{What levels of activity} are recommended in my range cluster?

Burns, Oregon: For example, in Range Cluster 6, under Alternative 6, high levels of livestock management are recommended. High means 12 $20 \%$ of all public rangeland in Range Cluster 6 could be treated per decade.

Where in the cluster that percentage is located is largely a local decision, to be made by local resource managers.

Here's how acreages treated in Range Cluster 6 were calculated:

Total acres of Range Cluster 6 in the Project Area: Total acres High Activity: X $12-20 \%$ 2000-2690 thousand acres treated per decade

\section{Management Activities}

\section{Livestock Management}

A summation of livestock management variables that affect rangeland health including: grazing systems, changing riparian grazing management, season of use (length and timing), number of head, change of class, distribution, grazing deferment, and herding.

\section{Improve Rangelands}

Capital Investments: fencing, stock water improvements, seedings, control of invasion or spread of exotics, and non-fire shrub and juniper control.

\section{Decrease Road Density}

Permanent closure of primarily native surface roads.

\section{Riparian Restoration}

Includes improving road condition (surface and/or drainage), riparian plantings, in-channel restoration, and riparian exclosures.

\section{Prescribed Burning}

Management-ignited fire. 
Acres Treated (thousands/first decade only) or Miles Reduced (percent/first decade only)
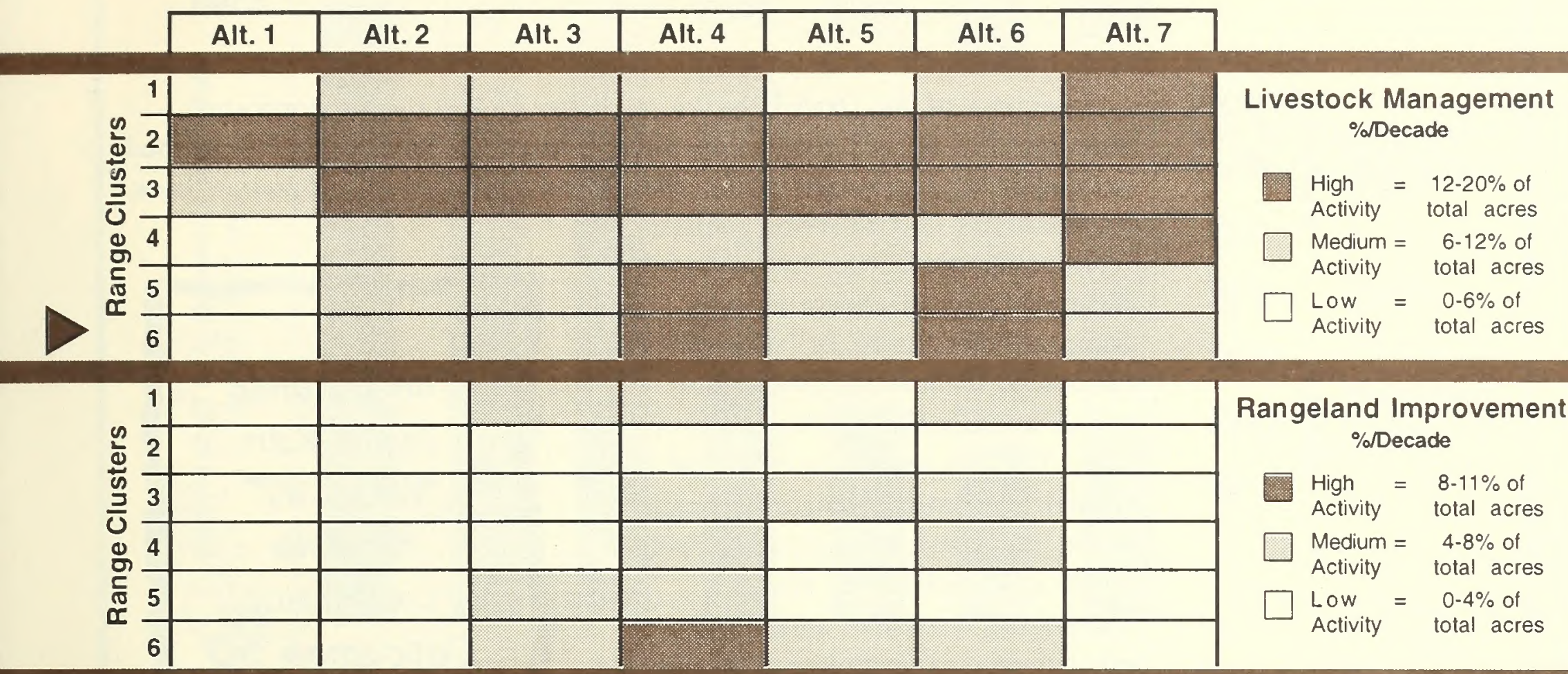

Rangeland Improvement $\% /$ Decade

\begin{tabular}{|c|c|}
\hline $\begin{array}{l}\text { High } \\
\text { Activity }\end{array}$ & $\begin{array}{c}=8-11 \% \text { of } \\
\text { total acres }\end{array}$ \\
\hline $\begin{array}{l}\text { Medium = } \\
\text { Activity }\end{array}$ & $\begin{array}{l}4-8 \% \text { of } \\
\text { total acres }\end{array}$ \\
\hline $\begin{array}{l}\text { Low } \\
\text { Activity }\end{array}$ & $\begin{array}{c}=0-4 \% \text { of } \\
\text { total acres }\end{array}$ \\
\hline
\end{tabular}

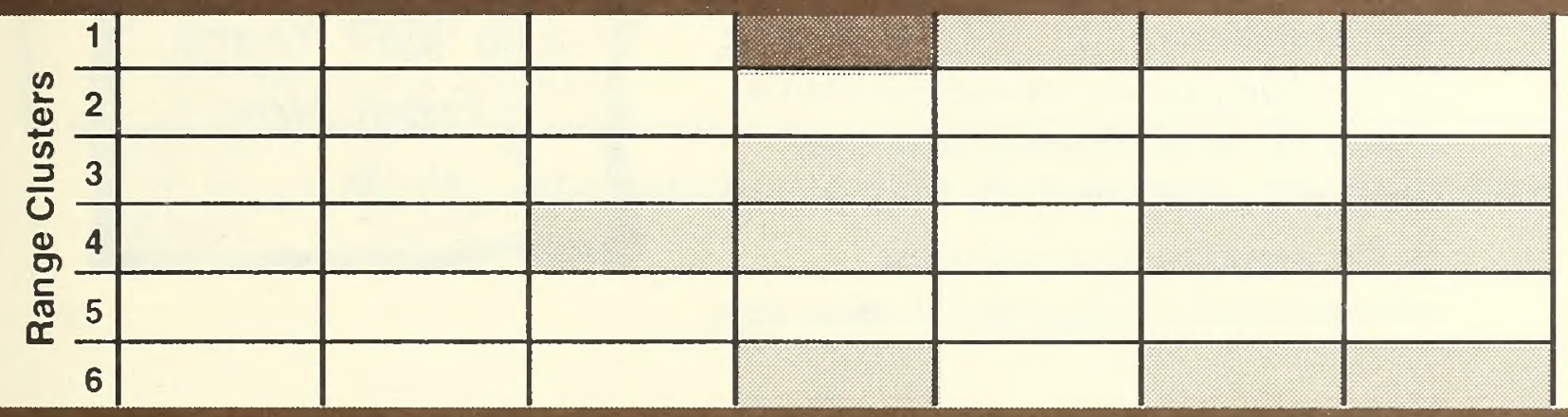

Road Miles Reduced $\% / F i r s t$ Decade Only

High $=50+\%$ of Activity total miles Medium $=25-50 \%$ of Activity total miles

$\square$ Low $=0-25 \%$ of Activity total miles

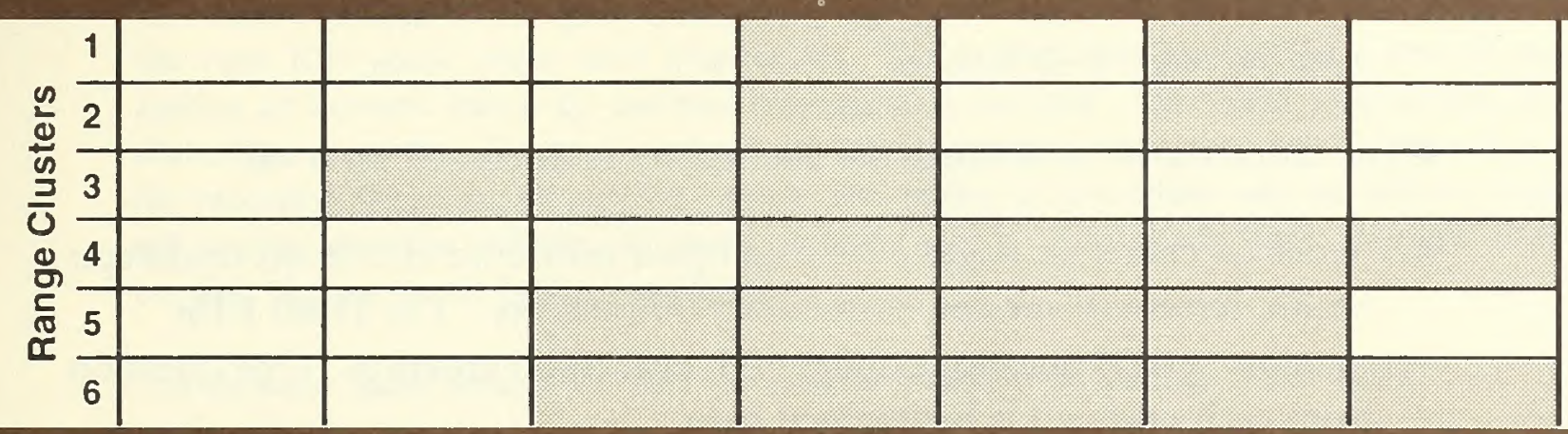

Riparian Restoration $\% /$ Decade

High $=50-75 \%$ of Activity total acres Medium $=25-50 \%$ of Activity total acres Low $=0.25 \%$ of Activity total acres

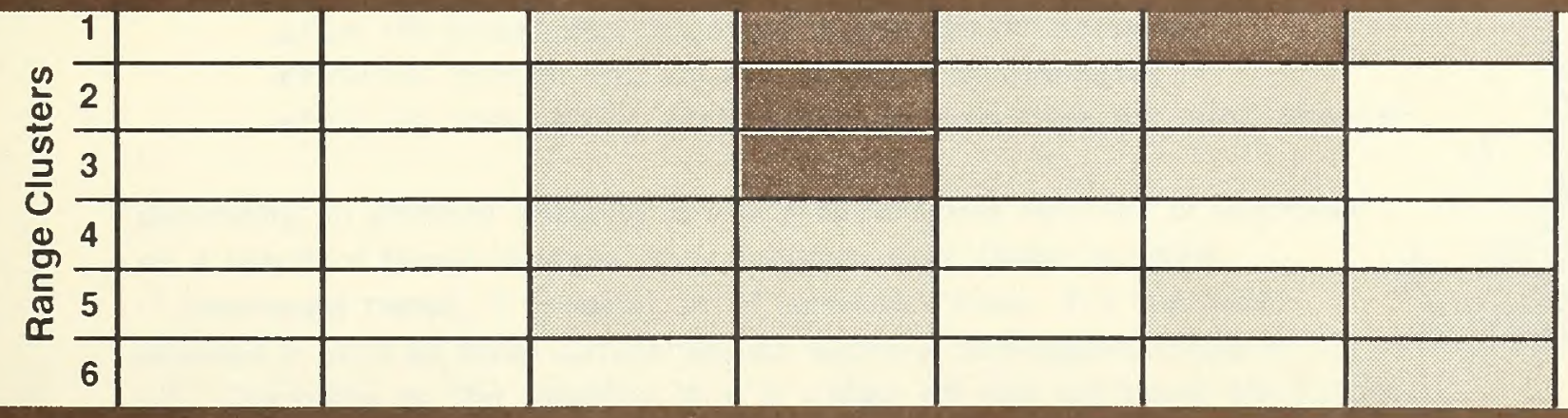

Prescribed Burning $\% /$ Decade

High = 6-9\% of Activity total acres Medium $=3-6 \%$ of Activity total acres Low $=0-3 \%$ of Activity total acres 


\section{Environmental Consequences}

How do the effects of the alternatives differ?
Chapter 4 of the Draft EISs is a predictive look at the environmental consequences of each action alternative. The evaluation process is described in detail in the Evaluation of the Alternatives by the Science Integration Team, a scientifically peer-reviewed publication.

Basically, the Science Integration Team ran each alternative through computer simulations, or "what if?" models, to see how conditions and trends would look $50-100$ years from now. The outcomes were evaluated relative to: 1) maintaining or restoring forest, rangeland, riparian, and aquatic health and productivity; and 2) maintaining economic, social, and cultural systems (including tribal trust responsibilities).

The likely outcomes and cumulative effects of the alternatives were then estimated across the entire Project Area. In this summary, we report these

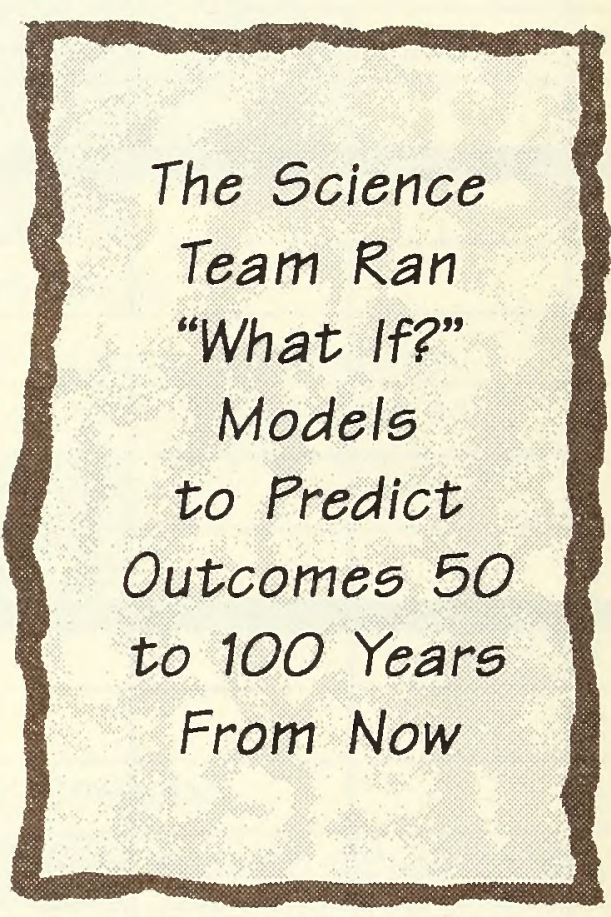
environmental consequences in three ways:

- The chart on the opposite page predicts ecological integrity trends over the next $50-100$ years.

- The criteria used to evaluate the alternatives is discussed on p. 46.

- A series of charts on pages 47-53 compare projected effects on landscape health, terrestrial species, commodity outputs, etc. The Draft EISs examine several questions under each evaluation criterion. One question from each criterion is highlighted here. 


\section{Composite Ecological Integrity Trends}

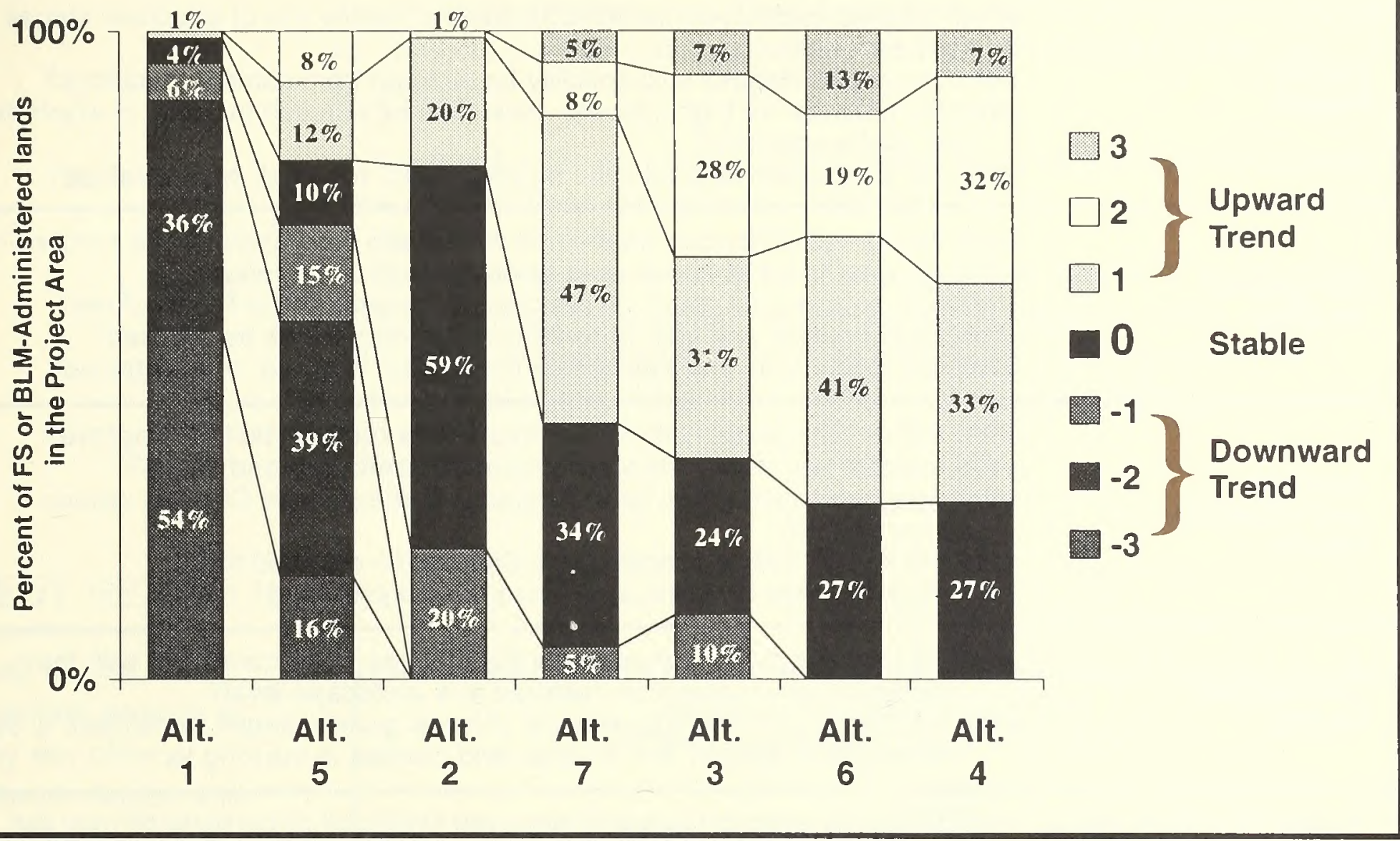

NOTE: alternatives are NOT in numerical order for this table.

This chart compares how the ecological integrity of Federal lands within the Project Area will change in the next 100 years under each aiternative. The Science Integration Team drew these conclusions by looking at current integrity, planned management actions under each alternative, and unplanned disturbance events. Doctors perform similar predictions when they try to assess a patient's chances for recovery; they look at current health, the regime of preventive and corrective treatments the patient will receive, and the outside demands on their health. Adding ail these together, they are able to project the patient's future condition.

The Sclence Team arrived at their composite measure by asking, under each alternative:

- How will forest and rangeland vegetation be managed?

- How will riparian and aquatic systems be managed?

- How will road density (the number of road miles per acre) change?

Depending on whether integrity in a sub-basin would increase or decrease as a result of these changes, they assigned each factor a score:

-1 (downward trend), $O$ (stable), or +1 (upward trend). If a sub-basin received $a+1$ in all three categories, its score, a summation, would be a

+3. Depending on the condition it is in today, +3 may not mean the sub-basin

will achieve high integrity over the next 100 years. It simply means it's improving. 


\section{What Criteria Will Be Used to Evaluate the Alternatives?}

\begin{tabular}{|c|c|}
\hline $\begin{array}{l}\text { Forest } \\
\text { Health }\end{array}$ & $\begin{array}{l}\text {-Will forested landscapes be moved toward a healthy mix of structural stages } \\
\text { and composition? } \\
\text {-Will insect and disease susceptibility be reduced from current conditions? } \\
\text {-Will the potential for high-intensity crownfires be reduced in areas in which they } \\
\text { are uncharacteristic? } \\
\text {-Will soil productivity and function be conserved, restored, or maintained? }\end{array}$ \\
\hline $\begin{array}{l}\text { Rangeland } \\
\text { Health }\end{array}$ & $\begin{array}{l}\text {-Will the spread of noxious weeds and cheatgrass on rangelands be reduced? } \\
\text {-Will encroachment of woody species on rangelands be reduced? } \\
\text {-Will native rangeland plants be restored, in general, in the Project Area? } \\
\text {-Will fragmentation and loss of connectivity in rangelands be reduced? } \\
\text {-Will soil productivity and function be conserved, restored, or maintained? }\end{array}$ \\
\hline $\begin{array}{l}\text { Aquatic } \\
\text { and Riparian } \\
\text { Health }\end{array}$ & $\begin{array}{l}\text {-Will native fish species within the Project Area remain stable or improve? } \\
\text {-Will resident key salmonids show improved distribution and status? } \\
\text {-Will core population areas for steelhead and stream-type Chinook salmon } \\
\text { be conserved? } \\
\text {-Will the habitat needs of ocean-type Chinook be provided for? } \\
\text {-Will riparian areas be adequately restored and protected? }\end{array}$ \\
\hline $\begin{array}{l}\text { Landscape } \\
\text { Health }\end{array}$ & $\begin{array}{l}\text { Will disturbance processes (such as fire) that are more consistent with the } \\
\text { biophysical environment be restored at a landscape level? } \\
\text {-Will landscape patterns and diversity of forest growth stages be resilient to the } \\
\text { interaction of drought, fire, insects, and disease in the long term? }\end{array}$ \\
\hline $\begin{array}{l}\text { Viable Populations } \\
\text { of Terrestrial Species }\end{array}$ & $\begin{array}{l}\text {-Will terrestrial species have and improved likelihood of persistence over the } \\
\text { next } 100 \text { years? }\end{array}$ \\
\hline T \& E Species & $\begin{array}{l}\text { - Will threatened and endangered terrestrial species show an improved likelihood } \\
\text { of persistence? }\end{array}$ \\
\hline $\begin{array}{l}\text { Federal Trust } \\
\text { Responsibility to } \\
\text { Tribes }\end{array}$ & $\begin{array}{l}\text {-Will tribal concerns be addressed at appropriate levels of government-to- } \\
\text { government consultation? } \\
\text {-Will tribal rights and interests be considered? }\end{array}$ \\
\hline $\begin{array}{l}\text { Goods and } \\
\text { Services }\end{array}$ & $\begin{array}{l}\text {-Will commercial timber harvest volumes and related jobs increase or decrease? } \\
\text {-Will livestock production and costs increase or decrease? } \\
\text {-Will recreation-related jobs and income increase or decrease? } \\
\text {-Will the level and diversity of recreational and aesthetic opportunities (including } \\
\text { amenity settings and environmental quality) be maintained or increased? }\end{array}$ \\
\hline $\begin{array}{l}\text { Community } \\
\text { Vitality and } \\
\text { Resiliency }\end{array}$ & $\begin{array}{l}\text {-Will the level of goods and services and the likelihood/predictability of meeting } \\
\text { these levels be adequate? } \\
\text {-Will the physical conditions and amenity setting of communities near public } \\
\text { lands be maintained? }\end{array}$ \\
\hline Quality of Life & $\begin{array}{l}\text { Will quality of life be maintained or improved? (As measured by the level and } \\
\text { predictability of goods and services, recreational and aesthetic opportunities, } \\
\text { community vitality and resiliency, collateral impacts to private lands, access } \\
\text { to decision making, and public acceptance.) }\end{array}$ \\
\hline
\end{tabular}




\section{How Do the Alternatives Compare?}

\section{FOREST HEALTH}

How well do the

alternatives provide a

healthy mix of

structural stages and

composition?

EIS Team members used three resources to develop the evaluation criteria: the project's purpose and need statement, issues raised by the public, and project goals.

The Draft EISs examine several questions under each evaluation criterion. One question from each criterion is highlighted here.

The alternatives were rated on a relative ability scale of 0 to 10 . The alternative best able to fulfill the criteria was assigned the value of 10 . The other alternatives were rated proportionally. Unless otherwise noted, the ability rankings refer to the entire project area.
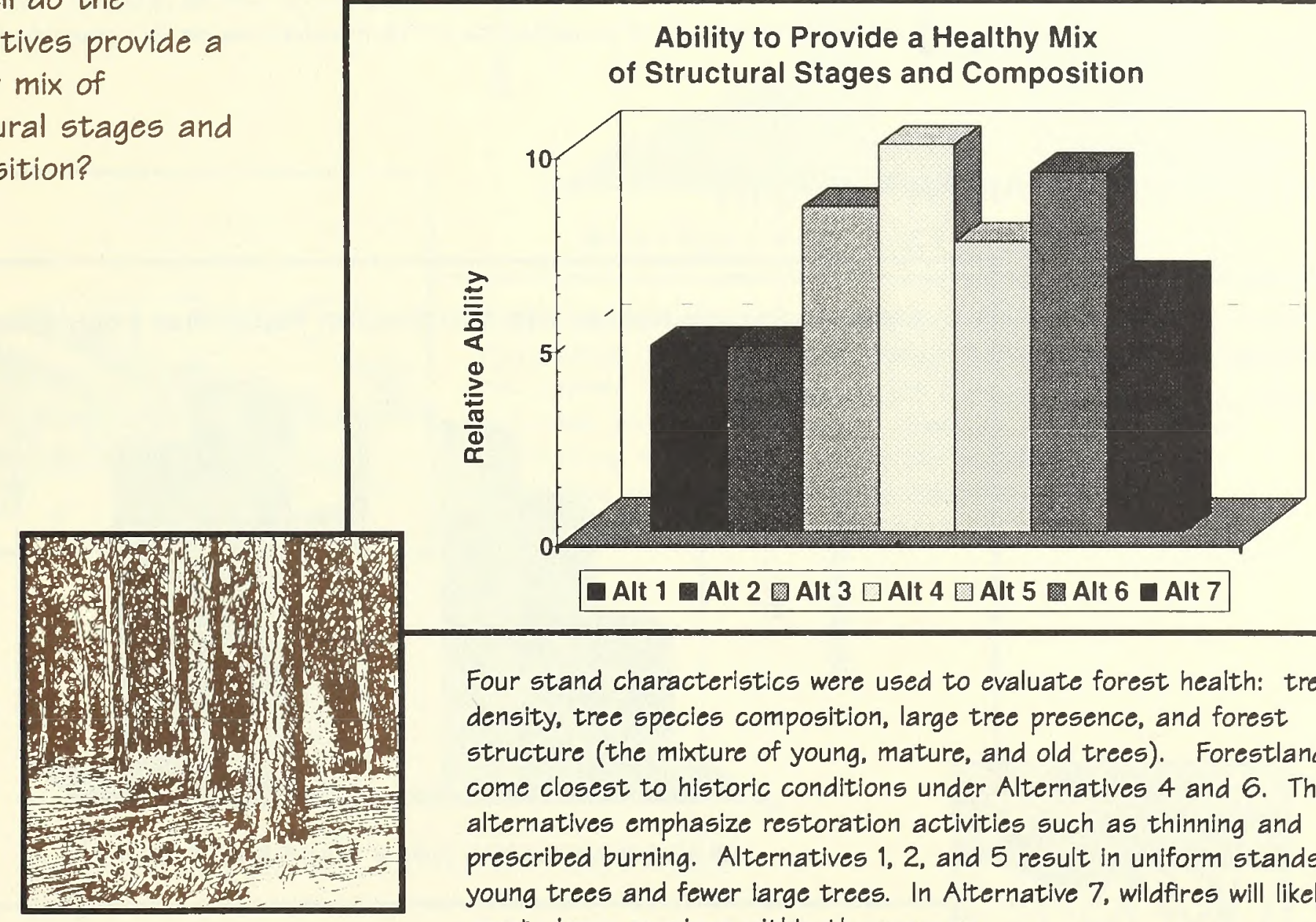

Four stand characteristics were used to evaluate forest health: tree density, tree species composition, large tree presence, and forest structure (the mixture of young, mature, and old trees). Forestlands come closest to historic conditions under Alternatives 4 and 6 . Those alternatives emphasize restoration activities such as thinning and prescribed burning. Alternatives 1,2, and 5 result in uniform stands of young trees and fewer large trees. In Alternative 7, wildfires will likely create large openings within the reserves. 


\section{RANGELAND HEALTH}

How well do the

alternatives prevent

noxious weed spread?

\section{Ability to Prevent Noxious Weed Spread}

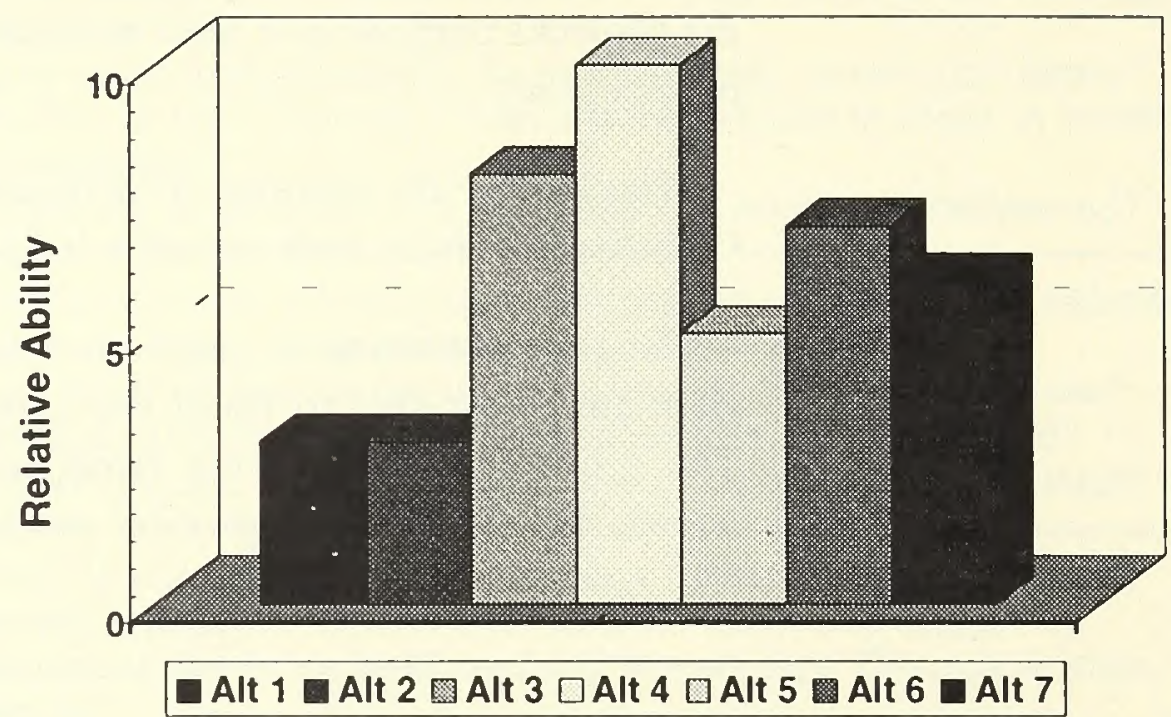

Management activities that contribute to Rangeland Health include, road management and range Improvement. Alternative 4 is the most effective weed reducer. It prescribes the most widespread weed control program. Overall, none of the alternatives is predicted to shrink infestations on dry grasslands.

\section{AQUATIC AND RIPARIAN HEALTH}

How well do the alternatives provide habitat that will support viable fish populations?

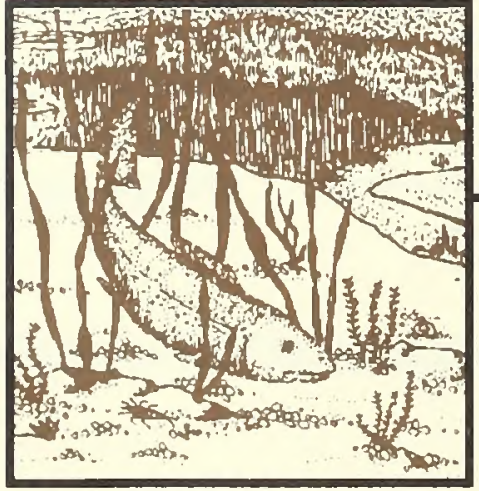

Ability to Provide Habitat That Will Support Viable Fish Populations

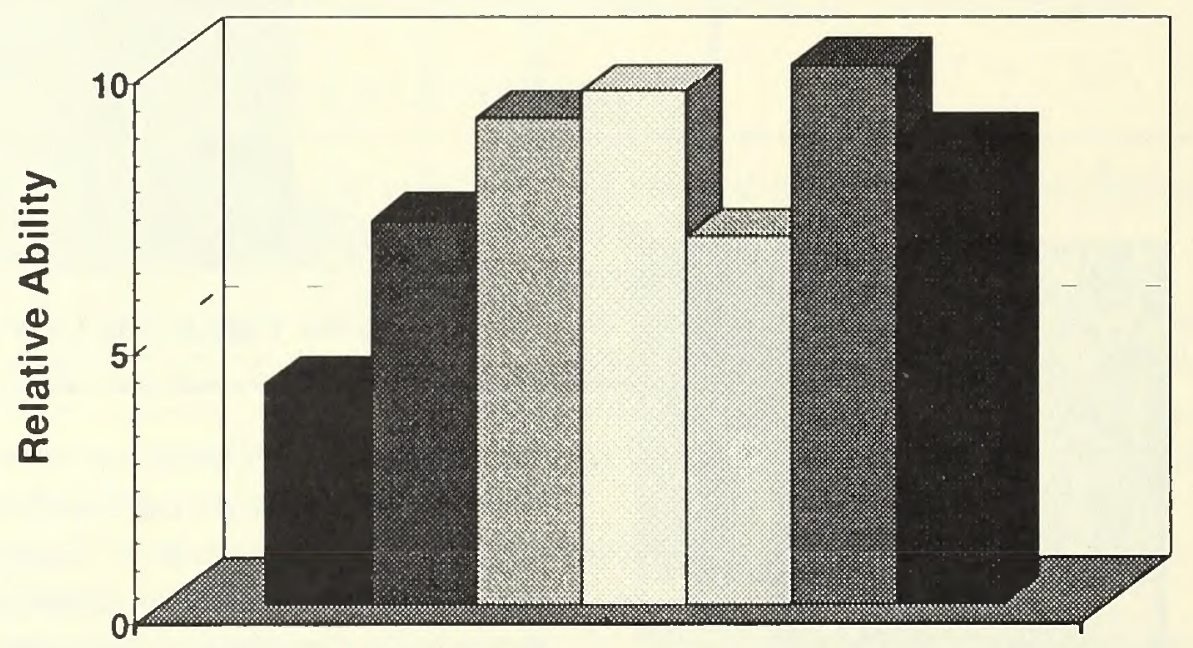

Alt 1 Alt 2 Alt $3 \square$ Alt $4 \square$ Alt 5 圆 Alt $6 \square$ Alt 7

Alternatives 6 and 7 have the most effective short-term strategies for aquatic and riparian health. In the long term (50-100 years) however, Alternative 7 has a high risk of wildfires and other large-scale disturbances that affect fish habitat. As a result, Alternatives 6 and 4 received the highest long-term rating. 


\section{LANDSCAPE HEALTH}

How well do the alternatives restore landscape health?

\section{Ability to Restore Landscape Health}

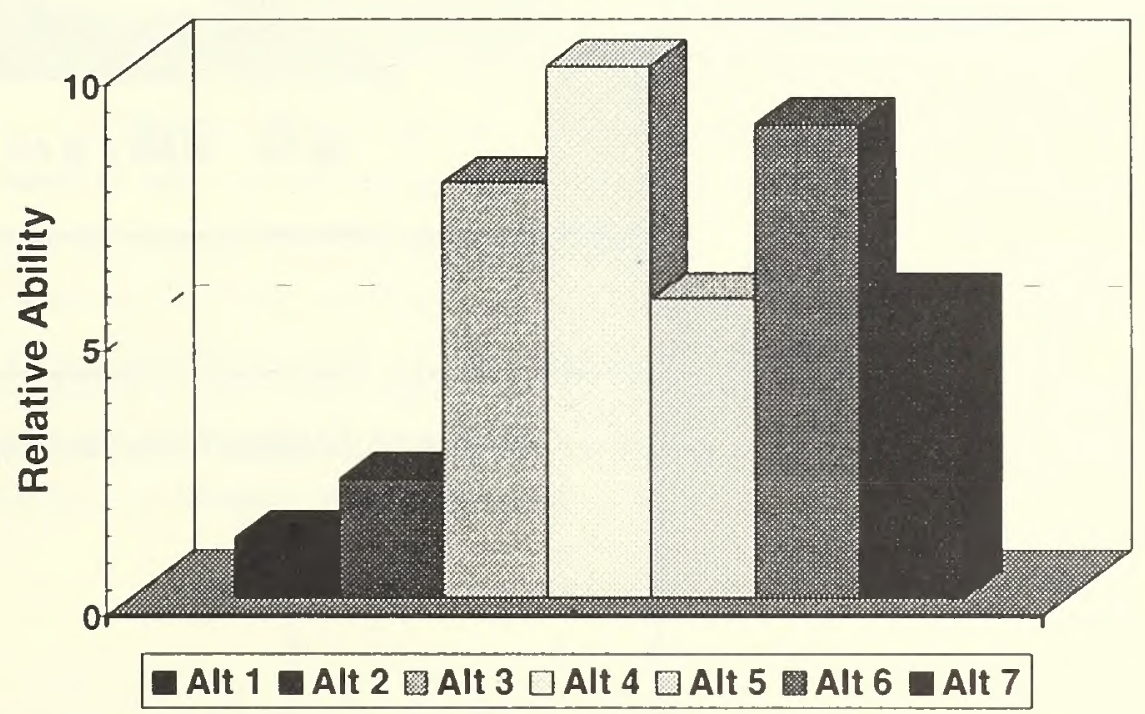

Factors used to evaluated Landscape Health included: succession and disturbance regimes, soil disturbance, noxious weed invasion, terrestrial and riparian habitat restoration (at a landscape scale), fire risk reduction, and commodities and amenities desired by people. Aternatives 4 and 6 will result in the healthiest landscapes. Landscape health improves under Alternatives 3-7. 


\section{VIABLE POPULATIONS OF TERRESTRIAL SPECIES}

How well do the

alternatives support

terrestrial species

populations?
Ability to Support Terrestrial Species Populations-Eastside Area

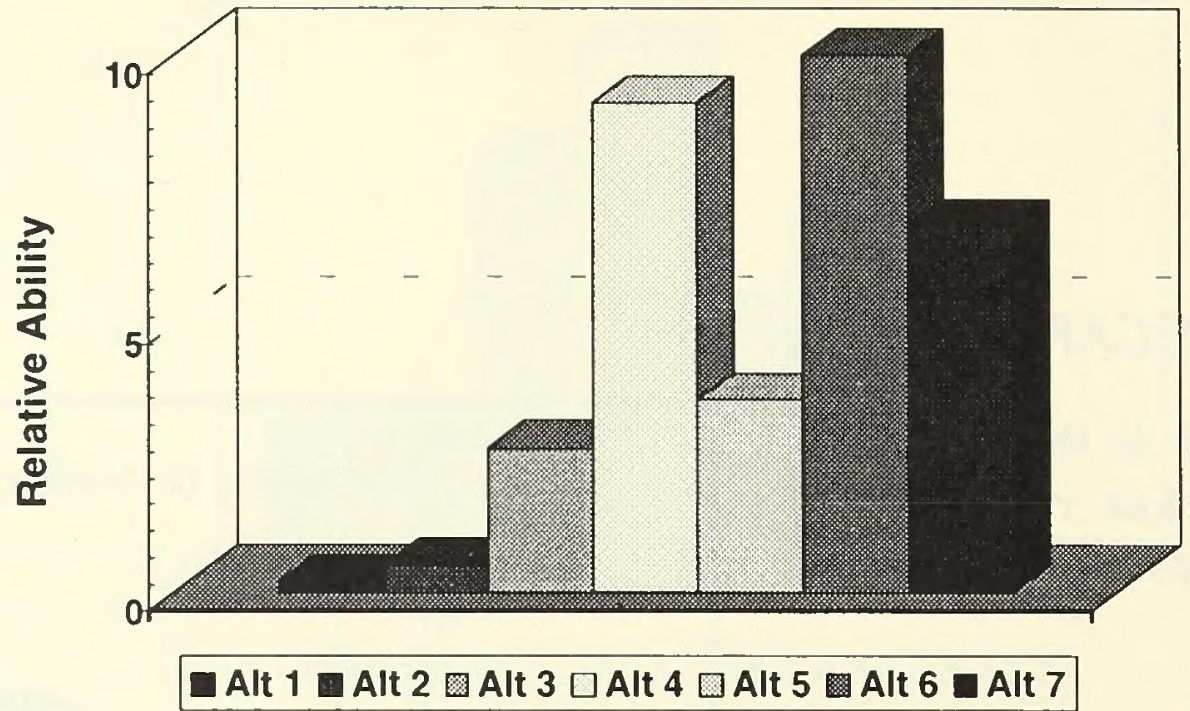

Ability to Support Terrestrial Species Populations-UCRB Area

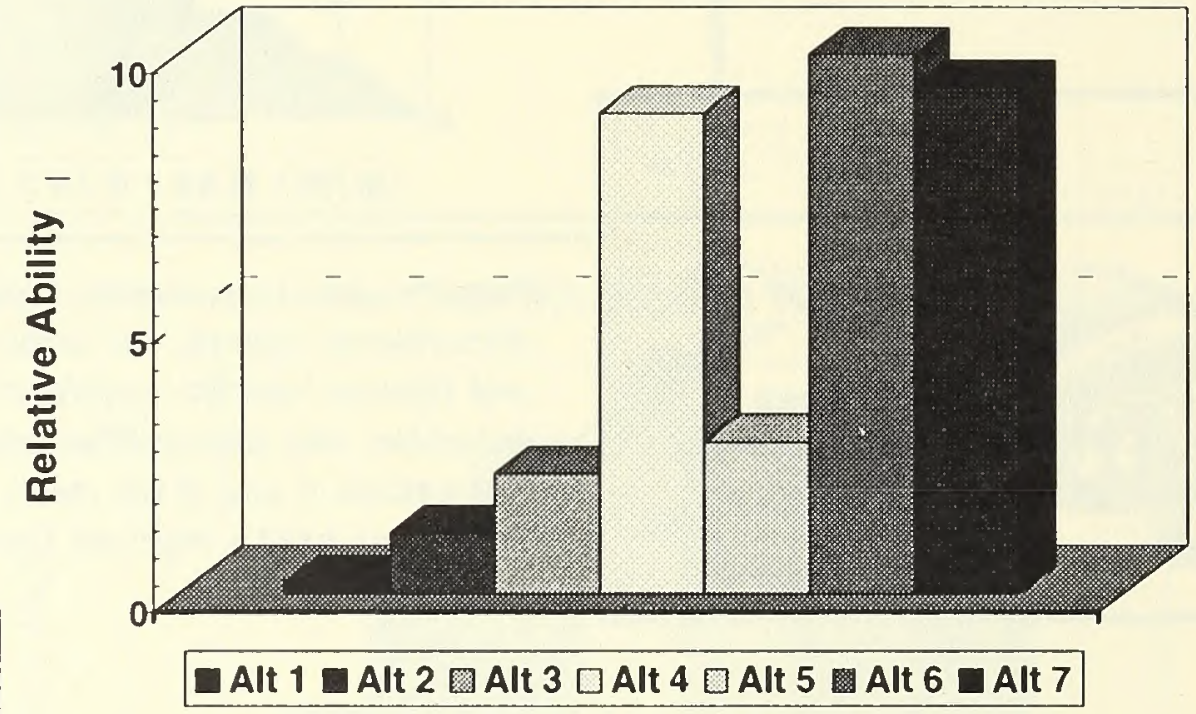

Species persistence is most successful under Alternatives 6, 4, and 7. respectively. For the species analyzed, none of the alternatives approach historic habitat conditions. Many species, including species that are listed as endangered, threatened or sensitive, are influenced by factors beyond Forest Service and BLM control. influences include conversion of off-site habitat to other uses and species migration. 


\section{FEDERAL TRUST RESPONSIBILITIES TO TRIBES}

How well do the

alternatives support

government to

government tribal

consultation?

\section{Ability to Support Effective Government to Government Tribal Consultation}

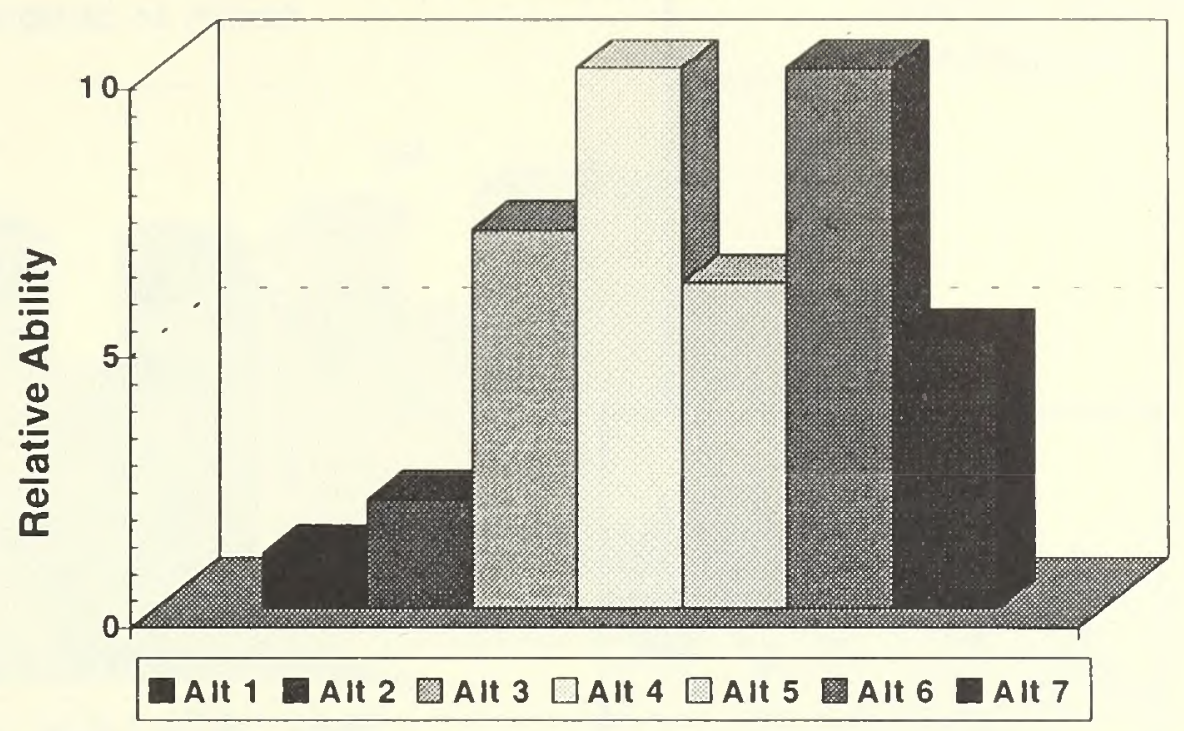

Factors evaluated included opportunities for pre-decislonal Involvement. consistencles among interagency consultation policles, and consultation barrlers. Alternatives 3-7 standardize consultation processes.

Alternatives 4 and 6 provide more opportunities for pre-decislonal Involvement; they are more flexible than the alternatives that establish reserves or management emphases.
How well do the

alternatives protect and

provide access to

significant places?

\section{Ability to Protect and Provide Access to Significant Places}

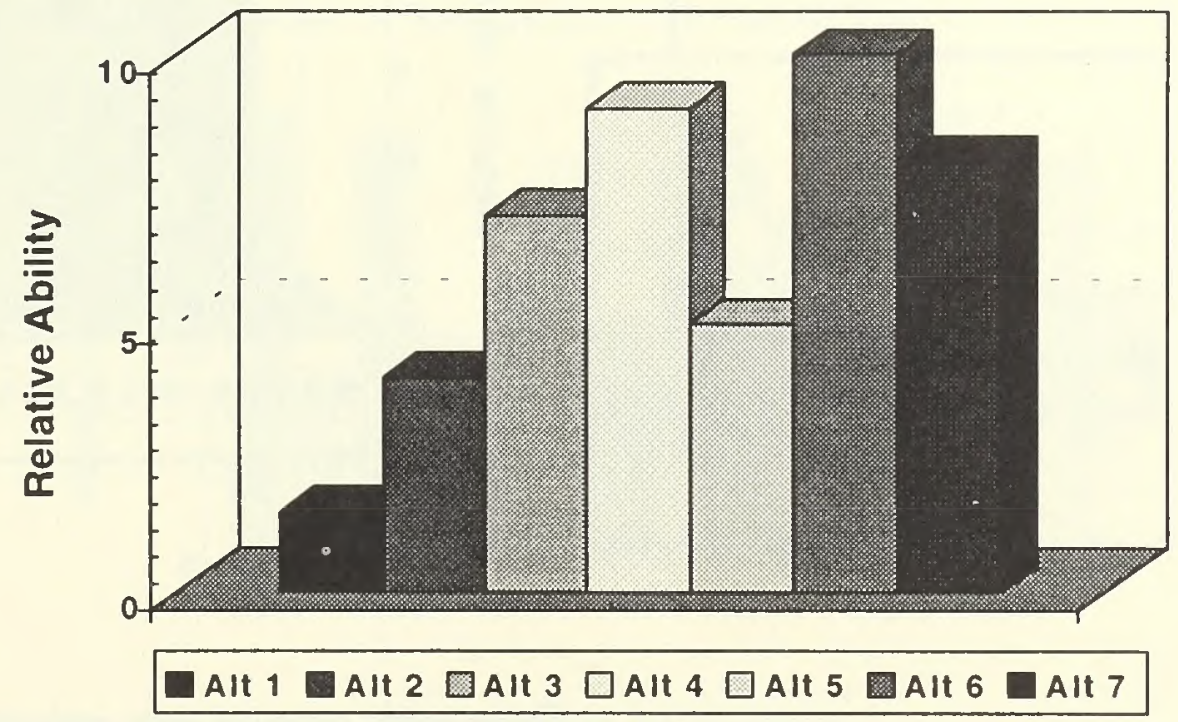

Three elements determined the ratings: government to government consultatlon, tribal rights and interests (especlally aquatic health), and the abillty to protect, yet provide access to signiflcant places. These objectives are best met under Alternatives 6, 4, and 7 respectively. 


\section{GOODS AND SERVICES}

How well do the alternatives support

timber production?

Ability to Support Timber Production

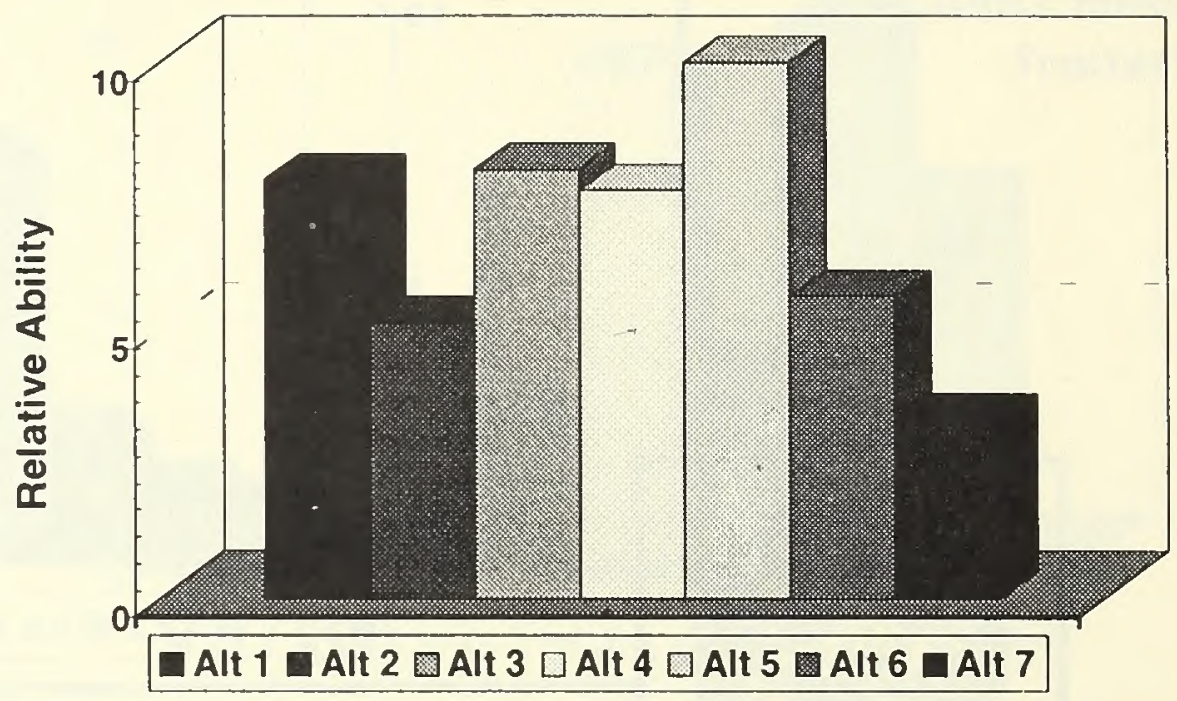

How well do the

alternatives support

livestock production?

\section{Ability to Support Livestock Production}

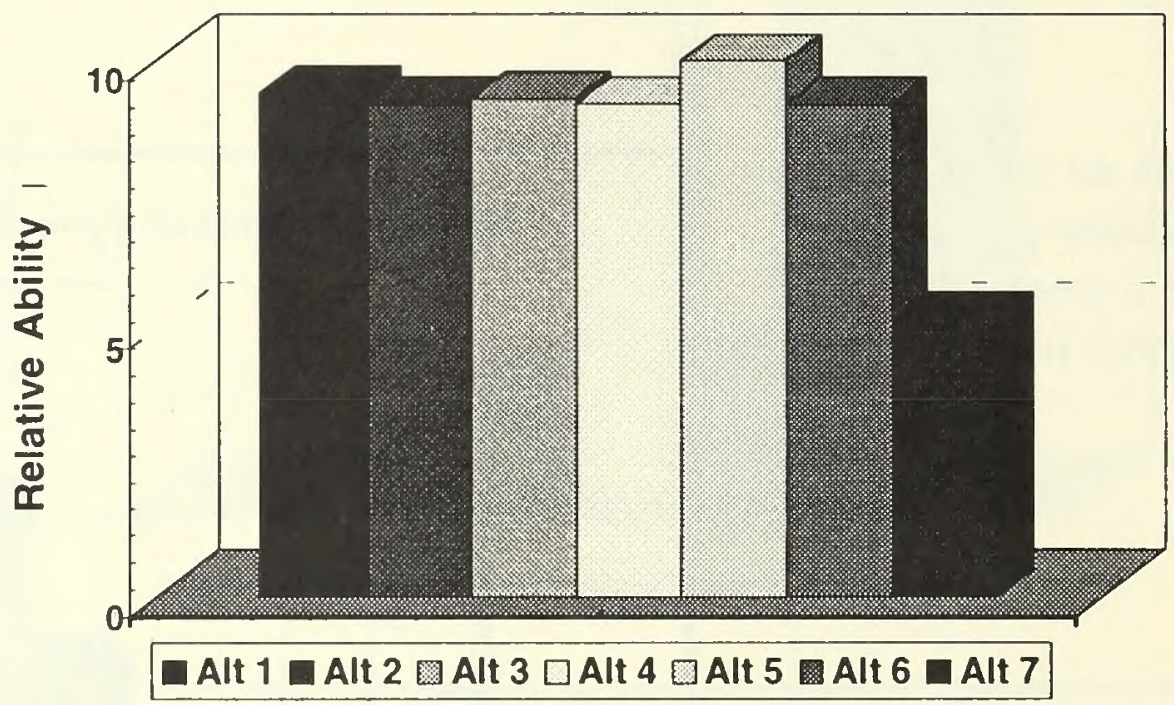

Three major outputs were evaluated: recreation value (not illustrated), livestock production, and timber volume. Recreation value is consistently high across all alternatives. Livestock production is lowest under Alternative 7. which eliminates grazing within the reserves. Timber volume is highest under Alternatives 5, 1, and 4 respectively. 


\section{COMMUNITY VITALITY AND RESILIENCY}

How well do the alternatives generate jobs?
Ability to Generate Jobs

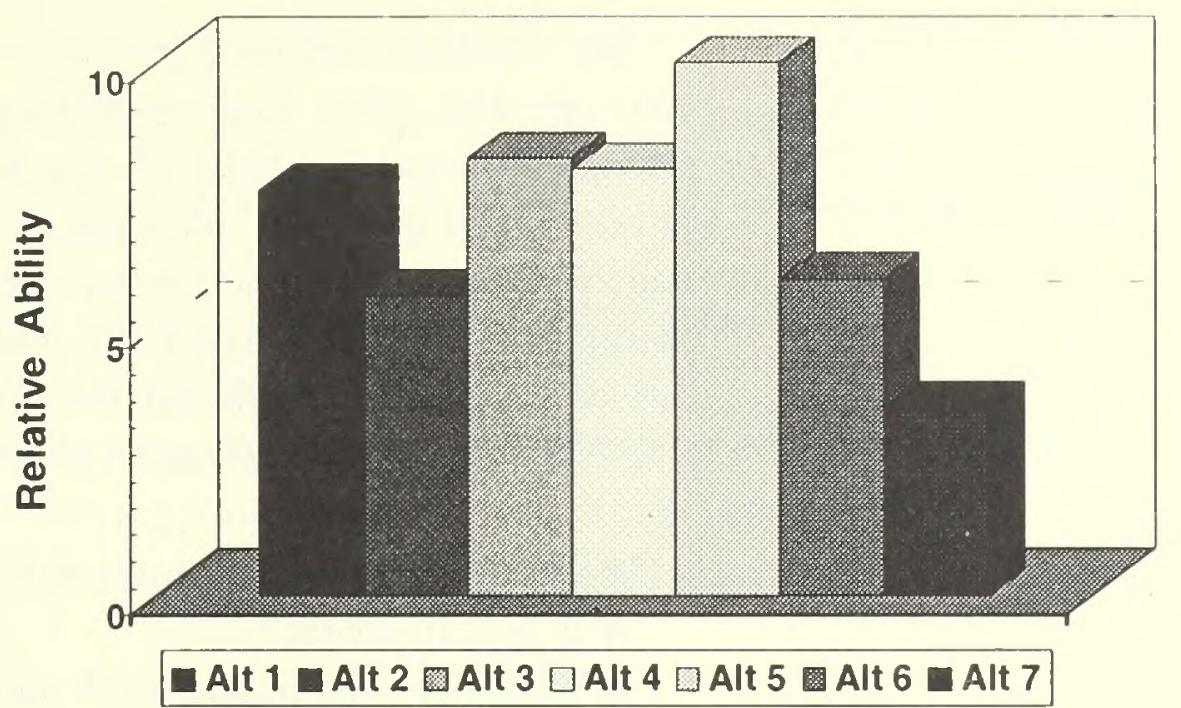

Timber, ranching, recreation, and restoration jobs are aggregated in this chart. Alternatives 3-7 share a common objective: to support the economic needs of areas that are vulnerable to Forest Service and BLM management changes. Job locations cannot be estimated reliably; however, it is likely they would follow management priorities and activities.

\section{QUALITY OF LIFE}

How well do the

alternatives reduce

environmental risk?
Ability to Reduce Environmental Risk

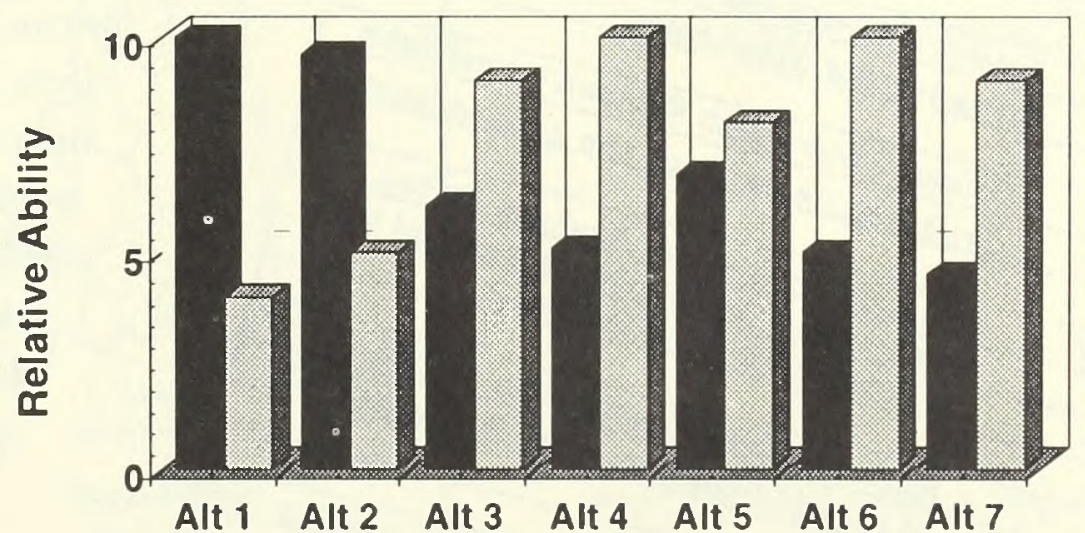

E Short-term $\square$ Long-term

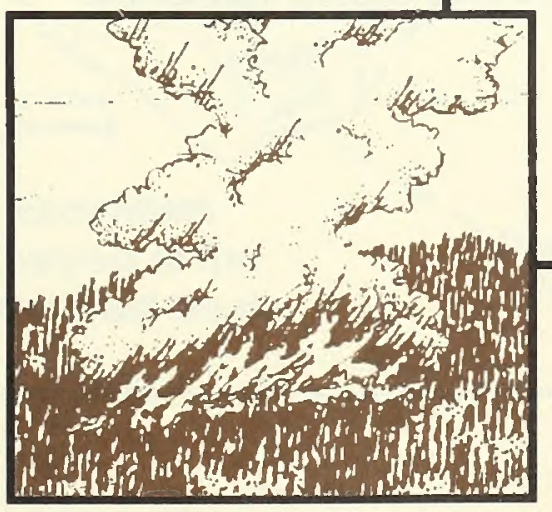

Environmental risks assessed include fire, smoke, floods, sediment, landslides, and scenic degradation. Alternatives 1 and 2 most effectively reduce short-term risk. Long-term risk is best addressed in Alternatives 4 and 6. 


\section{Implementation}

How is

natural

resource

planning done?
Two levels of planning set direction on BLM and Forest Service administrative units: land-use plans and project-specific plans. Land-use plans, which usually have a 10-year life, determine management methods, priorities, and goals for individual Forests and BLM Districts. They set the stage for projects, such as timber sales, grazing strategies, and new campgrounds. This is where the second level of planning comes into play. Before any project is initiated, the National Environmental Policy Act (NEPA) requires land managers to answer the following questions:

What is the project's purpose?

Why is it needed?

-What does the public think about the proposed projectwhat are the issues?

-What alternative strategies could accomplish the project's purpose and address the public's issues?

- How healthy are wildlife and fish habitats, soils, forests, rangelands, and other parts of the ecosystem?

- How would the alternative strategies affect these natural resources?

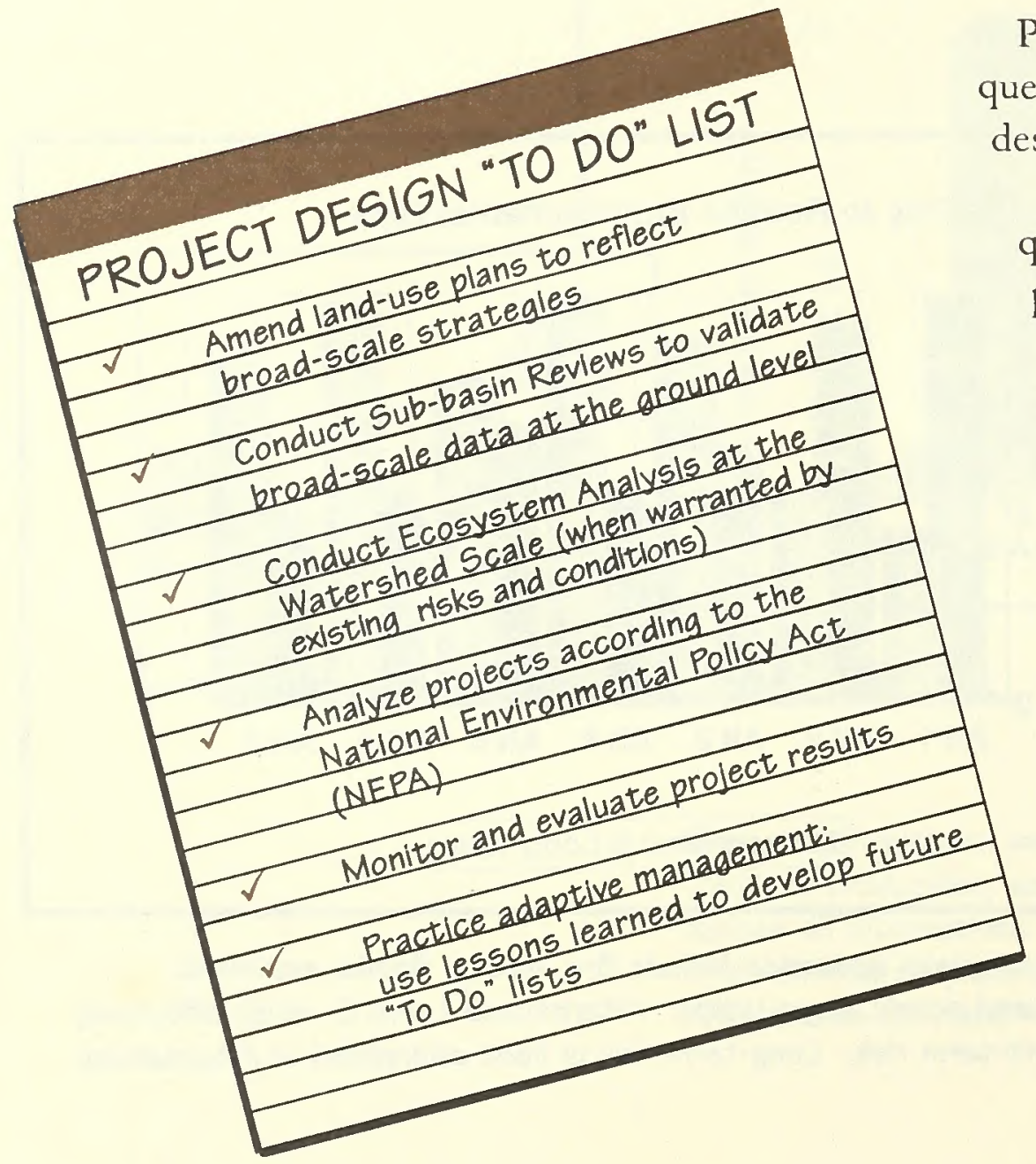

People are key players in this process. Their questions and concerns weigh heavily in project design and implementation.

Land managers currently answer NEPA questions with localized scientific information and perspectives. Although it is vital to sound decision making, site-specific information tells only part of the story. Land managers and the public now have a "big picture" perspective as well. This mountaintop view will give land managers the ability to align their strategies, so that broad-scale issues like salmon recovery and wildfires can be addressed. 
How will these EISs change pl anning practices?
The final EISs will amend National Forest and BLM District land-use plans. Changes will reflect broad-scale goals, priorities, and implementation strategies.

Local managers will incorporate broad-scale information in two ways: Sub-basin Reviews and Ecosystem Analysis at the Watershed Scale.

Completing Sub-basin Reviews is the first step. In this brief process, local managers will use existing information (Science Assessment, field data, GIS, etc.) to:

$\checkmark$ validate science information at the ground level;

$\checkmark$ identifiy priorities and opportunities;

- highlight projects that can contribute to ecosystem health:

$\checkmark$ note data gaps and priorities for future research; and

$\checkmark$ develop strategies for pooling federal, state, and tribal efforts.

\section{Project design requires information from multiple perspectives.}

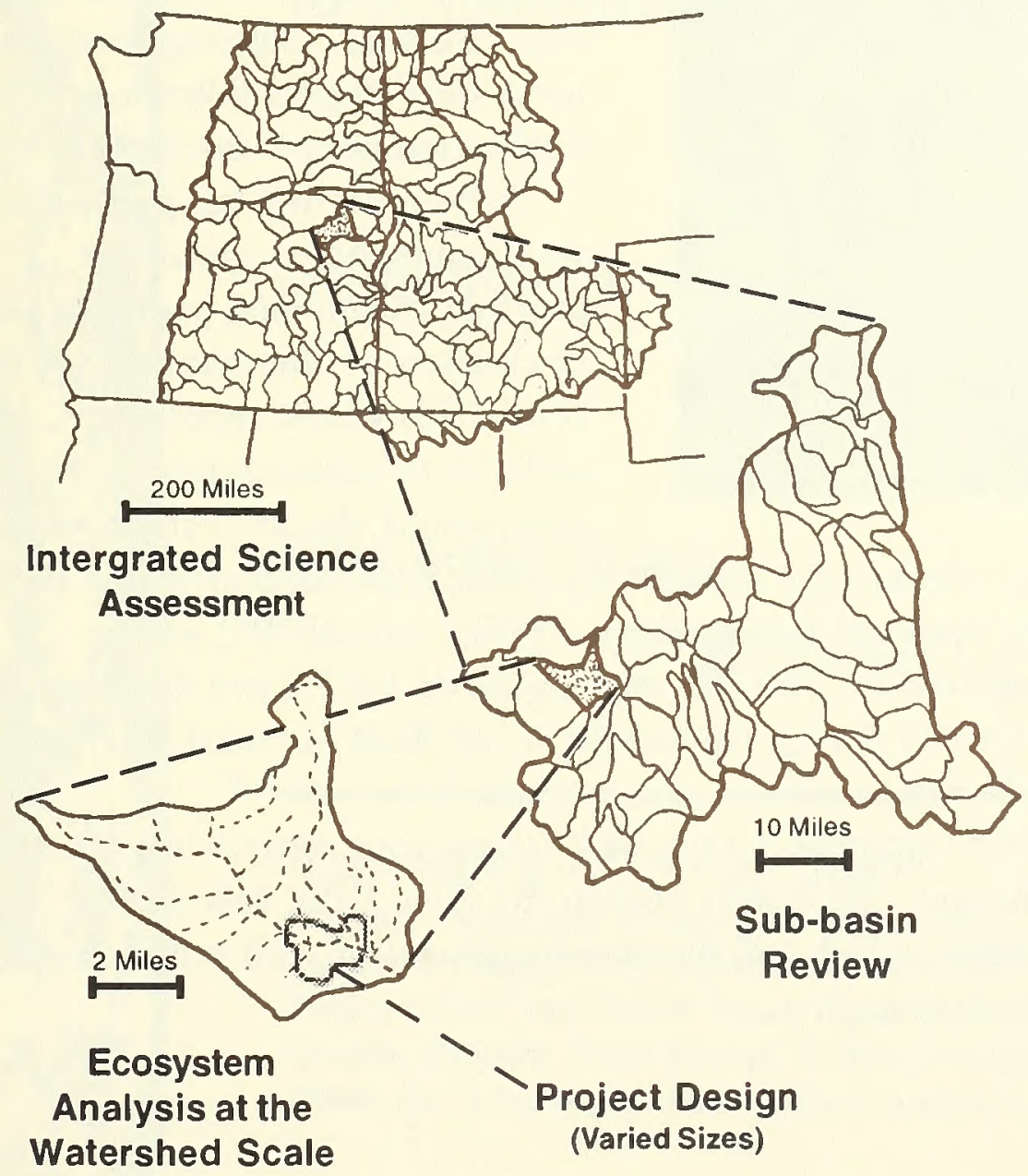

The second step, Ecosystem Analysis at the Watershed Scale, highlights the capabilities and limitations of a given watershed. Analysis requirements vary between the alternatives; however, analysis scope and depth is always determined by on-the-ground conditions.

Information generated by one watershed analysis can be used on several projects. Collectively, the information will be used to update land-use plans.
Four levels of analysis and review link broad-scale information to local decisions. These "mountaintop" perspectives give land managers the ability to align their strategles, so that broad-scale issues like salmon recovery and wildfires can be addressed. 


\section{The Next Step}

How can I stay involved?

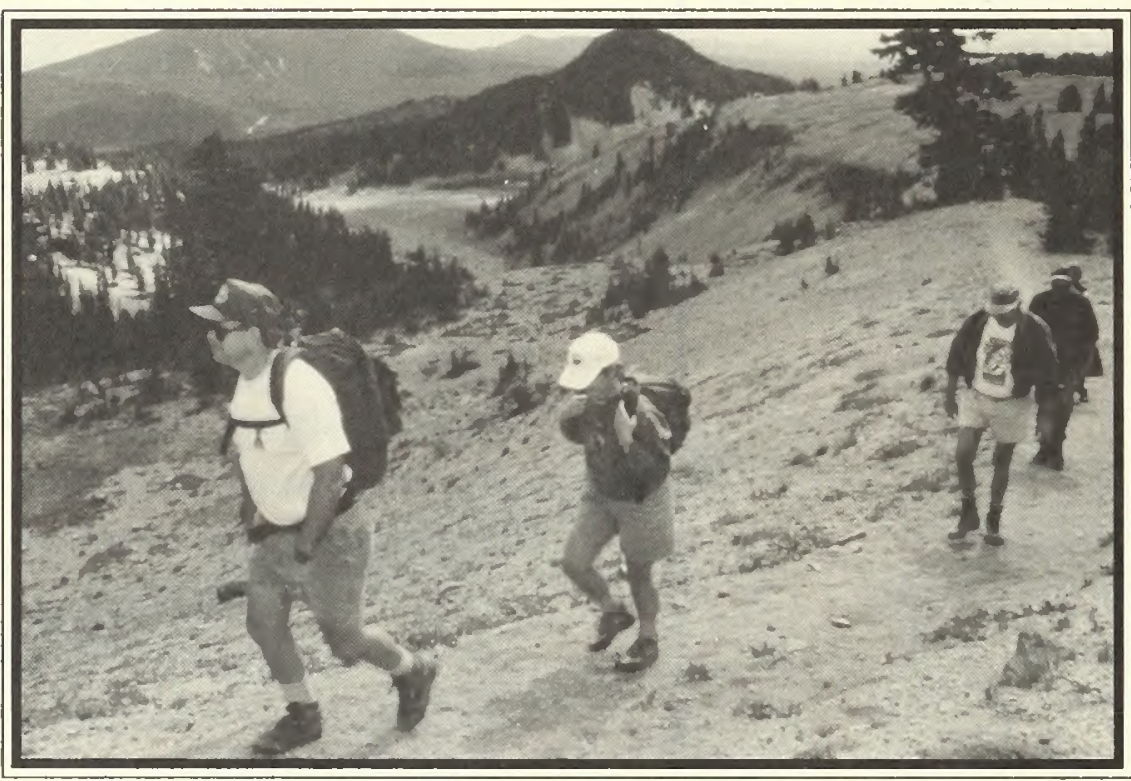

Even though we're using the best science that is available, science doesn't make hard decisions. People do. The decision space exists somewhere between the legal thresholds (minimum standards set by laws such as the Clean Water Act, Clean Air Act, Endangered Species Act, National Forest Management Act, and Federal Land Policy and Management Act) and the land's biological potential. Within that space, alternatives will focus on various combinations of social, economic, or ecological considerations. In most cases, achieving the highest combination of all values will mean that no single value will be achieved at its maximum level. In other words, there will be trade-offs, and trade-offs are ultimately chosen by society.

We hope that after reading this summary, and perhaps the Draft EISs, you'll send us your comments, or even deliver them in person at one of our meetings. Watch your mail and your local newspaper for public involvement opportunities in your area. We'll be collecting comments for at least 90 days following publication of this document.

To be most helpful, please make your comments as specific as possible, mentioning particular pages or chapters of this summary or the Draft EISs where appropriate. In addition to commenting on the pros and cons of the alternatives, you

might also tell us whether you thought the Draft EISs adequately met the provisions of the National Environmental Policy Act (NEPA) and its implementing regulations. You can view copies of NEPA and the Council on Environmental Quality (CEQ) regulations at any BLM or Forest Service office or at your public library.

After the public comment period, we'll review your suggestions and make the necessary changes. We'll then publish the Final EISs, followed by Records of Decision, which will direct management of your public lands into the twenty-first century. 


\section{How Does This Summary \\ Relate to the Draft EISs?}

The Essentials

Restoring Ecological Integrity

圆Chapter 1-Purpose and Need

Learning from the Land and Its People

- Chapter 2-Affected Environment

Alternative Pathways to a Sustainable Future 圊Chapter 3-Alternatives

\section{Environmental Consequences \\ 国 Chapter 4-Environmental Consequences}

Implementation

闵Implementation Appendix

The Next Step

㬝Chapter 5-Consultation and Coordination

"Considering All Things" Team:

Writing: Research Information Staff, North Central Forest Experiment Station

Document Design, Illustrations, and Production: Traci Mc. Merritt, Deschutes National Forest

Project Liaison and Editor: Heidi Bigler Cole, Interior Columbia Basin Ecosystem Management Project

Graphic Support: Irene Stumpf, Willamete National Forest

Photos by: John Hutmacher, Deschutes National Forest

The Uniled Siales Deparıment of Agriculıure (USDA) prohibits discrimination in irs programs on the basis of race, color, lational origin, sex, religion, age, disability, political beliefs and mafial or familial srarus, Persons with disabiliries who reguire alternative

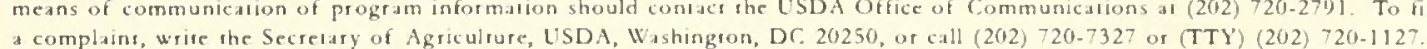

(1)

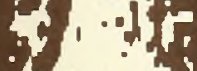






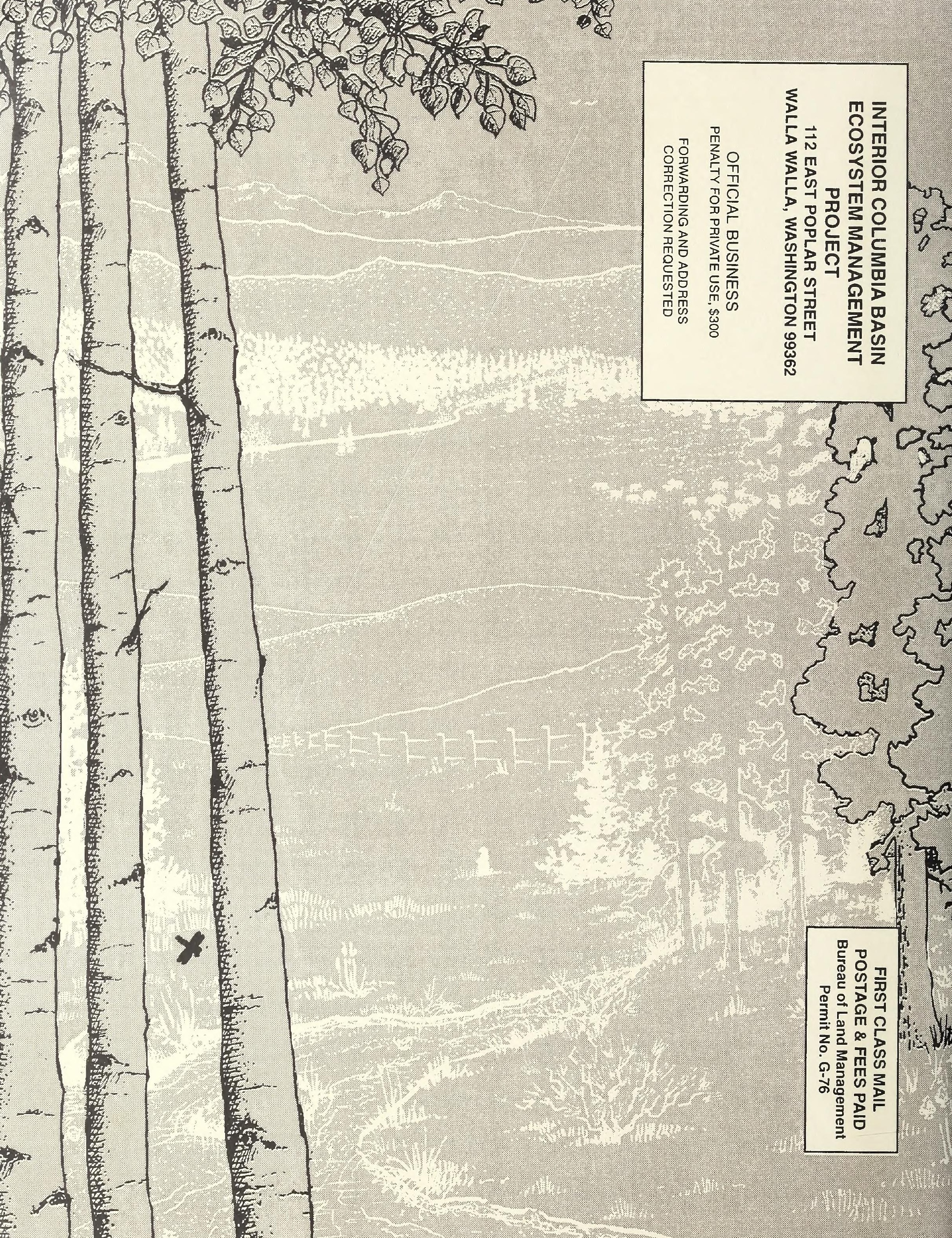

